\title{
CONSTRUÇÃO E AVALIAÇÃO DE HIDROCICLONE PARA PRÉ-FILTRAGEM DA ÁGUA DE IRRIGAÇÃO
}

\author{
OLÍVIO JOSÉ SOCCOL
}

\author{
Tese apresentada à Escola Superior de Agricultura \\ "Luiz de Queiroz", Universidade de São Paulo, \\ para obtenção do título de Doutor em Agronomia, \\ Área de Concentração: Irrigação e Drenagem.
}

P I R A C I C A B A

Estado de São Paulo - Brasil

Janeiro - 2003 


\title{
CONSTRUÇÃO E AVALIAÇÃO DE HIDROCICLONE PARA PRÉ-FILTRAGEM DA ÁGUA DE IRRIGAÇÃO
}

\section{OLÍVIO JOSÉ SOCCOL}

Engenheiro Agrônomo

\section{Orientador: Prof. Dr. TARLEI ARRIEL BOTREL}

\author{
Tese apresentada à Escola Superior de Agricultura \\ “Luiz de Queiroz”, Universidade de São Paulo, \\ para obtenção do título de Doutor em Agronomia, \\ Área de Concentração: Irrigação e Drenagem.
}

P I R A C I C A B A

Estado de São Paulo - Brasil

Janeiro - 2003 


\section{Dados Internacionais de Catalogação na Publicação (CIP) DIVISÃO DE BIBLIOTECA E DOCUMENTAÇÃO - ESALQ/USP}

Soccol, Olívio J osé

Construção e avaliação de hidrocic lone para pré-filtragem da água de imigação / Olívio J osé Soccol. - - Piracic aba, 2003.

89 p. : il.

Tese (doutorado) - Escola Superior de Agricultura Luiz de Queiroz, 2003.

Bibliografia.

1. Água para inigação [Qualidade] 2. Areia 3. Filtração 4. Granulometria 5. Hidrocic lones 6. Imigação 7. Solo a rgiloso I. Título

CDD 631.7

'Permitida a cópia total ou parcial deste documento, desde que citada a fonte - $\mathrm{O}$ autor" 
Aos meus pais Deonísio Soccol “in memoriam” e Ruth Kreiss Soccol, pela vida. Aos meus irmãos Carlos, Dionísio e Ana Maria, pelo apoio.

\section{OFEREÇO}

A Marcilene, companheira de jornada, pela força dispensada nos momentos difíceis, 


\section{AGRADECIMENTOS}

A Deus, por tudo que me tem dado.

Ao Departamento de Engenharia Rural da Escola Superior de Agricultura "Luiz de Queiroz" (ESALQ/USP), pela oportunidade de realizar o curso e desenvolver o trabalho.

Ao Departamento de Engenharia Rural da Universidade do Estado de Santa Catarina (UDESC), por ter me liberado das atividades durante a realização do curso.

A CAPES/PICDT, pela bolsa de estudo durante o período do curso.

Ao Professor Tarlei Arriel Botrel, pela orientação, oportunidade de desenvolver este e outros trabalhos, e acima de tudo pela amizade e paciência.

Ao mestre e hoje colega Professor Mario Nestor Ullmann, pelo seu incentivo.

Ao Professor Sérgio Nascimento Duarte, pela revisão e sugestões dispensadas à redação do trabalho.

Aos colegas de curso Luis Artur Alvarenga Vilela e Eliezer Santurbano Gervásio, pela automação do sistema de coleta de dados da bancada experimental, ao Miguel Angel Isaac Toledo del Pino pela confecção dos desenhos dos hidrociclones e ao João Célio de Araújo pelas fotos.

Aos funcionários Gilberto Rech (CAV/UDESC), Davilmar, Sandra, Cesar, Antônio, Hélio, Gilmar e Osvaldo do Departamento de Engenharia Rural (ESALQ/USP) e Sílvia da Biblioteca (ESALQ/USP), pela colaboração no decorrer do curso. 


\section{SUMÁRIO}

Página

LISTA DE FIGURAS …........................................................................ vii

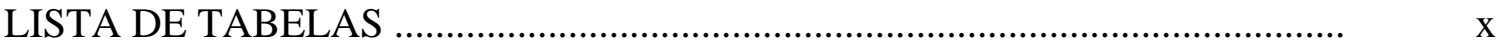

LISTA DE SÍMBOLOS …...................................................................... xii

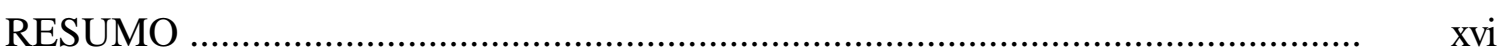

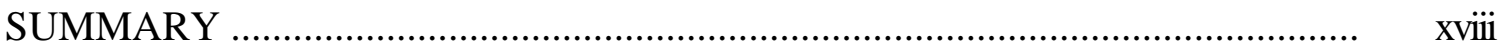

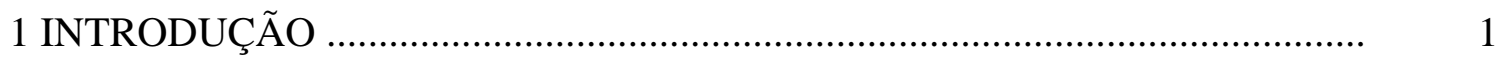

2 REVISÃO DE LITERATURA ….............................................................. 4

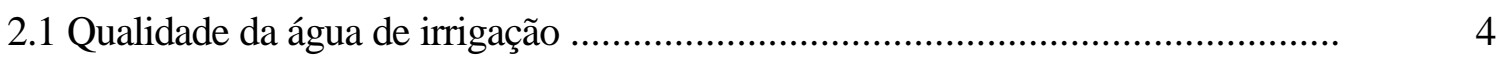

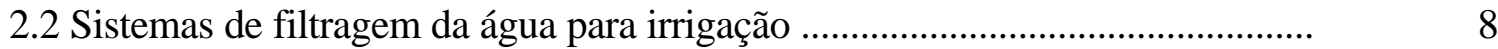

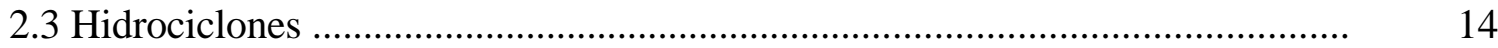

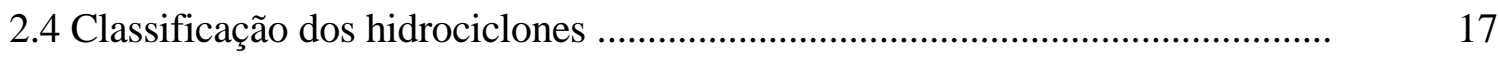

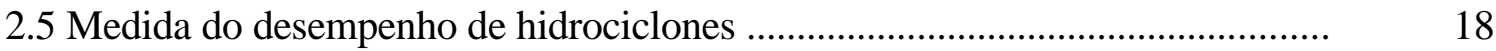

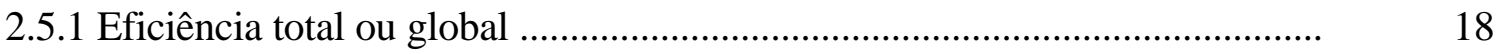

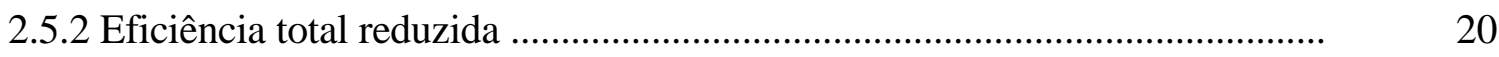

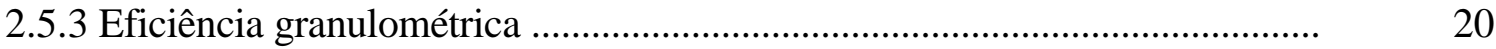

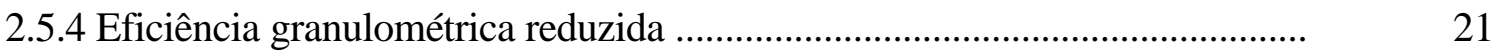

2.6 Grupos adimensionais importantes no estudo de hidrociclones ........................... 23

2.7 Modelos de separação de partículas .................................................................... 25

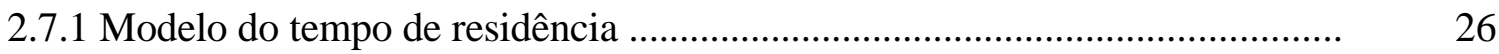

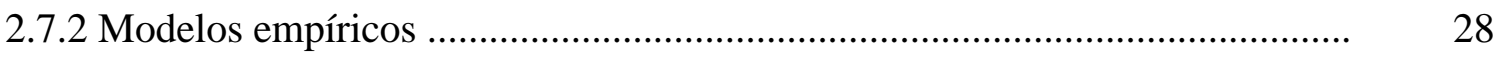

2.8 Equações para previsão do diâmetro de corte ................................................... 30

3 MATERIAL E MÉTODOS ….................................................................... 32 


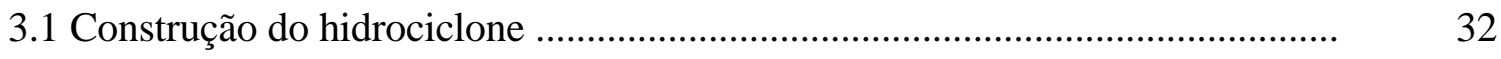

3.2 Material de ensaio .............................................................................

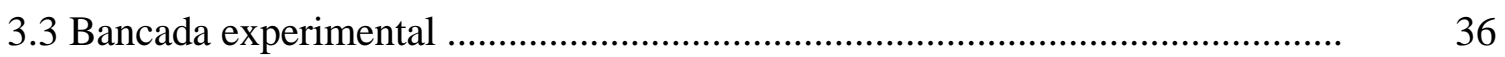

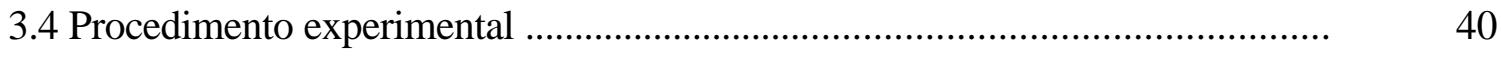

Acionamento do sistema …........................................................................

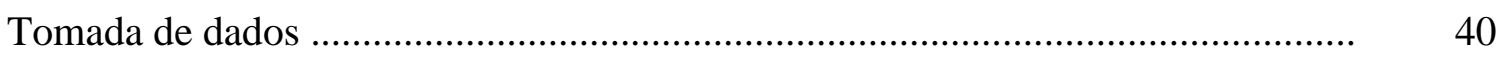

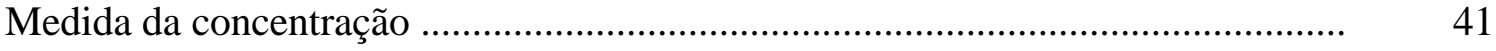

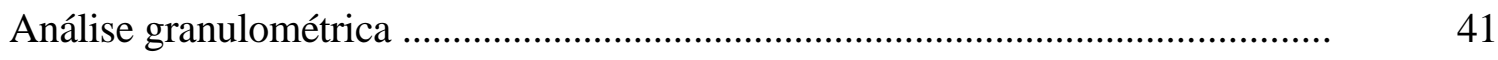

Cálculo da vazão de alimentação ...............................................................................

Queda de pressão no hidrociclone ....................................................................

4 RESULTADOS E DISCUSSÃO ……………………………………....... 46

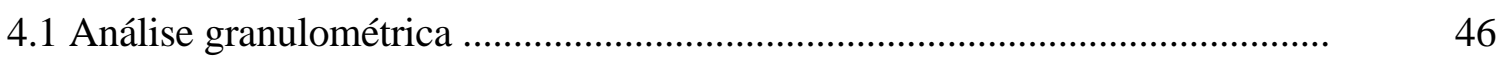

4.2 Desempenho dos hidrociclones ................................................................ 53

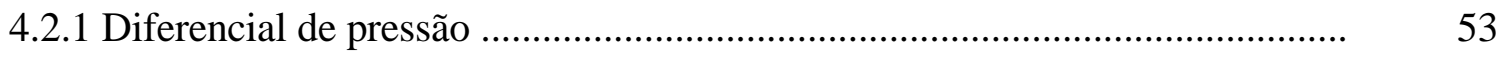

4.2.2 Hidrociclone I ................................................................................

4.2.3 Hidrociclones II, III e IV .......................................................................... 57

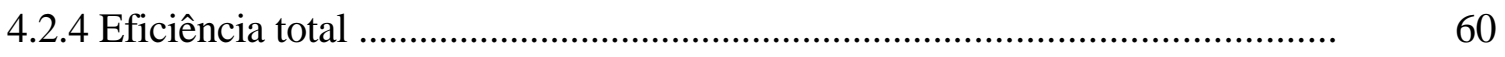

4.3 Comparação com modelos empíricos ………………………………………... 64

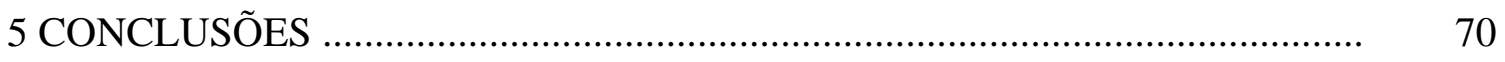

ANEXOS ……..................................................................................

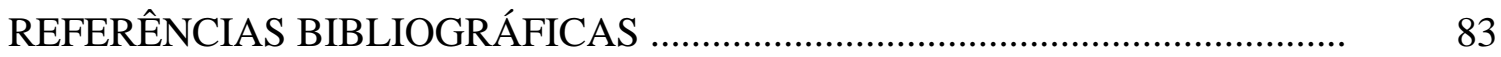




\section{LISTA DE FIGURAS}

Página

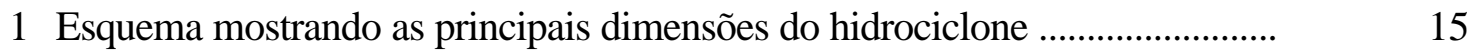

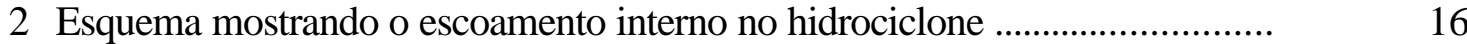

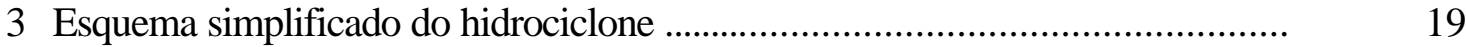

4 Posições de entrada da partícula no hidrociclone na posição $\mathrm{D}_{\mathrm{i}} / 2$ (a) e na posição mais desfavorável a sua separação (b) ................................................ 26

5 Hidrociclones com bocal de alimentação circular (a) e retangular (b) .............. 34

6 Peças utilizadas na construção dos hidrociclones: peças e tarugo de PVC (a); peças prontas e o molde do cone (b); molde do cone sobre a parte cilíndrica (c) e hidrociclone já construído (d)

7 Histograma com a porcentagem relativa das partículas de areia com diâmetro maior do que o considerado .................................................................... 36

8 Esquema da bancada de ensaio mostrando seus componentes ......................... 37

9 Tela principal do programa Aquidados .......................................................

10 Bancada experimental utilizada no ensaio dos hidrociclones, mostrando o reservatório, medidor de vazão, hidrociclone e o agitador submersível ........... 39

11 Bancada experimental utilizada no ensaio dos hidrociclones, mostrando o conversor de sinal do medidor de vazão, a balança, o conjunto motobomba e o microcomputador

12 Tomada de dados: acionamento do programa Aquidados (a); tomada da vazão do concentrado (b); coleta da amostra da alimentação (c) e pesagem das amostras (d)

13 Jogo de peneiras utilizadas na análise da areia (a); pesagem da fração 
mássica retida na peneira (b); proveta utilizada no ensaio de sedimentação do solo (c) e amostras coletadas nos diferentes tempos de sedimentação (d) .......

14 Distribuição granulométrica da areia, pontos experimentais e curvas ajustadas, na alimentação e no concentrado, para o hidrociclone I ...................

15 Distribuição granulométrica da areia, pontos experimentais e curvas ajustadas, na alimentação e no concentrado, para o hidrociclone II

16 Distribuição granulométrica da areia, pontos experimentais e curvas ajustadas, na alimentação e no concentrado, para o hidrociclone III

17 Distribuição granulométrica da areia, pontos experimentais e curvas ajustadas, na alimentação e no concentrado, para o hidrociclone IV

18 Distribuição granulométrica do solo, pontos experimentais e curvas ajustadas, na alimentação e no concentrado, para o hidrociclone I

19 Distribuição granulométrica do solo, pontos experimentais e curvas ajustadas, na alimentação e no concentrado, para o hidrociclone II

20 Distribuição granulométrica do solo, pontos experimentais e curvas ajustadas, na alimentação e no concentrado, para o hidrociclone III

21 Distribuição granulométrica do solo, pontos experimentais e curvas ajustadas, na alimentação e no concentrado, para o hidrociclone IV

22 Queda de pressão em função da vazão de alimentação para os hidrociclones ensaiados

23 Concentração da suspensão de areia (a) e solo (b) na alimentação e no diluído para o hidrociclone I

24 Concentração da suspensão de areia (a) e solo (b) na alimentação e no diluído para o hidrociclone II

25 Concentração da suspensão de areia (a) e solo (b) na alimentação e no diluído para o hidrociclone III

26 Concentração da suspensão de areia (a) e solo (b) na alimentação e no diluído para o hidrociclone IV

27 Diferencial de pressão no hidrociclone I estimados pelo modelo de Plitt versus os valores experimentais, para a suspensão de areia (a) e solo (b) 
28 Diferencial de pressão no hidrociclone II estimados pelo modelo de Plitt versus os valores experimentais, para a suspensão de areia (a) e solo (b) ........

29 Diferencial de pressão no hidrociclone III estimados pelo modelo de Plitt versus os valores experimentais, para a suspensão de areia (a) e solo (b) ........

30 Diferencial de pressão no hidrociclone IV estimados pelo modelo de Plitt versus os valores experimentais, para a suspensão de areia (a) e solo (b) .......

31 Vazão no hidrociclone I estimada pelo modelo de Plitt e Lynch \& Rao versus os valores experimentais, para a suspensão de areia (a) e solo (b) .......

32 Vazão no hidrociclone II estimada pelo modelo de Plitt e Lynch \& Rao versus os valores experimentais, para a suspensão de areia (a) e solo (b) ........

33 Vazão no hidrociclone III estimada pelo modelo de Plitt e Lynch \& Rao versus os valores experimentais, para a suspensão de areia (a) e solo (b) ........

34 Vazão no hidrociclone IV estimada pelo modelo de Plitt e Lynch \& Rao versus os valores experimentais, para a suspensão de areia (a) e solo (b) ........ 


\section{LISTA DE TABELAS}

Página

1 Risco potencial de entupimento pelo uso de água de irrigação ......................... 6

2 Causas de entupimento dos sistemas de irrigação localizada ............................

3 Classificação do solo por tamanho de partículas com correspondente número de mesh da tela

4 Linhas gerais para seleção do sistema de filtragem na irrigação localizada ....

5 Proporções geométricas dos dois grupos de hidrociclones

6 Constantes $k$ e $n$ das equações (17), (18) e (19), sugeridas por Medronho

7 Dimensões do hidrociclone com o tubo de alimentação circular, segundo recomendações de Rietema

8 Características dos bocais utilizados na alimentação dos hidrociclones .......... 33

9 Custo e relação do material utilizado na construção de um hidrociclone ......... 35

10 Concentração inicial da suspensão de areia e solo

11 Dados médios dos ensaios experimentais realizados com o hidrociclone I operando com suspensão de areia

12 Dados médios dos ensaios experimentais realizados com o hidrociclone I operando com suspensão de solo

13 Dados médios dos ensaios experimentais realizados com o hidrociclone II operando com suspensão de areia

14 Dados médios dos ensaios experimentais realizados com o hidrociclone II operando com suspensão de solo

15 Dados médios dos ensaios experimentais realizados com o hidrociclone III 
operando com suspensão de areia .......................................................... 58

16 Dados médios dos ensaios experimentais realizados com o hidrociclone III operando com suspensão de solo ......................................................... 58

17 Dados médios dos ensaios experimentais realizados com o hidrociclone IV operando com suspensão de areia ........................................................... $\quad 59$

18 Dados médios dos ensaios experimentais realizados com o hidrociclone IV

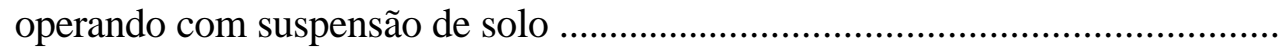

19 Valores médios da eficiência total, do diferencial de pressão e da vazão de alimentação calculados a partir de todos os ensaios realizados com os

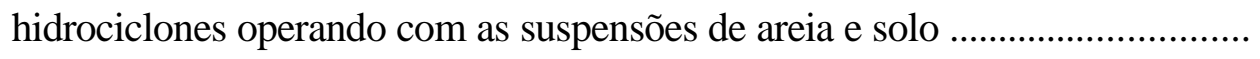




\section{LISTA DE SÍMBOLOS}

$\begin{array}{ll}\text { [ A ] } & \text { Concentração de sólidos na alimentação }\left(\mathrm{M} \mathrm{L}^{-3}\right) \\ \mathrm{C} & \text { Concentração da amostra coletada no tempo }\left(\mathrm{M} \mathrm{L}^{-3}\right) \\ \mathrm{Co} & \text { Concentração inicial }\left(\mathrm{M} \mathrm{L}^{-3}\right) \\ {[\mathrm{C}]} & \text { Concentração de sólidos no concentrado }\left(\mathrm{M} \mathrm{L}^{-3}\right) \\ \mathrm{Cd} & \text { Coeficiente de descarga } \\ \mathrm{C}_{\mathrm{P}} & \text { Concentração em peso na alimentação } \\ \mathrm{Cy}_{50} & \text { Constante de Rietema } \\ \mathrm{Cv} & \text { Concentração volumétrica na suspensão de alimentação } \\ \mathrm{Cv}_{\mathrm{u}} & \text { Concentração volumétrica na suspensão do concentrado } \\ \mathrm{d} & \text { Diâmetro de partícula (L) } \\ \mathrm{d}^{*} & \text { Constante do modelo de Rosin-Rammler-Bennet } \\ \mathrm{d}^{\prime}{ }_{50} & \text { Diâmetro de corte reduzido (L) } \\ \mathrm{DN} & \text { Diâmetro nominal (L) } \\ \mathrm{d}_{\mathrm{Stk}} & \text { Diâmetro de Stokes (L) } \\ \mathrm{Dc} & \text { Diâmetro do hidrociclone (L) } \\ \mathrm{Di} & \text { Diâmetro do duto de alimentação (L) } \\ \text { Do } & \text { Diâmetro do duto do diluído (L) } \\ \text { e } & \text { Base dos logaritmos neperianos } \\ \text { Du } & \text { Diâmetro do orifício do concentrado (L) } \\ \text { ET } & \text { Eficiência total } \\ \text { ET } & \text { Eficiência total reduzida } \\ \text { Eu } & \text { Número de Euler baseado no diâmetro do hidrociclone } \\ \overline{E T} & \text { Eficiência total média de todos os ensaios }\end{array}$




\begin{tabular}{|c|c|}
\hline $\mathrm{G}$ & Eficiência granulométrica \\
\hline $\mathrm{G}^{\prime}$ & Eficiência granulométrica reduzida \\
\hline$\sigma$ & Aceleração devido a gravidade $\left(\mathrm{L} \mathrm{T}^{2}\right)$ \\
\hline $\mathrm{H}$ & Queda de pressão expressa em metro da suspensão de alimentação (L) \\
\hline $\mathrm{h}$ & Profundidade do ponto de amostragem com a pipeta $(\mathrm{L})$ \\
\hline $\mathrm{K}$ & Constante do modelo de Trawinski (1969) \\
\hline $\mathrm{K}_{1}$ & Constante do modelo de Svarovsky (1999) \\
\hline $\mathrm{K}_{2}$ & Constante do modelo de Svarovsky (1999) \\
\hline $\mathrm{k}_{1}$ & Constante do modelo de Castilho e Medronho (2000) \\
\hline $\mathrm{k}_{2}$ & Constante do modelo de Castilho e Medronho (2000) \\
\hline $\mathrm{k}_{3}$ & Constante do modelo de Castilho e Medronho (2000) \\
\hline \multirow[t]{2}{*}{$\mathrm{L}$} & Comprimento do hidrociclone (L) \\
\hline & Comprimento da reentrância do tubo do diluído (L) \\
\hline $\mathrm{L}_{1}$ & Comprimento da parte cilíndrica do hidrociclone (L) \\
\hline $\mathrm{n}$ & Parâmetro do modelo de Rosin-Rammler-Bennet \\
\hline $\mathrm{n}_{1}$ & Constante do modelo de Castilho e Medronho (2000) \\
\hline $\mathrm{n}_{2}$ & Constante do modelo de Castilho e Medronho (2000) \\
\hline $\mathrm{n}_{3}$ & Constante do modelo de Castilho e Medronho (2000) \\
\hline $\mathrm{n}_{4}$ & Constante do modelo de Castilho e Medronho (2000) \\
\hline $\mathrm{n}_{5}$ & Constante do modelo de Castilho e Medronho (2000) \\
\hline $\mathrm{n}_{6}$ & Constante do modelo de Castilho e Medronho (2000) \\
\hline $\mathrm{P}$ & Diferencial de pressão observado nas entradas do transdutor $\left(\mathrm{M} \mathrm{L}^{-1} \mathrm{~T}^{-2}\right)$ \\
\hline PVC & Cloreto de polivinila ou polivinil clorado \\
\hline Q & Vazão da suspensão de alimentação $\left(\mathrm{L}^{3} \mathrm{~T}^{-1}\right)$ \\
\hline $\mathrm{Qu}$ & Vazão da suspensão concentrada $\left(\mathrm{L}^{3} \mathrm{~T}^{-1}\right)$ \\
\hline$r^{2}$ & Coeficiente de determinação \\
\hline $\operatorname{Re}$ & Número de Reynolds baseado no diâmetro do hidrociclone \\
\hline RL & Razão de líquido \\
\hline $\mathrm{S}$ & Seção do bocal (L $\left.{ }^{2}\right)$ \\
\hline Stk $_{50}$ & Número de Stokes \\
\hline
\end{tabular}


$\mathrm{Stk}_{50} \mathrm{Eu} \quad$ Produto entre o número de Stokes e o número de Euler

t Intervalo de tempo (T)

tr $\quad$ Tempo de residência $(\mathrm{T})$

$\mathrm{V}_{\mathrm{c}} \quad$ Velocidade na alimentação baseada na seção cilíndrica $\left(\mathrm{L} \mathrm{T}^{-1}\right)$

$\mathrm{v}_{\mathrm{i}} \quad$ Velocidade de alimentação $\left(\mathrm{L} \mathrm{T}^{-1}\right)$

$\mathrm{v}_{\mathrm{r}} \quad$ Velocidade radial da partícula $\left(\mathrm{L} \mathrm{T}^{-1}\right)$

Vsp Tensão elétrica entre os pinos de saída e terra $(\mathrm{mV})$

$\mathrm{v}_{\mathrm{Z}} \quad$ Velocidade axial da partícula $\left(\mathrm{L} \mathrm{T}^{-1}\right)$

Wa Vazão mássica da suspensão na alimentação $\left(\mathrm{M} \mathrm{T}^{-1}\right)$

Ws Vazão mássica de sólidos na alimentação $\left(\mathrm{M} \mathrm{T}^{-1}\right)$

$\mathrm{Ws}_{\mathrm{o}} \quad$ Vazão mássica de sólidos no diluído $\left(\mathrm{M} \mathrm{T}^{-1}\right)$

$\mathrm{Ws}_{\mathrm{u}} \quad$ Vazão mássica de sólidos no concentrado $\left(\mathrm{M} \mathrm{T}^{-1}\right)$

X Fração mássica das partículas menores que dado diâmetro $d$ na alimentação

$\mathrm{X}_{\mathrm{o}} \quad$ Fração mássica das partículas menores que dado diâmetro $d$ no diluído

$\mathrm{X}_{\mathrm{u}} \quad$ Fração mássica das partículas menores que dado diâmetro $d$ no concentrado

$\alpha \quad$ Constante do modelo de Lynch e Rao (1975)

$\Delta \mathrm{P} \quad$ Queda de pressão entre as correntes de alimentação e diluído $\left(\mathrm{M} \mathrm{L}^{-1} \mathrm{~T}^{-2}\right)$

$\overline{\Delta P} \quad$ Diferencial de pressão médio de todos os ensaios (L)

$\mu \quad$ Viscosidade absoluta do fluido $\left(\mathrm{M} \mathrm{L}^{-1} \mathrm{~T}^{-1}\right)$

$\pi \quad$ Razão entre o perímetro e o diâmetro de uma circunferência

$\rho \quad$ Densidade do fluido $\left(\mathrm{M} \mathrm{L}^{-3}\right)$

$\rho_{\mathrm{s}} \quad$ Densidade do sólido $\left(\mathrm{M} \mathrm{L}^{-3}\right)$

$\theta \quad$ Ângulo do cone do hidrociclone (graus) 


\section{CURRICULUM VITAE}

Olívio José Soccol, filho de Deonísio Soccol e Ruth Kreiss Soccol, nasceu em Lages - SC, em 14 de março de 1962. Em agosto de 1983, ingressou no curso de Agronomia da Universidade do Estado de Santa Catarina - UDESC, concluindo-o em agosto de 1988. Em fevereiro de 1989, iniciou suas atividades como professor de Irrigação e Drenagem no curso de Agronomia da Universidade do Estado de Santa Catarina - UDESC, onde se encontra até hoje. No ano de 1992, realizou o curso de Especialização em Engenharia da Irrigação, na Universidade Federal de Viçosa - MG. Em março de 1993, iniciou o curso de mestrado em Engenharia Agrícola, na área de concentração em Irrigação e Drenagem, na Universidade Federal de Viçosa - MG, concluindo-o em agosto de 1996. Em agosto de 1999, iniciou o curso de Doutorado em Agronomia, na área de concentração em Irrigação e Drenagem, na Escola Superior de Agricultura "Luiz de Queiroz" (ESALQ/USP). 


\title{
CONSTRUÇÃO E AVALIAÇÃO DE HIDROCICLONE PARA PRÉ-FILTRAGEM DA ÁGUA DE IRRIGAÇÃO
}

\author{
Autor: OLÍVIO JOSÉ SOCCOL
}

Orientador: Prof. Dr. TARLEI ARRIEL BOTREL

\section{RESUMO}

$\mathrm{Na}$ agricultura irrigada, a qualidade da água utilizada é de fundamental importância para o perfeito funcionamento dos sistemas de irrigação e de seus componentes. A utilização de água contendo sedimentos em suspensão tem sido a causa de sérios problemas em sistemas de irrigação, reduzindo a vida útil de seus componentes, promovendo o entupimento de tubulações e emissores, ocasionando como conseqüência, irrigações não uniformes e queda na eficiência dos mesmos. A escolha do tipo e capacidade do sistema de filtragem é de fundamental importância, evitando-se assim, aumento nos custos de operação e manutenção do sistema de irrigação, devido a necessidade de limpeza e trocas freqüentes de seus componentes. Pré-filtros, como os hidrociclones, desempenham importante papel, pois se caracterizam por significativo poder de separação de partículas, maiores do que $100 \mu \mathrm{m}$, presentes na água; mantendo constante a perda de carga ao longo do tempo, o que não ocorre com os outros tipos de filtros normalmente utilizados nos sistemas de irrigação. Apesar de algumas referências feitas aos hidrociclones em literatura internacional, não se dispõe, no Brasil, de dados do desempenho dos hidrociclones, quando empregados em pré-filtragem da água utilizada 
nos sistemas de irrigação. Assim, um experimento conduzido no Laboratório de Hidráulica do Departamento de Engenharia Rural da ESALQ/USP, compreendeu a construção de quatro hidrociclones do tipo Rietema, com diâmetro de $50 \mathrm{~mm}$, um com bocal de alimentação circular e os demais com bocais de seção retangular, cujas seções foram decrescentes. A avaliação do desempenho dos mesmos foi realizada utilizando-se suspensões de areia fina e solo argiloso, sob diferentes diferenciais de pressão, adotando-se como critério de comparação, a capacidade de vazão e o poder de separação, medido pela eficiência total e eficiência total reduzida. Os resultados obtidos mostraram que o hidrociclone dotado com bocal de alimentação circular apresentou os maiores índices nos critérios de comparação, tanto para a suspensão de areia, quanto para a de solo. 


\title{
CONSTRUCTION AND EVALUATION OF HYDROCYCLONE FOR PRE- FILTERING IRRIGATION WATER
}

\author{
Author: OLÍVIO JOSÉ SOCCOL
}

Adviser: Dr. Prof. TARLEI ARRIEL BOTREL

\section{SUMMARY}

Good water quality is uppermost in irrigated agriculture for the perfect functioning of irrigation systems and their components. The use of water containing suspended sediments has caused serious problems to irrigation systems, reducing the useful life of their components, clogging pipes and emitters, consequently causing nonuniform irrigations and low efficiency. Choosing the right filtering system type and capacity is essential to avoid increases in operational and maintenance costs of irrigation systems due to the need for cleaning and frequent replacing of their components. Prefilters, such as hydrocyclones, are important for their significant capability to retain particles larger than $100 \mu \mathrm{m}$ present in water, keeping the head loss constant with the time, unlike other filters normally used in irrigation systems. Despite being present in the international literature, data on the performance of hydrocyclones used for prefiltering irrigation water in Brazil are not available. Therefore, four Rietema type hydrocyclones (50 $\mathrm{mm}$ diameter) were construction in the Hydraulics Laboratory of the Rural Engineering Department - ESALQ/USP- one presenting circular-end feeding tube and the other three presenting rectangular-end feeding tubes with decreasing sections. 
The evaluation of the hydrocyclones performance was conducted by using suspensions of fine sand and clay soil under various pressure differentials. The comparison criteria used were the discharge and the separation capability, given by total efficiency and reduced total efficiency. Results showed that the hydrocyclone with circular-end feeding tube presented the highest indexes for the comparison criteria adopted, considering sand and soil suspensions. 


\section{INTRODUÇÃO}

A qualidade da água utilizada na agricultura irrigada é de fundamental importância para o desempenho dos sistemas de irrigação e de seus componentes. Sedimentos carregados pela água de irrigação reduzem a vida útil de componentes dos sistemas de irrigação, tais como: rotores das bombas, bocais de aspersores, dispositivos de controle da vazão e da pressão e engates de tubulações.

A qualidade da água, aqui definida, refere-se as características que podem afetar a adaptabilidade para determinado uso, ou seja, a relação entre qualidade da água e as necessidades do usuário. Esta qualidade é definida por uma ou mais características físicas, químicas ou biológicas.

Água contendo sedimentos em suspensão tem sido a causa de sérios problemas em sistemas de irrigação localizada, principalmente, o entupimento de tubulações e de emissores, ocasionando como conseqüência, irrigações não uniformes e queda na sua eficiência.

A quantidade de sedimentos presentes na água de irrigação vai influenciar o dimensionamento do sistema de irrigação para o seu adequado desempenho. A escolha do tipo e capacidade do sistema de filtragem é de fundamental importância, evitando-se assim, o aumento dos custos de operação e manutenção do sistema de irrigação, devido a necessidade de limpeza e trocas freqüentes de seus componentes.

O entupimento físico de componentes dos sistemas de irrigação pode ser causado por fatores, tais como, a suspensão de partículas inorgânicas (areia, silte, argila, etc.) e material orgânico (fragmentos de plantas, resíduos de animais, etc.). A manutenção preventiva e constante constitui-se na melhor solução para reduzir ou eliminar as causas de entupimento. Esta manutenção inclui a filtragem, inspeção à campo, esvaziamento 
das linhas laterais e tratamento químico. É importante ressaltar que a filtragem se constitui em uma prática geralmente essencial, principalmente nos sistemas de irrigação localizada.

Os sistemas de filtragem normalmente utilizados em sistemas de irrigação, são constituídos por filtros de areia, de tela ou de discos. Se a água apresentar alta quantidade de sólidos, pode ser necessária a instalação de bacias de sedimentação ou mesmo pré-filtros na tomada de água, antes do cabeçal de controle. Dentre estes são citados os hidrociclones, que podem desempenhar esse papel, mas normalmente são instalados dentro do cabeçal de controle.

Tem-se observado que muitos equipamentos de filtragem instalados nos sistemas de irrigação têm operado abaixo de nível ótimo, o que pode ser explicado pela inadequada seleção e manutenção do equipamento, resultando no comprometimento do desempenho dos mesmos.

A necessidade de água com qualidade torna fundamental o planejamento do sistema de filtragem e o tratamento da água para a pior condição esperada. Deste modo os pré-filtros, como os hidrociclones, desempenham importante papel, pois se caracterizam por retirarem da água até $98 \%$ de partículas maiores que $100 \mu \mathrm{m}$, mantendo-se constante ao longo do tempo a perda de carga, o que não ocorre com os filtros de areia, de tela e de discos. Mesmo não retirando todas as impurezas presentes na água, o hidrociclone proporciona uma menor freqüência de limpeza daqueles filtros.

Apesar de terem seu uso difundido em outras áreas do conhecimento como, na engenharia de minas, na engenharia química e na engenharia de alimentos, os hidrociclones não têm sido utilizados no Brasil com a mesma frequiência que são usados em sistemas de irrigação de países como Israel e Estados Unidos. Este fato pode ser explicado pela falta de um procedimento simples de dimensionamento ou, pelo fato dos técnicos de irrigação desconhecerem o potencial deste equipamento, ou mesmo, pelo desinteresse das empresas do setor em comercializar um produto de baixo custo e que não necessita de manutenção e reposição de componentes.

Diante disso, este trabalho teve como objetivo construir e avaliar quatro hidrociclones, com as mesmas dimensões, mas variando a forma e dimensão dos tubos 
de alimentação, buscando obter parâmetros de desempenho dos mesmos operando com suspensão de areia e de solo. Com a alteração na forma e dimensão dos bocais, buscouse aumentar a eficiência do hidrociclone, uma vez que a distância radial a ser percorrida pelas partículas seria menor. 


\section{REVISÃO DE LITERATURA}

\subsection{Qualidade da água de irrigação}

A agricultura irrigada depende tanto da quantidade como da qualidade da água. No entanto, o aspecto da qualidade tem sido desprezado devido ao fato de que no passado, as fontes de água, no geral eram abundantes, de boa qualidade e de fácil utilização. $\mathrm{O}$ uso intensivo de praticamente todas as águas de boa qualidade implica em que, tanto para os projetos novos como para os antigos que requerem águas adicionais, tem que se recorrer às águas de qualidade inferior. Para minimizar problemas oriundos do uso da água de baixa qualidade, deve existir planejamento efetivo que assegure melhor uso possível da água de acordo com sua qualidade (Ayers \& Westcot, 1991). Para estes autores o conceito de qualidade da água refere-se às características que podem afetar a adaptabilidade para uso específico, em outras palavras, a relação entre a qualidade da água e as necessidades do usuário. A qualidade da água define-se por uma ou mais características físicas, químicas ou biológicas. Usos específicos podem ter diferentes requisitos de qualidade. Assim, a água pode ser considerada de melhor qualidade, se produzir melhores resultados, ou causar menores problemas. Por exemplo, a água de rio que pode ser considerada de boa qualidade para determinado sistema de irrigação pode, por sua carga de sedimentos, ser inaceitável para uso urbano, sem antes ser tratada para extrair os sedimentos. Na avaliação da qualidade da água para irrigação, levam-se em consideração, principalmente, as características químicas e físicas.

Thompson \& Krider (1983) afirmam que as características da água disponível nas propriedades têm significativo efeito na seleção do sistema de irrigação. Muitos fatores como o local, a quantidade disponível, a quantidade distribuída no tempo e a 
qualidade da água têm efeito sobre as considerações para definir e avaliar a aplicabilidade do sistema de irrigação na propriedade. A quantidade de sedimentos carregados pela água pode influenciar o dimensionamento para um adequado desempenho do sistema de irrigação. Quando altas cargas de sedimentos são encontradas, a irrigação localizada requer um sistema de filtragem que assegure um desempenho confiável.

Para Lopez (1998), a água de irrigação utilizada na agricultura pode conter contaminantes indesejáveis, tais como, sais dissolvidos, sedimentos suspensos, elementos tóxicos de ocorrência natural, nematóides e outros agentes infecciosos. Contaminantes físicos e partículas orgânicas podem causar efeitos adversos aos sistemas de irrigação. Quando presentes faz-se necessária à prevenção com filtros adequados para sua eficaz remoção. Sedimentos carregados pela água reduzem a vida útil dos componentes dos sistemas de irrigação, tais como, os rotores das bombas, os bocais de aspersores, os emissores e as tubulações dos sistemas de irrigação localizada e, em casos extremos, chega-se a necessidade da troca dos mesmos a cada ano. Diferentes tipos de filtros são necessários para evitar este tipo de problema (Lopez, 1998). Material suspenso na água de irrigação pode causar o mu funcionamento de medidores de vazão, válvulas, engates de tubos, comportas, entre outros. Um bom manejo da água de irrigação requer um completo controle da água derivada. Bacias de sedimentação de considerável tamanho e hidrociclones separadores de areia podem ser utilizados para reduzir o tamanho e custo dos sistemas de filtragem, especialmente quando se utiliza filtro de areia (Keller \& Bliesner, 1990).

Segundo Cuenca (1989), critérios de julgamento dos materiais com potencial de entupimento dos emissores têm sido desenvolvidos possibilitando aos engenheiros tomar decisões que habilitem a água ao uso para a irrigação. Estes critérios têm ajudado, juntamente com outros, os engenheiros projetistas a decidir pela escolha do sistema de irrigação ou o tipo de sistema de filtragem adequado à severidade do problema.

Cabello (1996) comenta que até o presente não se dispõe de um método garantido para avaliar o risco de obstrução ocasionado pelo uso de uma determinada água de irrigação. Segundo o autor, a questão não é fácil, pois alguns dos fatores 
intervenientes são variáveis, como é o caso da temperatura, que afeta a formação de precipitados e o desenvolvimento de microrganismos e outros que não dependem só da água, mas também dos produtos que a ela são adicionados, principalmente fertilizantes. Como orientação, Bucks et al. (1979) e Bucks \& Nakayama (1980) sugerem uma classificação da água quanto ao risco potencial de entupimento, apresentada na Tabela 1. Estas classificações baseiam-se em várias fontes, incluindo trabalhos de laboratório e experimentos de campo, realizados em vários locais e com diferentes qualidades de água.

Tabela 1. Risco potencial de entupimento pelo uso da água de irrigação.

\begin{tabular}{lccl}
\hline Tipos de problema & Reduzido & $\begin{array}{c}\text { Risco } \\
\text { Médio }\end{array}$ & Alto \\
\hline Fí́sicos & $<50$ & $50-100$ & $>100$ \\
$\begin{array}{l}\text { Sólidos suspensos (ppm) } \\
\text { Químico }\end{array}$ & $<7,0$ & $7,0-8,0$ & $>8,0$ \\
pH & $<500$ & $500-2.000$ & $>2.000$ \\
Sólidos dissolvidos (ppm) & $<0,1$ & $0,1-1,5$ & $>1,5$ \\
Mn (ppm) & $<0,1$ & $0,1-1,5$ & $>1,5$ \\
$\mathrm{Fe}(\mathrm{ppm})$ & $<0,5$ & $0,5-2,0$ & $>2,0$ \\
$\mathrm{SH}_{2}(\mathrm{ppm})$ & & & \\
Biológico & $<10.000$ & $10.000-50.000$ & $>50.000$ \\
População bacteriana $\left(\mathrm{n}^{\mathbf{0}} \mathrm{cm}^{-3}\right)$ & & & \\
\hline
\end{tabular}

Fonte: Bucks \& Nakayama (1980).

Ayers \& Westcot (1991) afirmam que a presença de sedimentos em suspensão na água de irrigação é motivo de preocupação em muitas regiões, pois além dos problemas com os componentes do sistema de irrigação, os sedimentos podem causar outro efeito negativo, que é a redução da permeabilidade dos terrenos, com a formação de crostas sobre a superfície do solo. Os sedimentos têm dificultado muito o funcionamento de equipamentos de irrigação por aspersão. $\mathrm{O}$ entupimento de tubulações e bocais tem feito com que a irrigação não seja uniforme e sua eficiência seja baixa, elevando os custos de operação e manutenção, devido a necessidade de limpeza e trocas freqüentes dos bocais. 
López et al. (1992) afirmam que o problema mais grave e freqüente nas instalações de irrigação localizada, em particular no gotejamento, é o entupimento, e que, dependendo do tipo de sólidos em suspensão ou impurezas da água, os sistemas devem ser providos de algum tipo de equipamento de filtragem. Segundo os autores, se forem consideradas a natureza das obstruções, as mesmas podem ser causadas por partículas orgânicas ou inorgânicas ou, por precipitações e/ou proliferação de bactérias. Quanto ao fator tempo, podem classificar-se em atuais ou imediatas e, em potenciais ou lentas. De modo geral, as obstruções atuais ou imediatas se identificam com as causadas por partículas orgânicas e inorgânicas, da mesma maneira, as potenciais ou lentas são associadas às produzidas por precipitações ou bactérias.

Para Gilbert \& Ford (1986), o tipo e quantidade de impurezas presentes na água de irrigação irão ditar o tipo de tratamento necessário para prevenção do entupimento. $\mathrm{O}$ entupimento físico pode ser causado por fatores tais como, a suspensão de partículas inorgânicas (areia, silte e argila), material orgânico (fragmentos de plantas, resíduos de animais, peixes, caracóis, etc.). A areia e o silte podem ser levados com a água de irrigação pela abertura de canais ou bombeamento de poços. Entupimentos por fatores físicos podem ser controlados com adequada filtração e periódico esvaziamento das linhas laterais. Segundo os mesmos autores, estudos estatísticos mostram que o entupimento dos emissores tem sido a maior causa de variação de vazão nos sistemas de irrigação localizada. A manutenção preventiva e constante tem sido a melhor solução para reduzir ou eliminar o entupimento dos emissores. Os autores relataram que a manutenção preventiva inclui a filtragem, inspeção do campo, esvaziamento das laterais e tratamento químico. A filtragem da água e a inspeção do campo são absolutamente essenciais.

Howell et al. (1983) e Keller \& Bliesner (1990) afirmam que o desenho dos emissores tem sido reconhecidamente condicionados para ter pequenas aberturas, proporcionando vazões mais próximas das taxas de infiltração da água no solo, mas resultando em maior probabilidade de entupimento quando comparados com os bocais dos aspersores. Alguns dos materiais que causam entupimento dos emissores são facilmente identificados nas fontes de água, tais como, as suspensões de areia, silte ou 
argila, e a necessidade de um sistema de filtragem para removê-los é óbvia. Outros componentes, como os precipitados químicos e as bactérias não são visíveis e podem se tornar aparentes somente após o início da operação do sistema. Cabello (1996) cita as causas do entupimento dos sistemas de irrigação localizada, apresentadas na Tabela 2.

Tabela 2. Causas de entupimento dos sistemas de irrigação localizada.

\begin{tabular}{ll}
\hline Partículas Minerais & Areia \\
& Limo \\
& Argila \\
& Outros \\
Partículas Orgânicas & Algas \\
& Bactérias \\
Precipitados Químicos & Restos vegetais ou animais \\
& Sais da água \\
& Deposição de Fe, S e Mn \\
& Fertilizantes \\
\hline
\end{tabular}

Fonte: Cabello (1996).

Segundo o autor, as medidas para se evitar o entupimento se dividem em dois tipos: uma preventiva, que consiste na filtragem e em alguns casos no tratamento da água; a outra é aplicada quando o sistema já apresenta entupimento parcial ou total, e consiste freqüentemente no tratamento da água ou mesmo o desentupimento com a aplicação de água ou ar com alta pressão.

\subsection{Sistema de filtragem da água para irrigação}

Para Gilbert \& Ford (1986), a seleção do tipo de filtro, tamanho e capacidade, depende da qualidade da água e das características do emissor. Segundo eles, a recomendação dos fabricantes de emissores é de que o nível de filtração requerido seja seguido, no entanto, não existem informações disponíveis. Na prática recomenda-se que os orifícios do filtro tenham $1 / 10$ do diâmetro dos emissores, evitando assim, que partículas agrupadas possam vir a entupir a passagem. Para estes autores, se as condições físicas da água indicarem situação severa, dois ou mais tipos de filtros podem 
ser necessários. López et al. (1992) afirmam que quando a água apresenta alta quantidade de sólidos, pode ser interessante a instalação de pré-filtros na tomada de água, antes do cabeçal de controle. Dentre estes, citam os hidrociclones, que podem fazer a função de pré-filtro, porém normalmente são instalados dentro do cabeçal de controle. São dispositivos que conseguem separar até $98 \%$ de partículas maiores de que $100 \mu \mathrm{m}$, separando apenas partículas mais densas de que a água. Os autores afirmam ainda, que a diferença entre o hidrociclone e os outros tipos de filtros, é que neste a perda de carga se mantém constante ao longo do tempo, variando apenas com a vazão do sistema. Segundo Bernardo (1989), os filtros comumente usados na irrigação localizada, são os filtros de areia, de tela e de ação centrífuga. Segundo Cuenca (1989) e Keller \& Bliesner (1990), os diferentes dispositivos de filtragem são efetivos na remoção de diferentes tipos de material da água. Os filtros comumente utilizados nos sistemas de irrigação localizada são os filtros de areia, de tela e os filtros centrífugos. O filtro de tela é o filtro mais utilizado em sistemas de irrigação localizada, sendo que a malha da tela depende do tamanho de partícula que se pretende remover. Muitos emissores disponíveis comercialmente requerem filtros com malhas para reter material com tamanho de 150 a $75 \mu \mathrm{m}$ (100 a 200 mesh). Os filtros de areia podem remover relativamente grandes quantidades de sólidos suspensos na água e estão disponíveis para remoção de partículas com tamanho variando de 25 a $100 \mu \mathrm{m}$. Os filtros centrífugos são utilizados na remoção de partículas mais pesadas que a água e maiores que $75 \mu \mathrm{m}$, sendo algumas vezes instalados na sucção da bomba, de modo a realizar a remoção primária da areia do sistema. Isto reduz o desgaste do rotor pela areia e remove a nesma do sistema de distribuição (Keller \& Bliesner, 1990).

A necessidade de água com qualidade torna importante o planejamento do sistema de filtragem e o tratamento da água para a pior condição esperada. Quando fontes de água de superfície são usadas, faz-se necessário o uso de um complexo sistema de filtragem. O sistema pode ser constituído por um pré-filtro, tal como uma bacia de sedimentação ou hidrociclone, seguido de um filtro de areia e de um filtro de tela. $\mathrm{O}$ sistema de filtragem necessário depende do tipo e quantidade de contaminantes presentes e da qualidade da água requerida para satisfazer a operação do sistema de 
irrigação (Keller \& Bliesner, 1990). Os autores afirmam ainda, que o tamanho da partícula que pode ser tolerada, depende da construção do emissor e deveria ser indicada pelo fabricante. Muitos fabricantes recomendam a remoção partículas maiores que 75 $\mu \mathrm{m}$, mas alguns permitem partículas maiores que $600 \mu \mathrm{m}$. Obviamente, é importante que partículas maiores que o orifício sejam removidas. Segundo Cabello (1996), quando a água transporta uma alta concentração de sólidos em suspensão, pode ser útil a instalação de pré-filtros antes do cabeçal de controle. O autor cita que existe uma grande variedade dos mesmos, no entanto os comumente utilizados em irrigação são os decantadores e os hidrociclones. Segundo o autor, os hidrociclones permitem eliminar as partículas de densidade superior a 1,5 e tamanhos superiores a $74 \mu \mathrm{m}$. As perdas de carga são da ordem de 30-70 kPa, dependendo da vazão, no entanto são constantes no tempo, o que os diferencia dos outros filtros, onde as perdas aumentam a medida que se acumulam os sedimentos. Os hidrociclones devem ser instalados como pré-filtros antes do cabeçal de controle e que devem conduzir a água até um filtro de malha como medida de segurança, no caso de alguma falha impedir seu funcionamento ou, até que entrem em regime de operação, podem deixar passar partículas.

Keller \& Bliesner (1990) apresentam uma tabela em que o tamanho das partículas do solo são relacionados a um correspondente número mesh, como pode ser observado na Tabela 3. Nota-se que uma tela com 200 mesh, que tem pequenos tamanhos de orifícios, normalmente utilizada em filtros de irrigação localizada pode reter apenas parte da areia muito fina.

Os mesmos autores afirmam que os filtros de tela, onde são apropriados, se constituem num meio simples e eficiente de filtragem da água. O tamanho dos orifícios e a área total de abertura são determinantes na eficiência e no limite operacional destes filtros. Os filtros removem de forma eficiente partículas muito finas de areia ou pequenas quantidades de algas. Um filtro de tela com grande vazão em relação a área de abertura requer limpezas mais freqüentes e tem uma vida útil reduzida. Os fatores que devem ser levados em consideração por ocasião da escolha do filtro são: qualidade da água, vazão do sistema, área de filtragem, porcentagem de área aberta por filtro, tempo desejado para o ciclo de limpeza e a perda de carga permissível. 
Tabela 3. Classificação do solo por tamanho de partículas com correspondente número mesh da tela.

\begin{tabular}{lcc}
\hline \multicolumn{1}{c}{$\begin{array}{c}\text { Classificação } \\
\text { do solo }\end{array}$} & $\begin{array}{c}\text { Tamanho da partícula } \\
\mu \mathrm{m}\end{array}$ & $\begin{array}{c}\text { Número mesh } \\
\text { da tela }\end{array}$ \\
\hline Areia muito grossa & $1000-2000$ & $18-10$ \\
Areia grossa & $500-1000$ & $35-18$ \\
Areia média & $250-500$ & $60-35$ \\
Areia fina & $100-250$ & $160-60$ \\
Areia muito fina & $50-100$ & $270-160$ \\
Silte & $2-50$ & $400-270^{*}$ \\
Argila & $<2$ & - \\
\hline
\end{tabular}

Nota: *400 mesh é a tela que tem a malha de menor tamanho, aproximadamente $0,03 \mathrm{~mm}$.

Fonte: Keller \& Bliesner (1990).

Para Gilbert \& Ford (1986), algas presentes na água tendem a causar o entupimento da tela, podendo reduzir a capacidade de filtragem. Fabricantes recomendam telas com malhas finas de 100 ou 200 mesh $(150$ ou $75 \mu \mathrm{m})$, a grossas de 30 mesh $(600 \mu \mathrm{m})$. Este tipo de filtro requer limpeza e inspeção de rotina, de modo a assegurar a operação satisfatória do sistema de irrigação localizada.

Segundo Phillips (1995), muitos equipamentos de filtragem instalados nos sistemas de irrigação localizada têm operado abaixo do nível ótimo. Observando o desempenho dos mesmos, verificou erros de seleção dos produtos e inadequado monitoramento e manutenção a campo, o que resulta no comprometimento do desempenho do sistema de filtragem. O autor comenta ainda, que a mais de 20 anos o uso da irrigação localizada na produção agrícola tem se expandido significativamente. Durante estas duas décadas observou-se uma contínua melhoria no dimensionamento e tecnologia dos produtos de filtragem destinados a irrigação, melhorias que têm resultado em sucessos e falhas de operação no campo. Filtros de tela não são indicados para condições onde haja altas cargas de sujeira; sua seleção, em alguns casos, cria intensa manutenção e dificuldades operacionais. Portanto, ecomenda-se o filtro de tela, apenas onde haja baixas cargas de areia, silte, pedriscos ou contaminantes inorgânicos. 
Keller \& Bliesner (1990) comentam que os filtros de areia são utilizados principalmente para reter cargas pesadas de areia muito fina e material orgânico. São freqüentemente construídos para a retrolavagem automática quando necessária, recomendando-se na prática, também o uso de filtros de tela, na seqüência, de modo a coletar o material que possa passar por ocasião desta operação. Eles são muito efetivos para filtrar material orgânico, porque podem coletar os contaminantes através da camada de areia, acumulando grandes quantidades de algas. Gilbert \& Ford (1986) afirmam que os filtros de areia não são facilmente entupidos por algas, podendo remover relativamente uma grande quantidade de sólidos suspensos antes que a limpeza seja necessária. Porém eles podem oferecer condições favoráveis à proliferação de bactérias. São normalmente usados para reter partículas com tamanho de 25 a $100 \mu \mathrm{m}$. Phillips (1995) comenta que os filtros de areia são indicados em situações em que há alta concentração de material inorgânico ou qualquer tipo de contaminante orgânico.

Segundo Keller \& Bliesner (1990), as bacias de sedimentação removem grandes quantidades de areia e silte, devendo ser construídas para que a água leve um quarto de hora para atravessá-la, tempo suficiente para partículas inorgânicas maiores que $80 \mu \mathrm{m}$ (acima de 200 mesh) sedimentarem. Para isto, necessita-se de uma bacia com 1,2 m de profundidade por 3,3 $\mathrm{m}$ de largura por $13,7 \mathrm{~m}$ de comprimento, para possibilitar um tempo de residência (permanência) de um quarto de hora para uma vazão de $57 \mathrm{~L} \mathrm{~s}^{-1}$. Os autores afirmam que, modernamente, tem se utilizado separadores centrífugos, como os hidrociclones, que podem remover mais de $98 \%$ de partículas de areia, que poderiam ser contidas por uma tela de 200 mesh. Os mesmos dependem da força centrífuga para remover e lançar partículas de alta densidade para fora da água e conseqüentemente podem remover material orgânico. São eficientes dispositivos que retiram grande quantidade de areia muito fina de poços, correntes, rios ou canais. Porém, devem ser seguidos de filtros de tela, que por segurança, podem reter contaminantes que passem por eles. Para Gilbert \& Ford (1986), os hidrociclones ou filtros centrífugos removem partículas suspensas que tenham peso específico maior que a água e tamanho maior que $75 \mu \mathrm{m}$, porém são ineficientes na remoção de sólidos orgânicos. São eficientes na 
remoção de um grande número de partículas de areia e são usados eficientemente em pré-filtragem, quando instalados antes dos outros tipos de filtros.

Phillips (1995) afirma que a partir da década 80, o padrão de filtragem para a irrigação localizada inclui o uso de um filtro primário e na sequiência um filtro secundário. O uso dos dois filtros tem se dado, em muitos casos, pelo inadequado desempenho do filtro primário. $\mathrm{O}$ autor sugere algumas linhas gerais para a seleção do sistema de filtragem da irrigação localizada, as quais são apresentadas na Tabela 4.

Tabela 4. Linhas gerais para a seleção do sistema de filtragem na irrigação localizada.

\begin{tabular}{|c|c|c|c|c|c|c|}
\hline $\begin{array}{c}\text { Tipo de } \\
\text { contaminante }\end{array}$ & Concentração & $\begin{array}{c}\text { Carga } \\
\text { aproximada }\end{array}$ & $\begin{array}{c}\text { Tela na sucção } \\
\text { da bomba }\end{array}$ & $\begin{array}{l}\text { Separador } \\
\text { centrífugo }\end{array}$ & $\begin{array}{l}\text { Filtro } \\
\text { de tela }\end{array}$ & $\begin{array}{c}\text { Filtro de } \\
\text { areia }\end{array}$ \\
\hline \multirow{7}{*}{$\begin{array}{l}\text { Orgânico } \\
\text { ou mistura } \\
\text { orgânico / } \\
\text { inorgânico }\end{array}$} & Leve & $\leq 10 \mathrm{mg} \mathrm{L}^{-1}$ & Sim & Sim & Não & Sim \\
\hline & & $50-1$ & Nota 1 & Nota 2 & & \\
\hline & Moderada & $10-25 \mathrm{mg} \mathrm{L}$ & $\begin{array}{c}\text { Sim } \\
\text { Nota } 1\end{array}$ & $\underset{\text { Nota } 2}{\text { Sim }}$ & Não & Sim \\
\hline & Média & $25-50 \mathrm{mg} \mathrm{L}^{-1}$ & Sim & Sim & Não & Sim \\
\hline & Média/alta & $50-75 \mathrm{mg} \mathrm{L}^{-1}$ & $\begin{array}{c}\text { Nota } 1 \\
\text { Sim } \\
\text { Nota } 1\end{array}$ & $\begin{array}{c}\text { Nota } 2 \\
\text { Sim } \\
\text { Nota } 2\end{array}$ & Não & Sim \\
\hline & Alta & $75-100 \mathrm{mg} \mathrm{L}^{-1}$ & Sim & Sim & Não & Sim \\
\hline & Muito alta & $>100 \mathrm{mg} \mathrm{L}^{-1}$ & $\begin{array}{l}\text { Nota } 1 \\
\text { Sim } \\
\text { Nota 1 }\end{array}$ & $\begin{array}{c}\text { Nota } 2 \\
\text { Sim } \\
\text { Nota } 2\end{array}$ & Não & $\begin{array}{l}\text { Sim } \\
\text { Nota } 3\end{array}$ \\
\hline \multirow{8}{*}{ Inorgânicos } & Leve & $\leq 10 \mathrm{mg} \mathrm{L}^{-1}$ & Sim & Sim & Sim & Sim \\
\hline & Moderada & $10-25 \mathrm{mg} \mathrm{L}^{-1}$ & $\begin{array}{l}\text { Nota } 1 \\
\text { Sim }\end{array}$ & $\begin{array}{l}\text { Nota } 2 \\
\text { Sim }\end{array}$ & Sim & Sim \\
\hline & & & Nota 1 & Nota 2 & & \\
\hline & Média & $25-50 \mathrm{mg} \mathrm{L}^{-1}$ & Sim & Sim & Sim & Sim \\
\hline & & & Nota 1 & Nota 2 & Nota 3 & \\
\hline & Média/alta & $50-75 \mathrm{mg} \mathrm{L}^{-1}$ & $\underset{\text { Nota } 1}{\text { Sim }}$ & $\underset{\text { Nota } 2}{\text { Sim }}$ & $\underset{\text { Nota } 3}{\text { Sim }}$ & Sim \\
\hline & Alta & $75-100 \mathrm{mg} \mathrm{L}^{-1}$ & Sim & Sim & Não & Sim \\
\hline & Muito alta & $>100 \mathrm{mg} \mathrm{L}^{-1}$ & $\begin{array}{c}\text { Nota } 1 \\
\text { Sim } \\
\text { Nota } 1\end{array}$ & $\begin{array}{c}\text { Nota } 2 \\
\text { Sim } \\
\text { Nota } 2\end{array}$ & Não & $\begin{array}{c}\text { Sim } \\
\text { Nota } 3\end{array}$ \\
\hline
\end{tabular}

Nota: 1. Recomenda-se tela na sucção da bomba somente como pré-tratamento antes do filtro primário;

2. Recomenda-se separadores centrífugos somente para remoção de material inorgânico com peso específico $\geq 2 \mathrm{~g} \mathrm{~cm}^{-3}$ e deve ser usado em conjunto com o filtro de tela ou areia;

3. É recomendado um pré-tratamento com separador centrífugo.

Fonte: Phillips (1995). 


\subsection{Hidrociclones}

Os hidrociclones, também conhecidos pelos nomes de ciclone hidráulico, ciclone de líquido, hidroclones, cones de separação e separadores centrífugos, constituem uma classe importante de equipamentos destinados principalmente a separação de suspensões sólido-líquido (Silva, 1989; Souza et al., 2000). A primeira patente de hidrociclone data de 1891, no entanto, sua utilização industrial só teve início após a $2^{\text {a }}$ Guerra Mundial pelo "Dutch State Mines" nas indústrias de extração e processamento de minérios (Rietema, 1961a; Silva, 1989). Desde então, vêm sendo usados industrialmente, de maneira diversificada nas indústrias química, metalúrgica, têxtil, petroquímica, alimento, bioengenharia, etc. (Chu et al., 2002; Dai et al., 1999; Rovinsky, 1995; Silva, 1989).

Segundo Cilliers \& Harrison (1997), hidrociclones de pequenos diâmetros têm tido uso crescente, efetuando difíceis separações entre fases, devido a grande força centrífuga então gerada. O uso potencial de hidrociclones na concentração de suspensões microbiológicas é atraente, pois eles são contínuos, de alta capacidade de injeção, requerendo baixa manutenção, embora possuam o benefício adicional de poderem ser prontamente esterilizados. A separação de células microbiológicas de um meio de cultura tem sido requerido na maior parte dos processos microbiológicos, quando desejase produzir células dele mesmo num composto intra ou extracelular; é um desafio a separação destas pequenas partículas (tipicamente de 1 a $10 \mu \mathrm{m}$ de diâmetro) e a baixa diferença de densidade com relação ao meio suspenso.

Os hidrociclones foram originalmente desenhados para promover a separação de sólido-líquidos (Castilho \& Medronho, 2000), porém atualmente eles também têm sido usados para a separação sólido-sólido (Klima \& Kim, 1998), líquido-líquido (Smyth \& Thew, 1996) e gás-líquido (Marti, 1996).

O princípio de separação dos hidrociclones é o mesmo das centrífugas, isto é, a sedimentação centrífuga, em que as partículas em suspensão são submetidas a um campo centrífugo que provoca sua separação do fluido (Souza et al., 2000). Segundo os autores, de forma distinta das centrífugas, que usam o mesmo princípio, os hidrociclones não 
apresentam partes móveis, requerendo baixo custo de instalação e manutenção e são simples de operar.

O hidrociclone consiste de uma parte cônica ligada a uma parte cilíndrica, na qual existe uma entrada tangencial para a suspensão de alimentação. A parte superior do hidrociclone apresenta um tubo para saída da suspensão diluída (overflow) e na parte inferior há um orifício de saída da suspensão concentrada (underflow), conforme pode ser observado na Figura 1.

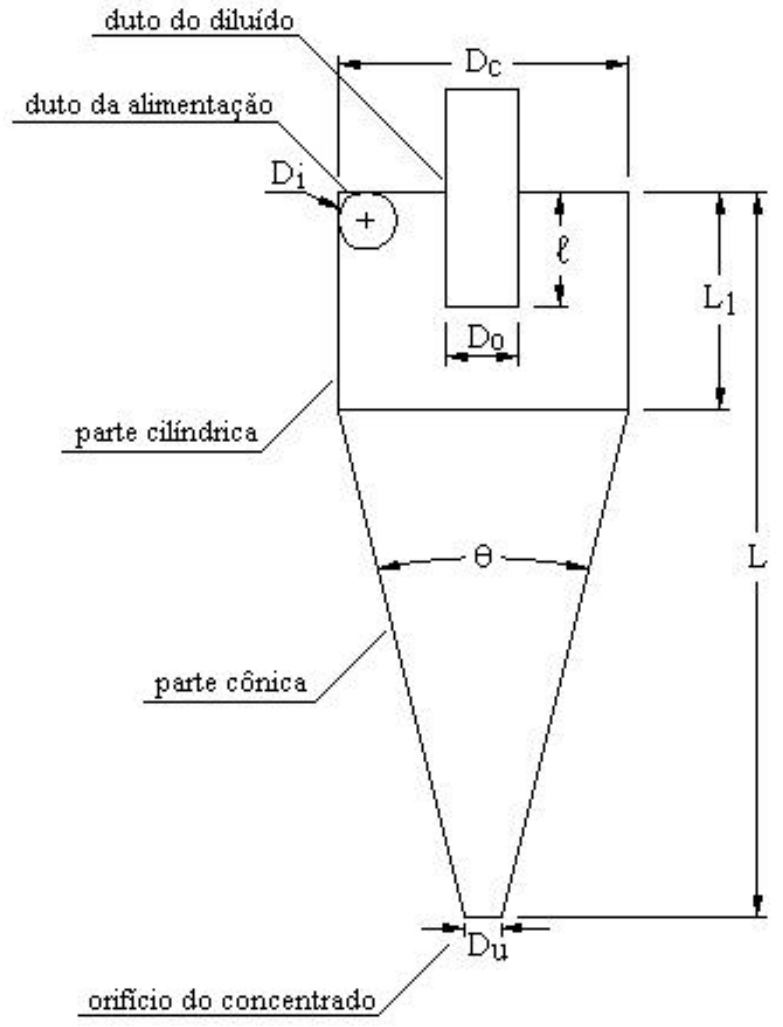

Figura 1 - Esquema mostrando as principais dimensões do hidrociclone.

A suspensão é bombeada através do tubo de alimentação e ao entrar no hidrociclone, é animada de um movimento rotacional descendente, que tenta sair pelo orifício do concentrado. Como esta abertura é relativamente pequena, apenas parte do líquido consegue sair, carregando consigo as partículas grossas. O líquido que não 
consegue sair por este caminho, volta, formando um vórtice ascendente interno, que escapa pelo tubo da suspensão diluída, juntamente com as partículas finas (Flintoff et al., 1987; Rietema, 1961a; Silva, 1989).

Flintoff et al. (1987) e Silva (1989) afirmam ainda, que a maior parte da suspensão de alimentação deixa o hidrociclone através do tubo de diluído. Assim, forças centrífugas elevadíssimas são geradas no vórtice interno, propiciando uma separação secundária de elevada eficiência. Pode-se observar na Figura 2 a trajetória do líquido dentro do hidrociclone.

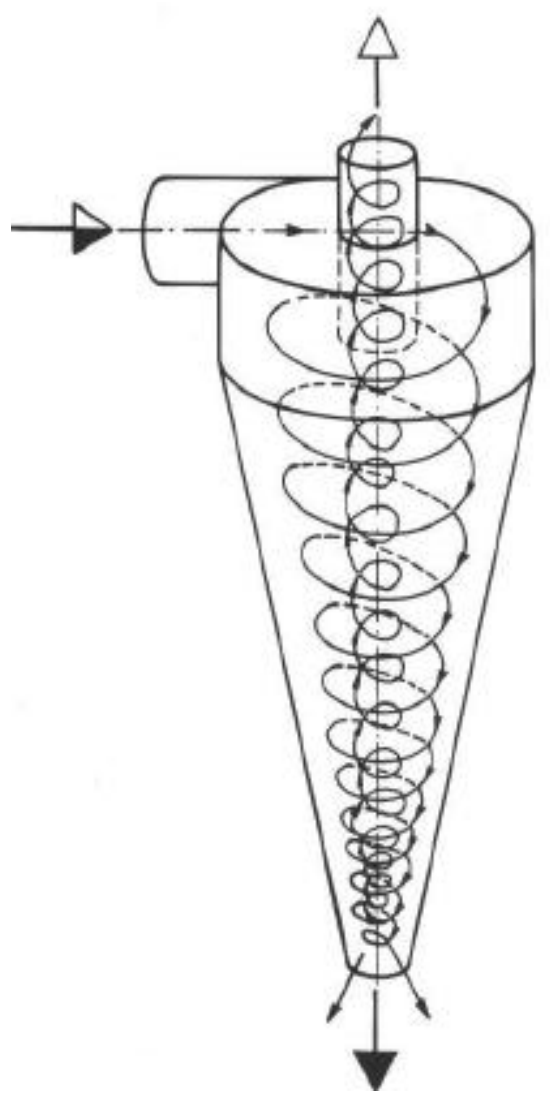

Figura 2 - Esquema mostrando o escoamento interno no hidrociclone.

Um ponto importante no escoamento interno dos hidrociclones é a formação de um núcleo central gasoso. O movimento de rotação do líquido cria uma zona central de 
baixa pressão, que normalmente resulta na formação de uma superfície livre de líquido, ao redor do eixo do hidrociclone. Se uma das saídas, ou ambas, encontram-se abertas para a atmosfera, o núcleo gasoso central será formado por ar, caso contrário, o núcleo gasoso pode ainda existir, formado por vapor ou gases dissolvidos no líquido. Este núcleo gasoso central pode ser suprimido evitando-se a comunicação direta das correntes de saída com a atmosfera e por meio do controle da pressão nas tubulações do diluído e do concentrado. Geralmente, a ausência do núcleo central gasoso produz um aumento na queda de pressão, para uma mesma vazão de alimentação, assim como uma queda na eficiência de separação (Flintoff et al., 1987; Rietema, 1961b; Silva, 1989).

Silva (1989) cita que os hidrociclones têm diâmetros entre $1 \mathrm{~cm}$ e $250 \mathrm{~cm}$, com diâmetro de corte para a maioria dos sólidos variando de $2 \mu \mathrm{m}$ a $250 \mu \mathrm{m}$. A vazão de alimentação varia de $0,1 \mathrm{~m}^{3} \mathrm{~h}^{-1}$ a $7200 \mathrm{~m}^{3} \mathrm{~h}^{-1}$, a queda de pressão varia de 34 a $600 \mathrm{kPa}$ e a concentração máxima de sólidos, que pode ser obtida no concentrado, raramente excede $45 \%$ a $50 \%$ em volume.

\subsection{Classificação dos hidrociclones}

Castilho \& Medronho (2000) citam que existem apenas dois grupos bem conhecidos de hidrociclones geometricamente semelhantes, que são as de Rietema (1961c) e de Bradley (1965). Os autores apresentam as proporções geométricas dos dois grupos de hidrociclones, que podem ser observadas na Tabela 5.

Tabela 5. Proporções geométricas dos dois grupos de hidrociclones.

\begin{tabular}{ccccccc}
\hline Hidrociclone & $\mathrm{D}_{\mathrm{i}} / \mathrm{D}_{\mathrm{c}}$ & $\mathrm{D}_{\mathrm{o}} / \mathrm{D}_{\mathrm{c}}$ & $\mathrm{L}_{\mathrm{D}} \mathrm{D}_{\mathrm{c}}$ & $\mathrm{L}_{1} / \mathrm{D}_{\mathrm{c}}$ & $\ell / \mathrm{D}_{\mathrm{c}}$ & $\theta$ \\
\hline Bradley & $1 / 7$ & $1 / 5$ & - & $1 / 2$ & $1 / 3$ & $9^{\circ}$ \\
Rietema & 0,28 & 0,34 & 5 & - & 0,40 & $20^{\circ}$ \\
\hline
\end{tabular}

Fonte: Castilho \& Medronho (2000). 


\subsection{Medida do desempenho de hidrociclones}

Na operação com hidrociclone, quando a suspensão de alimentação é introduzida no interior do mesmo, operando em regime permanente, uma fração do líquido junto com as partículas de maior velocidade terminal é descarregada, por meio do orifício de saída do concentrado. O restante do líquido com as partículas de menor velocidade terminal é descarregado, por meio do tubo de saída da suspensão diluída (Silva, 1989). Segundo o autor, mesmo que o hidrociclone não esteja separando, devido a ação centrífuga, uma certa quantidade de sólidos é removida no concentrado, numa razão igual a razão de líquido $R_{L}$. Isto acontece porque o hidrociclone age também como um divisor do escoamento, tal como uma conexão $T$ em tubulações.

A razão de líquido pode ser definida utilizando-se a Equação 1.

$$
R_{L}=\frac{Q_{u}\left(1-C v_{u}\right)}{Q(1-C v)}
$$

em que,

$\mathrm{Q}_{\mathrm{u}}$ - vazão da suspensão concentrada, $\mathrm{L} \mathrm{s}^{-1}$;

$\mathrm{Q}$ - vazão da suspensão de alimentação, $\mathrm{L} \mathrm{s}^{-1}$;

$\mathrm{CV}_{\mathrm{u}}$ - concentração volumétrica da suspensão concentrada, $\mathrm{L} \mathrm{L}^{-1}$; e

$\mathrm{Cv}$ - concentração volumétrica da alimentação, $\mathrm{L} \mathrm{L}^{-1}$.

\subsubsection{Eficiência total ou global}

Considere-se o esquema simplificado de um hidrociclone apresentado na Figura 3, em que $Q$ é a vazão da suspensão, $X$ é a fração mássica das partículas menores que um dado diâmetro $d$ e $W_{s}$ é a vazão mássica de sólidos na alimentação. Os subscritos $o$ e $u$ denotam diluído e concentrado, respectivamente.

O balanço de massa global no hidrociclone, considerando que não haja acúmulo dentro do mesmo, é dado por:

$$
W s=W s_{o}+W s_{u}
$$

em que, 
Ws - vazão mássica de sólidos na alimentação, $\mathrm{kg} \mathrm{s}^{-1}$;

$\mathrm{Ws}_{\mathrm{o}}$ - vazão mássica de sólidos no diluído, $\mathrm{kg} \mathrm{s}^{-1}$; e

$\mathrm{Ws}_{\mathrm{u}}$ - vazão mássica de sólidos no concentrado, $\mathrm{kg} \mathrm{s}^{-1}$.

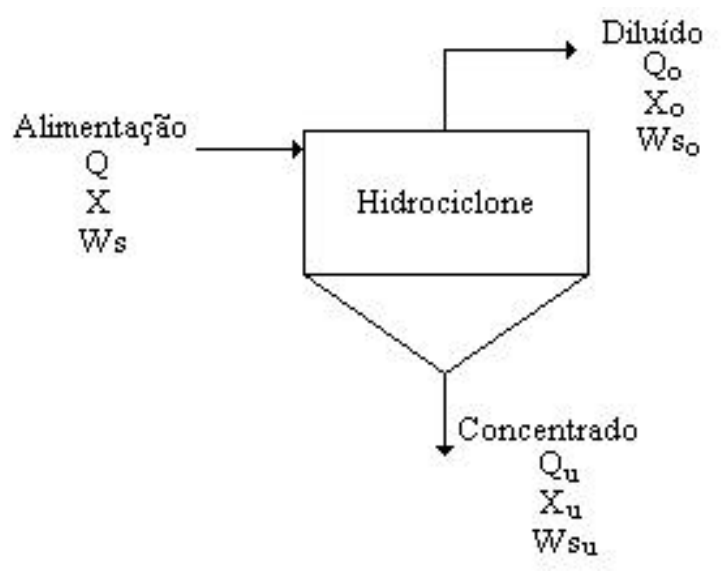

Figura 3 - Esquema simplificado do hidrociclone.

Segundo Scheid (1992), o mesmo balanço pode ser feito para partículas menores que um determinado diâmetro $d$ presentes na alimentação, considerando que não há modificação do tamanho das mesmas no interior do hidrociclone.

$$
W s X=W s_{o} X_{o}+W s_{u} X_{u}
$$

ou seja,

$$
X=\frac{W s_{o}}{W s} X_{o}+\frac{W s_{u}}{W s} X_{u}
$$

em que,

$\mathrm{X}$ - fração mássica das partículas menores que um dado diâmetro $d$ na alimentação, adimensional;

$\mathrm{X}_{\mathrm{o}}$ - fração mássica das partículas menores que um dado diâmetro $d$ no diluído, adimensional; e

$X_{\mathrm{u}}$ - fração mássica das partículas menores que um dado diâmetro $d$ no concentrado, adimensional. 
A eficiência total de separação do hidrociclone é definida como sendo a razão entre a massa total de sólidos coletados no concentrado e a massa total de sólidos na alimentação.

$$
E_{T}=\frac{W s_{u}}{W s}
$$

em que,

$\mathrm{E}_{\mathrm{T}}$ - eficiência total, adimensional.

\subsubsection{Eficiência total reduzida}

No cálculo da eficiência total são considerados todos os sólidos existentes no concentrado, inclusive aqueles que não foram separados devido à ação centrífuga. $O$ efeito $T$ verificado no hidrociclone garante uma eficiência mínima de separação. Sendo assim, a contribuição do "fluxo morto" (parte do líquido alimentado que é enviado ao concentrado) deve ser subtraída, obtendo-se assim, o verdadeiro desempenho de separação do hidrociclone. Várias expressões têm sido sugeridas levando em conta a correção da eficiência devido ao efeito $T$, dentre elas a mais utilizada é a da eficiência total reduzida, sugerida por Kelsall (1953).

$$
E_{T}^{\prime}=\frac{E_{T}-R_{L}}{1-R_{L}}
$$

em que,

E' ${ }_{\mathrm{T}}$ - eficiência total reduzida, adimensional.

\subsubsection{Eficiência granulométrica}

A eficiência granulométrica pode ser definida, como sendo a razão entre as vazões mássicas de sólidos no concentrado e na alimentação, só que neste caso para um determinado diâmetro $d$ de partícula. Sua definição é semelhante à da eficiência total, exceto pelo fato de que seu valor corresponde a um único tamanho de partícula, sendo também conhecida como eficiência individual ou eficiência por tamanho. Entretanto, a 
vazão mássica para um determinado diâmetro, é dada pelo produto da vazão mássica de sólidos na corrente em questão pela correspondente fração $d X / d d$, assim:

$$
G=\frac{W s_{u}}{W s} \frac{d X_{u} / d d}{d X / d d}
$$

substituindo a Equação 7 na Equação 5, tem-se:

$$
G=E_{T} \frac{d X_{u}}{d X}
$$

que na forma integral resulta,

$$
E_{T}=\int_{0}^{1} G d X
$$

em que,

G - eficiência granulométrica, adimensional.

A Equação 8 permite a determinação da eficiência granulométrica do hidrociclone, por meio do conhecimento da sua eficiência global e da distribuição granulométrica das correntes de alimentação e do concentrado. Os resultados são usualmente analisados por intermédio da curva de eficiência granulométrica, proporcionada pelo hidrociclone.

\subsubsection{Eficiência granulométrica reduzida}

Como na operação do hidrociclone sempre há uma eficiência mínima, igual a razão de líquido, tendo em vista o que já foi discutido a respeito do efeito $T$, a eficiência granulométrica reduzida $G$ ' poderá ser obtida da mesma forma que a eficiência total reduzida:

$$
G^{\prime}=\frac{G-R_{L}}{1-R_{L}}
$$

em que,

G'- eficiência granulométrica reduzida, adimensional. 
A curva de eficiência granulométrica reduzida começa na origem e o diâmetro da partícula, que possui uma eficiência reduzida de 50\%, é conhecido como diâmetro de corte reduzido $d^{\prime}{ }_{50}$. O diâmetro de corte é um diâmetro de partícula que de certa forma representa o poder de separação do hidrociclone, quanto menor este diâmetro melhor projetado foi o hidrociclone.

A literatura sobre hidrociclones apresenta alguns modelos empíricos para a curva de eficiência granulométrica obtidos por pesquisadores. Bradley (1965) ajustou uma equação que relaciona eficiência granulométrica reduzida versus $d / d^{\prime}{ }_{50}$ para os dados obtidos por Yoshioka e Hotta (1955), que trabalharam com um hidrociclone de $150 \mathrm{~mm}$ de diâmetro e com suspensões de argila a $1,5 \%$ e $2 \%$ em peso.

$$
G^{\prime}=1-e^{\left[-\left(\frac{d}{d_{50}}-0,115\right)^{3}\right]}
$$

Plitt (1971) propôs uma equação do tipo Rosin-Rammler-Bennet que é:

$$
G^{\prime}=1-e^{\left[-0,693\left(\frac{d}{d_{50}^{\prime}}\right)^{n}\right]}
$$

Plitt (1976) trabalhando com hidrociclones de diferentes configurações e suspensão de sílica, obteve uma equação para o cálculo do parâmetro $n$ da Equação 12.

$$
n=2,959\left[\frac{D_{c}^{2}(L-\ell)}{Q}\right]^{0,15} e^{\left(-1,58 R_{L}\right)}
$$

em que,

$\mathrm{D}_{\mathrm{c}}$ - diâmetro do hidrociclone, $\mathrm{m}$;

L - comprimento do hidrociclone, m;

$\ell$ - comprimento da reentrância do tubo de saída do diluído, m; e

$\mathrm{Q}$ - vazão da suspensão de alimentação, $\mathrm{m}^{3} \mathrm{~s}^{-1}$.

Segundo o autor, valores de $n$ superiores a 3 são indicativos de uma separação com bom poder de classificação, ao passo que, valores inferiores a 2 representa 
classificação relativamente ruim. Coelho \& Medronho (1994) citam que para hidrociclones, o valor de $n$ é igual a 2,9.

\subsection{Grupos adimensionais importantes no estudo de hidrociclones}

Pai Neto et al. (2000) afirmam que a modelagem matemática da operação de hidrociclones é extremamente complexa e que, uma alternativa utilizada para quantificar o desempenho destes dispositivos, baseia-se na obtenção experimental da relação entre os números adimensionais relevantes à operação dos mesmos. Silva (1989) cita que os números adimensionais de importância no estudo de hidrociclones são três: o número de Stokes $S t k_{50}$, o número de Euler Eu e o número de Reynolds $R e$.

Svarovsky (1984) comenta que para a determinação dos números adimensionais, em caso de suspensões diluídas, destacam-se como variáveis importantes: o diâmetro do hidrociclone $D_{c}$, a queda de pressão entre as correntes de alimentação e do diluído $\Delta P$, velocidade de alimentação baseada na seção cilíndrica do hidrociclone $v_{c}$, viscosidade do fluido $\mu$, densidade do fluido $\rho$, diferença entre as densidades do sólido e do fluido $\left(\rho_{s}-\rho\right)$ e o diâmetro de corte reduzido $d^{\prime}{ }_{50}$.

O número de Stokes pode ser calculado utilizando-se a Equação 14, e apresenta importância no scale-up de hidrociclone.

$$
S t k_{50}=\frac{\left(\rho_{s}-\rho\right) v_{c}\left(d_{50}^{\prime}\right)^{2}}{18 \mu D_{c}}
$$

O número de Euler que guarda relação com a queda de pressão, pode ser calculado empregando-se a Equação 15.

$$
E u=\frac{\Delta P}{\rho v_{c}^{2} / 2}
$$

O número de Reynolds é calculado utilizando-se a Equação 16.

$$
\operatorname{Re}=\frac{D_{c} v_{c} \rho}{\mu}
$$


e

$$
v_{c}=\frac{4 Q}{\pi D_{c}^{2}}
$$

em que,

Stk $_{50}$, Eu e Re são adimensionais;

$\Delta \mathrm{P}$ - queda de pressão entre as correntes de alimentação e diluído, $\mathrm{Pa}$;

$\mathrm{V}_{\mathrm{c}}$ - velocidade de alimentação baseada na seção cilíndrica, $\mathrm{m} \mathrm{s}^{-1}$;

d' 50 - diâmetro de corte reduzido, m;

$\mu$ - viscosidade do fluido, $\mathrm{kg} \cdot \mathrm{m}^{-1} \mathrm{~s}^{-1}$;

$\rho$ - densidade do fluido, $\mathrm{kg} \mathrm{m}^{-3}$; e

$\rho_{\mathrm{s}}$ - densidade do sólido, $\mathrm{kg} \mathrm{m}^{-3}$.

Em extenso trabalho experimental Medronho (1984) mostrou que o produto $S t k_{50} E u$ é uma função da razão de líquido e da concentração volumétrica da suspensão de alimentação. O autor propôs também um modelo composto pelas equações (17), (18) e (19), que descreve a operação de hidrociclones geometricamente semelhantes, quando utilizados na separação de sólido-líquido.

Outros dois parâmetros adimensionais que afetam o desempenho de hidrociclones, são a razão de líquido $R_{L}$ e a concentração volumétrica da alimentação $C_{v}$.

$$
\begin{aligned}
& S t k_{50} E u=k_{1}\left[\ln \left(\frac{1}{R_{L}}\right)\right]^{n_{1}} e^{\left(n_{2} C_{v}\right)} \\
& E u=k_{2} \operatorname{Re}^{n_{3}} e^{\left(n_{4} C_{v}\right)} \\
& R_{L}=k_{3}\left(\frac{D_{u}}{D_{c}}\right)^{n_{5}} E u^{n_{6}}
\end{aligned}
$$

Castilho \& Medronho (2000) apresentam os valores das constantes $k$ e $n$ presentes nas Equações (17), (18) e (19), para os hidrociclones de Bradley e Rietema, os quais constam na Tabela 6. Segundo os autores, os fabricantes de hidrociclones fornecem um limitado alcance de diâmetros. Um hidrociclone feito sob encomenda com 
determinado tamanho e com as aberturas de diferentes tamanhos e intercambiáveis está apto a cobrir uma grande faixa de diâmetros de corte e de vazão. Para tanto, se faz necessário o conhecimento exato da forma como as variáveis geométricas afetam o desempenho do equipamento.

Tabela 6. Constantes $k$ e $n$ das equações (17), (18) e (19) sugeridas por Medronho.

\begin{tabular}{cccc}
\hline Hidrociclone & $\mathrm{k}_{1}$ & $\mathrm{n}_{1}$ & $\mathrm{n}_{2}$ \\
\hline Bradley & 0,0550 & 0,66 & 12,0 \\
Rietema & 0,0474 & 0,74 & 9,0 \\
& $\mathrm{k}_{2}$ & $\mathrm{n}_{3}$ & $\mathrm{n}_{4}$ \\
Bradley & 258,0 & 0,37 & 0 \\
Rietema & 371,5 & 0,12 & $-2,12$ \\
& & & $\mathrm{n}_{6}$ \\
Bradley & $\mathrm{k}_{3}$ & $\mathrm{n}_{5}$ & $-1,12$ \\
Rietema & $1,21.10^{6}$ & 2,63 & $-0,30$ \\
\hline
\end{tabular}

Fonte: Medronho (1984) e Antunes \& Medronho (1992).

\subsection{Modelos de separação de partículas}

Os modelos de separação de partículas em hidrociclones, definidos segundo seus princípios teóricos, são classificados basicamente em quatro grupos: Modelo do Tempo de Residência, Modelo da Órbita de Equilíbrio, Modelo Populacional e Modelo do Escoamento Bifásico em Regime Turbulento (Svarovsky, 1990). 


\subsubsection{Modelo do tempo de residência}

O modelo do tempo de residência foi proposto por Rietema (1961d) e assume que dada partícula chegará a parede (será separada), quando o seu tempo de residência, no interior do hidrociclone, for maior ou igual ao tempo necessário para a mesma movimentar-se radialmente, do ponto de entrada até a parede. $\mathrm{O}$ modelo assume que: a) a influência de turbulência ra separação é desprezível; b) é válida a lei de Stokes; c) não ocorre sedimentação impedida; d) as partículas estão homogeneamente distribuídas no tubo de alimentação. Segundo a hipótese (d), o diâmetro de corte será o tamanho da partícula que, ao entrar exatamente no centro do tubo de alimentação, é separada precisamente no tempo de residência $t_{r}$ disponível, conforme esquema apresentado na Figura 4a. Isto implica que a velocidade radial da partícula $v_{r}$ integrada no tempo, deverá ser igual a metade do diâmetro do tubo de alimentação, conforme demonstra a Equação 20. Se considerarmos a partícula que entra no hidrociclone na posição mais desfavorável à separação, ver esquema na Figura 4b, a mesma terá que percorrer, na pior das hipóteses, uma distância radial igual ao diâmetro do tubo de alimentação para ser separada. O diâmetro desta partícula, corresponde ao diâmetro da menor partícula que dando entrada no hidrociclone na posição mais desfavorável, será completamente separada da corrente fluida.

$$
\int_{0}^{t} v_{r} d t=\frac{D_{i}}{2}
$$

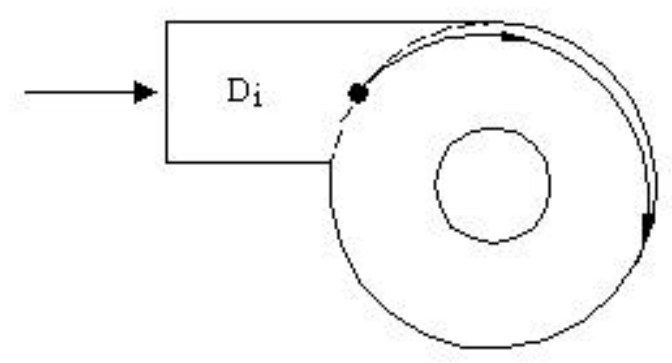

(a)

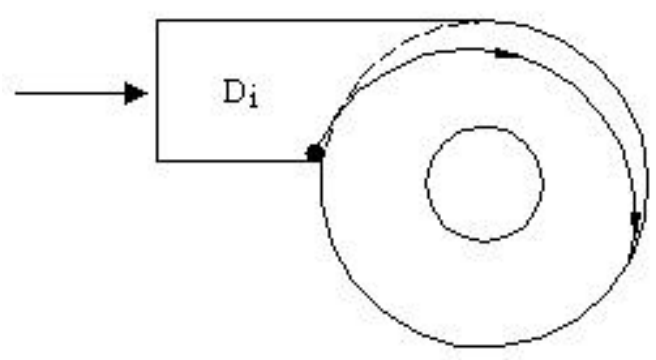

(b)

Figura 4 - Posições de entrada da partícula no hidrociclone na posição $D_{i} / 2$ (a) e na posição mais desfavorável a sua separação (b). 
Rietema (1961c) expressou a velocidade radial $v_{r}$ em termos do tamanho da partícula, da viscosidade e da força centrífuga e, após integração obteve:

$$
\frac{\Delta P\left(\rho_{s}-\rho\right)}{\mu \rho Q} L d_{50}^{\prime 2}=\frac{36}{\pi} \frac{v_{z}}{v_{i}} \frac{D_{c}}{D_{i}}
$$

em que,

$\mathrm{v}_{\mathrm{Z}}$ - velocidade axial, $\mathrm{m} \mathrm{s}^{-1}$;

$\mathrm{v}_{\mathrm{i}}$ - velocidade de alimentação, $\mathrm{m} \mathrm{s}^{-1} ; \mathrm{e}$

$\Delta \mathrm{P}(\mathrm{m})$.

Segundo o autor, acima de um determinado valor do número de Reynolds $R e$ mínimo, a razão entre as velocidades axial e de alimentação é constante. Desta forma concluiu que, o lado direito da Equação 21 é constante para um mesmo hidrociclone. $\mathrm{O}$ autor denominou esta constante de $C y_{50}$ e sua correlação final é:

$$
d_{50}^{\prime}=\left[C y_{50} \frac{\mu \rho Q}{\Delta P\left(\rho_{s}-\rho\right) L}\right]^{0,5}
$$

Reescrevendo a Equação 22 em termos do produto $S t k_{50} E u$, tem-se:

$$
S t k_{50} E u=\frac{\pi}{36} C y_{50} \frac{D_{c}}{L}
$$

Para hidrociclones com as relações ótimas sugeridas por Rietema (1961d), Cy $y_{50}$ é igual a 3,5 e o produto $S t k_{50} E u$ da Equação 23 é constante, para um mesmo grupo de hidrociclones, com as mesmas proporções geométricas.

Trawinski (1969; 1977), em trabalho desenvolvido, propôs um modelo que pode ser considerado como outra versão do modelo de tempo de residência. Em analogia com a sedimentação gravitacional no regime de Stokes, concluiu que:

$$
d_{50}^{\prime}=\left[\frac{9}{2 \pi} \frac{\mu \rho Q}{\left(\rho_{s}-\rho\right) \Delta P} \frac{D_{c}}{D_{o}(L-\ell)}\right]^{0,5}
$$


Para o produto $S t k_{50} E u$ :

$$
S t k_{50} E u=\frac{1}{8} \frac{D_{c}}{D_{o}} \frac{D_{c}}{(L-\ell)}
$$

O autor propôs também uma correlação entre vazão e a queda de pressão, sendo:

$$
E u=\frac{1}{8}\left[\frac{\pi}{K} \frac{D_{c}}{D_{i}} \frac{D_{c}}{D_{o}}\right]^{2}
$$

em que,

$\mathrm{D}_{\mathrm{i}}$ - diâmetro do tubo de alimentação, m;

$\mathrm{D}_{\mathrm{o}}$ - diâmetro do tubo de saída do diluído, m;

$\mathrm{K}$ - constante $(\mathrm{K}=0,22$, para pequenos hidrociclones e $\mathrm{K}=0,39$, para grandes hidrociclones), adimensional; e

$\Delta \mathrm{P}(\mathrm{Pa})$.

Neste caso, também, o produto $S t k_{50} E u$ é constante para hidrociclones geometricamente semelhantes.

Medronho (1984) verificou que o produto $S t k_{50} E u$ não era constante para um mesmo grupo de hidrociclones mas, que era uma função da razão de líquido e da concentração volumétrica da alimentação, que resultou na Equação (17).

\subsubsection{Modelos empíricos}

Segundo Coelho e Medronho (1992), os hidrociclones são muito simples de construir, no entanto, é muito difícil predizer seu desempenho usando somente teoria. Daí a razão do grande uso dos modelos de Plitt (1976) e de Lynch \& Rao (1975), para predizer o desempenho de hidrociclones.

Plitt (1976) construiu três hidrociclones com diâmetros de 32 mm, 64 mm e 152 mm, com partes intercambiáveis, possibilitando extensas combinações das relações geométricas, além de variar a queda de pressão e a concentração na alimentação. $O$ modelo formulado possibilita prever o desempenho de um hidrociclone, com razoável 
precisão, quando não se dispõe de dados experimentais. Seu modelo é formado pelas seguintes equações:

$$
\begin{aligned}
& d_{50}^{\prime}=\frac{50,5 D_{c}^{0,46} D_{i}^{0,6} D_{o}^{1,21} \mu^{0,5} e^{(0,063 C v)}}{D_{u}^{0,71}(L-\ell)^{0,38} Q^{0,45}\left(\rho_{s}-\rho\right)^{0,5}} \\
& \Delta P=\frac{1,88 Q^{1,78} e^{(0,0055 C v)}}{D_{c}^{0,37} D_{i}^{0,94}(L-\ell)^{0,28}\left(D_{u}^{2}+D_{o}^{2}\right)^{0,87}} \\
& \frac{R_{L}}{1-R_{L}}=\frac{1,9\left(D_{u} / D_{o}\right)^{3,31}(L-\ell)^{0,54}\left(D_{u}^{2}+D_{o}^{2}\right)^{0,36} e^{(0,0054 C v)}}{H^{0,24} D_{c}^{1,11}}
\end{aligned}
$$

em que,

H - queda de pressão expressa em metros da suspensão de alimentação; e d' $50(\mu \mathrm{m}), \mathrm{Q}\left(\mathrm{L} \mathrm{min}^{-1}\right), \Delta \mathrm{P}(\mathrm{kPa}), \mathrm{D}_{\mathrm{c}}(\mathrm{cm}), \mathrm{D}_{\mathrm{i}}(\mathrm{cm}), \mathrm{D}_{\mathrm{o}}(\mathrm{cm}), \mathrm{D}_{\mathrm{u}}(\mathrm{cm}), \mathrm{L}(\mathrm{cm}), \ell(\mathrm{cm}), \mathrm{Cv}$ $(\%), \mu(\mathrm{cP}), \rho\left(\mathrm{g} \mathrm{cm}^{-3}\right)$ e $\rho_{\mathrm{s}}\left(\mathrm{g} \mathrm{cm}^{-3}\right)$.

Lynch \& Rao (1975) usaram hidrociclones com diâmetros de 102 mm, 152 mm, $254 \mathrm{~mm}$ e $381 \mathrm{~mm}$. Trocando o diâmetro do tubo de saída do diluído $D_{o}$ e do concentrado $D_{u}$, eles obtiveram um grande número de dados experimentais. Com base nestes dados desenvolveram um modelo que, de acordo com os mesmos, requer a determinação de constantes que devem ser experimentalmente avaliadas para cada aplicação específica. O modelo é formado pelas seguintes equações:

$$
\begin{gathered}
\log d_{50}^{\prime}=0,0400 D_{o}-0,0576 D_{u}+0,0366 D_{i}+0,0299 C_{p}-0,0001 Q \\
Q=6,00 D_{o}^{0,73} D_{i}^{0,86} \Delta P^{0,42} \\
R_{L}=193 \frac{D_{u}}{W a}-\frac{271,6}{W a}-1,61 \\
G^{\prime}=\frac{e^{\left(\alpha \alpha / d_{50}^{\prime}\right)}-1}{e^{\left(\alpha d / d_{50}^{\prime}\right)}+e^{\alpha}-2}
\end{gathered}
$$

em que, 
Wa - vazão mássica da suspensão na alimentação, $\mathrm{t} \mathrm{h}^{-1}$;

$\mathrm{C}_{\mathrm{p}}$ - concentração da alimentação em peso, \%;

$\alpha$ - constante a ser determinada experimentalmente, adimensional; e

d' ${ }_{50}(\mu \mathrm{m}), \mathrm{Q}\left(\mathrm{L} \mathrm{min}^{-1}\right), \Delta \mathrm{P}(\mathrm{kPa}), \mathrm{D}_{\mathrm{c}}(\mathrm{cm}), \mathrm{D}_{\mathrm{i}}(\mathrm{cm}), \mathrm{D}_{\mathrm{o}}(\mathrm{cm})$ e $\mathrm{D}_{\mathrm{u}}(\mathrm{cm})$.

Plitt (1976) obteve uma relação entre $\alpha$ e $n$, por meio da equação:

$$
\alpha=1,54 n-0,47
$$

Coelho \& Medronho (1992) avaliaram os modelos de Plitt (1976) e Lynch \& Rao (1975), para cinco diferentes hidrociclones. Os autores concluíram que o modelo de Lynch \& Rao (1975) não pode ser usado com suas constantes originais, ou para dimensionamento e previsão do desempenho de hidrociclones. $\mathrm{O}$ modelo de Plitt (1976) mostrou precisão razoável na previsão da vazão, porém superestimou o diâmetro de corte reduzido e forneceu dados irreais para a razão de líquido.

\subsection{Equações para previsão do diâmetro de corte}

A literatura apresenta equações que podem ser utilizadas para previsão do diâmetro de corte $d_{50}$ ou o diâmetro de corte reduzido $d_{50}^{\prime}$. Como exemplo, pode-se citar as Equações (23) e (25), apresentadas anteriormente, que foram expressas em termos de $S t k_{50} E u$. Yoshioka \& Hotta (1955) apresentaram uma equação semi-empírica baseada no conceito de órbita de equilíbrio:

$$
d_{50}^{\prime}=0,2 D_{c}^{0,1} D_{i}^{0,6} D_{o}^{0,8}\left[\frac{\mu}{Q\left(\rho_{s}-\rho\right)}\right]^{0,5}
$$

em que,

0,2 - constante determinada experimentalmente, adimensional; e

$\mathrm{d}^{\prime}{ }_{50}(\mathrm{~m}), \mathrm{Q}\left(\mathrm{m}^{3} \mathrm{~s}^{-1}\right), \mathrm{D}_{\mathrm{c}}(\mathrm{m}), \mathrm{D}_{\mathrm{i}}(\mathrm{m}), \mathrm{D}_{\mathrm{o}}(\mathrm{m}), \mu\left(\mathrm{kg} \mathrm{m}^{-1} \mathrm{~s}^{-1}\right), \rho\left(\mathrm{kg} \mathrm{m}^{-3}\right)$ e $\rho_{\mathrm{s}}\left(\mathrm{kg} \mathrm{m}^{-3}\right)$.

Svarovsky (1990) propôs a seguinte equação para o cálculo do diâmetro de corte: 


$$
\frac{d_{50}^{\prime}}{D_{c}}=K_{1}\left[\frac{\mu D_{c}}{Q\left(\rho_{s}-\rho\right)}\right]^{0,5}\left(1-R_{L}\right)^{0,5} e^{\left(K_{2} C_{v}\right)}
$$

em que,

$\mathrm{K}_{1}$ e $\mathrm{K}_{2}$ - constantes.

Em trabalho posterior com hidrociclone de $125 \mathrm{~mm}$ de diâmetro, utilizando carbonato de cálcio na alimentação, com concentrações volumétricas que variaram de 0,3\% a 30\%, Svarovsky \& Bavishi citados por Silva (1989) obtiveram os valores de $\mathrm{K}_{1}=0,034$ e $\mathrm{K}_{2}=3,10$.

Peçanha \& Massarani (1980), em trabalho de avaliação de hidrociclone, com o objetivo de tornar a equação de estimativa do diâmetro de corte, válida para alimentação concentrada de partículas não esféricas, sugeriram:

$$
\frac{d_{50}^{\prime}}{D_{c}}=K_{1}\left[\frac{\mu D_{c}}{Q\left(\rho_{s}-\rho\right)}\right]^{0,5} e^{\left(K_{2} C v\right)}
$$

e obtiveram valores de $K_{1}=0,056$ e $K_{2}=4,0$, para suspensões de carvão, fluorapatita e barita, nas concentrações de 5\% a 10\% em peso, em hidrociclones com diâmetros de $51 \mathrm{~mm}$ a $102 \mathrm{~mm}$. 


\section{MATERIAL E MÉTODOS}

\subsection{Construção do hidrociclone}

Para o dimensionamento do hidrociclone utilizado no experimento foram seguidas as relações recomendadas por Rietema (1961d) e já apresentadas no item 2.4. Ao todo foram construídos quatro hidrociclones, que diferiram quanto a forma e dimensão do bocal utilizado como tubo de alimentação.

Primeiramente, dimensionourse o hidrociclone com o tubo de alimentação circular, denominado Hidrociclone I, cujas dimensões são apresentadas na Tabela 7.

Tabela 7. Dimensões do hidrociclone com o tubo de alimentação circular, segundo recomendações de Rietema.

\begin{tabular}{lll}
\hline $\mathrm{D}_{\mathrm{c}}$ & $50,00 \mathrm{~mm}$ \\
$\mathrm{D}_{\mathrm{i}}$ & $13,99 \mathrm{~mm}$ \\
$\mathrm{D}_{\mathrm{o}}$ & $18,00 \mathrm{~mm}$ \\
$\mathrm{D}_{\mathrm{u}}$ & $10,00 \mathrm{~mm}$ \\
$\mathrm{~L}$ & $250,00 \mathrm{~mm}$ \\
$\mathrm{~L}_{1}$ & $65,00 \mathrm{~mm}$ \\
$\ell$ & $20,00 \mathrm{~mm}$ \\
$\theta$ & $12,34^{\mathrm{O}}$ & \\
\hline
\end{tabular}

A partir deste hidrociclone foram construídos outros três com as mesmas dimensões, mas com tubos de alimentação diferentes na forma e tamanho da seção. Para o tubo de alimentação de forma circular, inicialmente definido, com diâmetro de $13,99 \mathrm{~mm}$ e perímetro de 43,98 mm, fixou-se a velocidade na entrada igual a $2 \mathrm{~m} \mathrm{~s}^{-1} \mathrm{e}$ utilizando-se a equação da continuidade, definiu-se a vazão de alimentação de $0,31 \mathrm{~L} \mathrm{~s}^{-1}$. 
Com o uso da Equação (38), e um coeficiente de descarga médio de bocais cônicos convergentes igual a 90\% (Neves, 1979), determinou-se as dimensões dos bocais retangulares para as quedas de pressões no hidrociclone de 50, 100 e $150 \mathrm{kPa}$, denominados Hidrociclones II, III e IV, respectivamente.

$$
Q=C_{d} S \sqrt{2 g \Delta P}
$$

em que,

$\mathrm{C}_{\mathrm{d}}$ - coeficiente de descarga, adimensional;

$\mathrm{S}$ - seção do bocal, $\mathrm{m}^{2} ; \mathrm{e}$

$\mathrm{g}$ - aceleração devido a gravidade, $\mathrm{m} \mathrm{s}^{-2}$.

Foi utilizado um tubo de cobre com diâmetro nominal $D N$ igual a $15 \mathrm{~mm}$, para a construção dos bocais empregados como tubos de alimentação, sendo que o circular se constituiu do próprio tubo comercial. A partir deste, foram construídos os bocais retangulares, utilizando-se gabaritos com as dimensões correspondentes. Os quatro bocais foram submetidos a bancada de ensaio, a fim de serem caracterizados do ponto de vista hidráulico. Na Tabela 8 estão dispostos os resultados da caracterização dos bocais. O diâmetro equivalente foi determinado substituindo-se a seção retangular, de cada hidrociclone, na expressão do cálculo da seção circular, e em seguida isolando-se o termo correspondente ao diâmetro.

Tabela 8. Características dos bocais utilizados na alimentação dos hidrociclones.

\begin{tabular}{|c|c|c|c|c|}
\hline \multirow{2}{*}{ Característica } & \multicolumn{4}{|c|}{ Bocal } \\
\hline & Circular & $50 \mathrm{kPa}$ & $100 \mathrm{kPa}$ & $150 \mathrm{kPa}$ \\
\hline \multicolumn{5}{|l|}{ Forma } \\
\hline Dimensões (mm) & $\mathrm{d}=13,99$ & $1,72 \times 20,30$ & $1,20 \times 20,81$ & $0,95 \times 21,40$ \\
\hline Seção $\left(\mathrm{mm}^{2}\right)$ & 153,77 & 34,92 & 24,97 & 19,99 \\
\hline $\mathrm{C}_{\mathrm{d}}(\%)$ & 72,10 & 82,55 & 83,45 & 86,33 \\
\hline $\begin{array}{l}\text { Diâmetro circular } \\
\text { equivalente }(\mathrm{mm})\end{array}$ & - & 6,67 & 5,64 & 5,05 \\
\hline
\end{tabular}


Os hidrociclones foram construídos em $P V C$ e fibra de vidro, e o tubo de alimentação em cobre. A seção cilíndrica se constituiu de uma luva de $P V C$, da linha soldável, com diâmetro nominal $D N$ de $50 \mathrm{~mm}$. A seção cônica foi feita em fibra de vidro, a partir de uma moldura com as dimensões pré-definidas. A Tabela 9 apresenta os custos e a relação de peças e materiais utilizados na construção de um hidrociclone.

$\mathrm{Na}$ Figura $5 \mathrm{a}$ e $5 \mathrm{~b}$ pode-se observar o desenho dos hidrociclones com bocal de alimentação circular e retangular, respectivamente. A Figura 6 apresenta algumas das peças utilizadas na construção dos hidrociclones.

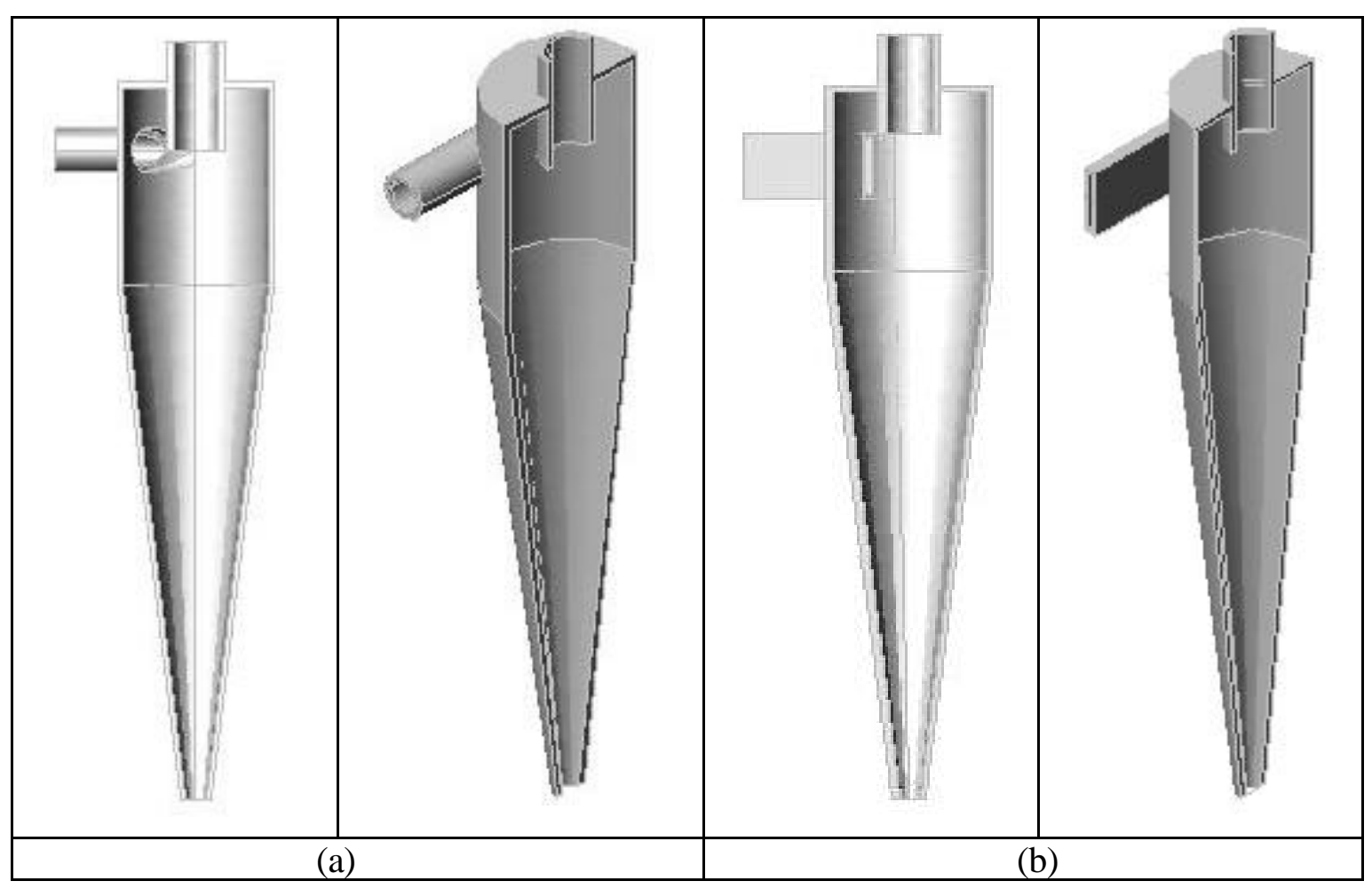

Figura 5 - Hidrociclones com bocal de alimentação circular (a) e retangular (b).

\subsection{Material de ensaio}

Utilizou-se como material particulado, areia e solo franco argiloso. A areia foi adquirida no mercado de material de construção e o solo foi coletado no campus da ESALQ/USP. 
Tabela 9. Custo e relação do material utilizado na construção de um hidrociclone.

\begin{tabular}{lccc}
\hline Especificação & Quantidade & Custo Unitário (R\$) & Total (R\$) \\
\hline Tubo cobre DN 15 mm & $0,20 \mathrm{~m}$ & $3,27 / \mathrm{m}$ & 0,65 \\
Conector F 15 mm x 1/2" & 1 & 1,42 & 1,42 \\
Adaptador 20 x 1/2" & 1 & 0,15 & 0,15 \\
Luva soldável 50 mm & 1 & 1,07 & 1,07 \\
Flange 50 mm x 1" & 2 & 1,00 & 2,00 \\
Tubo soldável 20 mm & $0,30 \mathrm{~m}$ & $0,74 / \mathrm{m}$ & 0,22 \\
Bucha red. soldável 25 x 20 mm & 1 & 0,09 & 0,09 \\
Manta fibra de vidro & $0,08 \mathrm{~m}^{2}$ & $12,00 / \mathrm{m}^{2}$ & 0,48 \\
Resina & $150 \mathrm{~g}$ & $7,00 / \mathrm{kg}$ & 1,05 \\
Gel & $30 \mathrm{~g}$ & $7,80 / \mathrm{kg}$ & 0,24 \\
Desemoldurante & $10 \mathrm{~g}$ & $6,00 / \mathrm{kg}$ & 0,06 \\
Catalizador & $1,50 \mathrm{~mL}$ & $1,00 / 30 \mathrm{~mL}$ & 0,05 \\
Cera & $5 \mathrm{~g}$ & $6,00 / \mathrm{kg}$ & 0,03 \\
Talco & $30 \mathrm{~g}$ & $1,00 / \mathrm{kg}$ & 0,03 \\
Total & & & 7,54 \\
\hline
\end{tabular}

Nota: US\$1,00 = R\$2,68

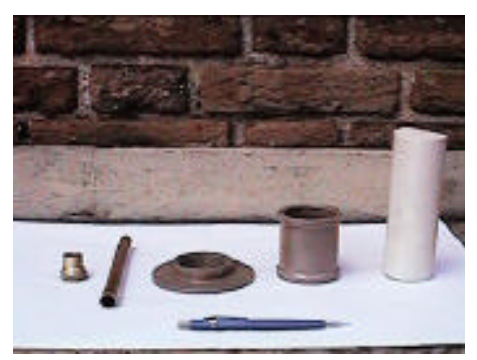

(a)

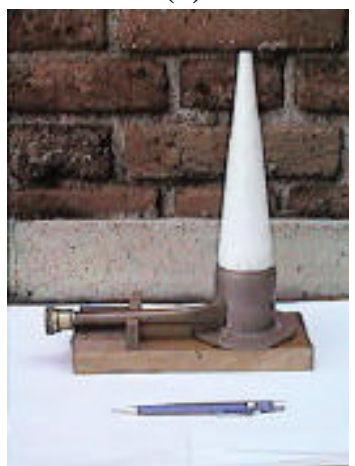

(c)

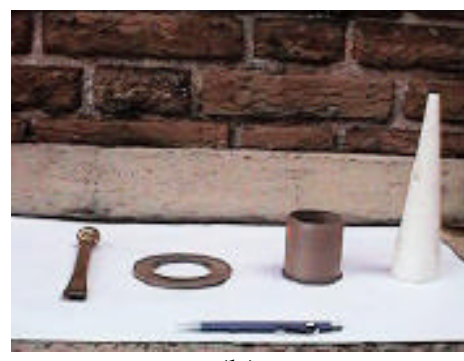

(b)

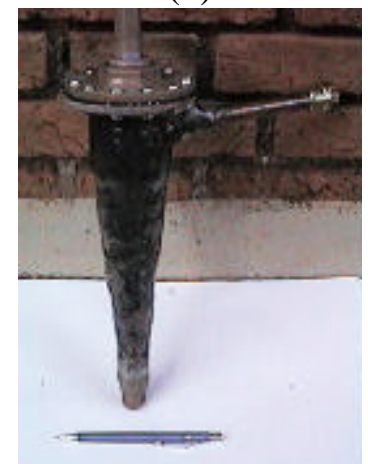

(d)

Figura 6 - Peças utilizadas na construção dos hidrociclones: peças e tarugo de PVC (a); peças prontas e o molde do cone (b); molde do cone sobre a parte cilíndrica (c) e hidrociclone já construído (d). 
A areia fina, lavada e isenta de material orgânico, foi passada em peneira com malha de $1,19 \mathrm{~mm}$ de abertura, de forma a reter as partículas maiores que a referida abertura, que pudessem vir obstruir o tubo de alimentação dos hidrociclones, principalmente os retangulares. Em seguida foi determinada a distribuição granulométrica da mesma, utilizando-se um jogo de peneiras, cujo resultado está demonstrado na Figura 7. O solo também foi peneirado, em peneira com malha de abertura igual a $0,54 \mathrm{~mm}$, com o objetivo de retirar pedriscos e material orgânico.

Determinou-se a densidade de partículas da areia e do solo, utilizando-se o método do picnômetro segundo recomendação de Day (1965) e Kiehl (1979), sendo que os valores para a areia e o solo foram de $2,65 \mathrm{~g} \mathrm{~cm}^{-3}$ e $2,70 \mathrm{~g} \mathrm{~cm}^{-3}$, respectivamente. Segundo recomendações dos autores foi determinada a granulometria do solo, encontrando-se valores de 73,55\% de argila, $18,26 \%$ de silte e $8,19 \%$ de areia.

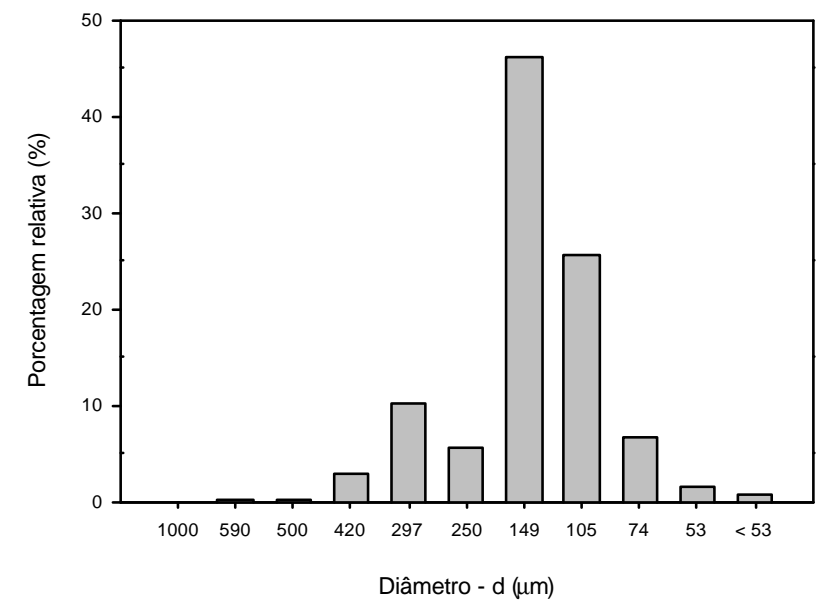

Figura 7 - Histograma com a porcentagem relativa das partículas de areia com diâmetro maior do que o considerado.

\subsection{Bancada experimental}

Para a condução do trabalho foi montada uma bancada de ensaio, em circuito fechado, localizada no Laboratório de Hidráulica do Departamento de Engenharia Rural da ESALQ/USP, contendo os elementos indicados na Figura 8 e descritos a seguir: 


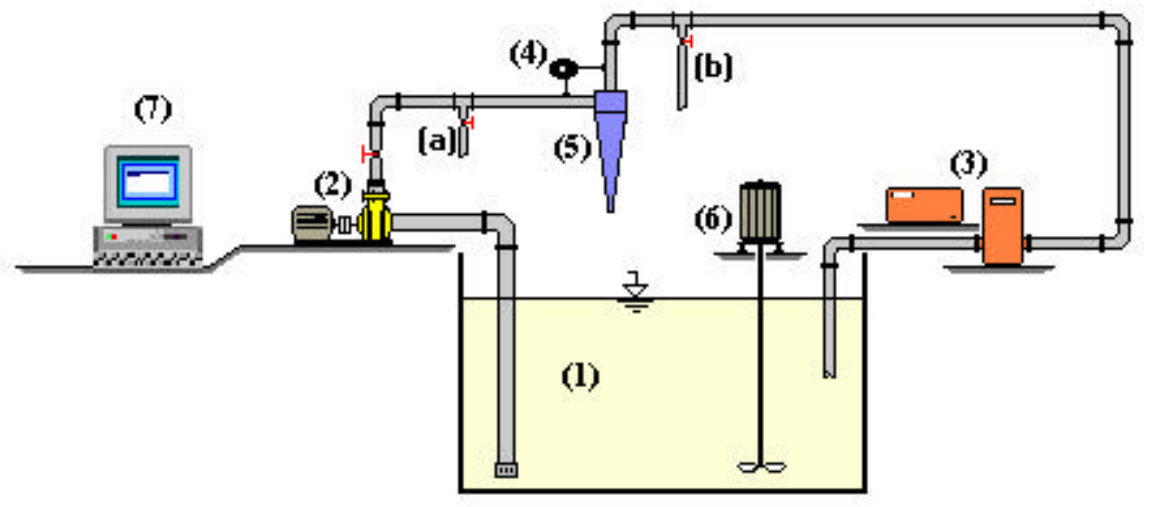

Figura 8 - Esquema da bancada de ensaio mostrando seus componentes.

(1) Reservatório: para a suspensão água-areia ou água-solo, com capacidade de 500 litros.

(2) Conjunto motobomba: composto por uma bomba centrífuga marca Jacuzzi, modelo 2VJF15-M 39B, com vazão e altura de elevação de $4500 \mathrm{~L} \mathrm{~h}^{-1}\left(0,00125 \mathrm{~m}^{3} \mathrm{~s}^{-1}\right)$ e $340 \mathrm{kPa}$, respectivamente; motor elétrico da marca Eberle, com potência nominal de $1470,60 \mathrm{~W}$ (2 cv) e velocidade de rotação de $3500 \mathrm{rpm}$.

(3) Medidor de vazão: foi utilizado um medidor de vazão eletromagnético Mag-Flux, modelo 462, série 8902-831, com vazão nominal de $1000 \mathrm{~L} \mathrm{~h}^{-1}\left(0,000278 \mathrm{~m}^{3} \mathrm{~s}^{-1}\right)$, equipado com conversor de sinal Mag-Flux, modelo 474.

(4) Sensor de pressão: o diferencial de pressão no hidrociclone foi medido por meio da instalação de tomadas de pressão, na tubulação da suspensão de alimentação e da tubulação da suspensão diluída; o elemento sensor de pressão se constituiu de um transdutor diferencial modelo MPX5700DP, fabricado pela empresa Motorola. O fabricante informa que o modelo é produzido para atender a uma faixa de pressão que varia de 0 a $700 \mathrm{kPa}$, apresentado erro máximo de 2,5\% para temperaturas entre 0 e $85^{\circ} \mathrm{C}$. Quando alimentados por uma tensão estabilizada de $5 \mathrm{Vcc}$, emitem sinais analógicos que variam de 0,2 a 4,7 Vcc, os quais foram transformados em leituras de pressão por meio da seguinte expressão:

$$
P=0,1555 V_{S P}-31,109
$$


em que,

$\mathrm{P}$ - diferença de pressão observada nas entradas do transdutor, $\mathrm{kPa}$; e

$\mathrm{V}_{\mathrm{SP}}$ - diferença de potencial elétrico entre os pinos de saída e terra, $\mathrm{mV}$.

As saídas do transdutor de pressão também foram ligadas ao conversor analógico digital $(A D)$, possibilitando o registro da queda de pressão no hidrociclone.

(5) Hidrociclone: a ser ensaiado; próximos ao hidrociclone, na tubulação de alimentação (a) e da suspensão diluída (b), foram instalados pontos de coleta de amostras das respectivas suspensões.

(6) Agitador submersível: composto por motor elétrico da marca WEG, com potência nominal de 1102,90 W (1,5 cv) e velocidade de rotação de $1650 \mathrm{rpm}$, tinha como objetivo manter a concentração da suspensão uniforme durante a tomada de dados.

(7) Microcomputador: foi utilizado um microcomputador Pentium $166 \mathrm{MHz}$, no qual foi instalado o programa Aquidados, desenvolvido por Vilela et al. (2001). O programa computacional foi desenvolvido em linguagem de programação Borland Delphi, versão 4.0, e controlava a operação de um conversor analógico digital, por intermédio de sinais enviados pela porta paralela do computador. Além desta função, o programa gerenciava a transmissão dos dados digitais, transformados pelo conversor $\mathrm{AD}$, para a $\mathrm{CPU}$ do computador. Essas informações eram processadas e apresentadas na tela principal do programa, em tempo real. Acionando o botão Leitura (Figura 9), o programa passava a calcular os valores médios de vazão e pressão, de acordo com o intervalo e o número de leituras preestabelecidas, os quais eram apresentados, após o término dos cálculos, na caixa Coleta de Dados. Simultaneamente era gravado um arquivo, denominado AquiDados.txt, contento esses resultados, além da data e horário das leituras.

Além dos materiais descritos acima foram utilizados: uma balança digital de prato superior com capacidade de leitura de $0,01 \mathrm{~g}$, a qual foi utilizada para quantificar o peso das amostras coletadas na suspensão de alimentação e do concentrado; cronômetro digital com capacidade de leitura de 0,01 segundo, utilizado na quantificação da vazão 
da suspensão do concentrado e um termômetro com escala de 0 a $100^{\circ} \mathrm{C}$ com capacidade de leitura igual $1{ }^{\circ} \mathrm{C}$, utilizado para a medida da temperatura da suspensão, durante a condução dos ensaios. Nas Figuras 10 e 11 são apresentados os componentes da bancada experimental.

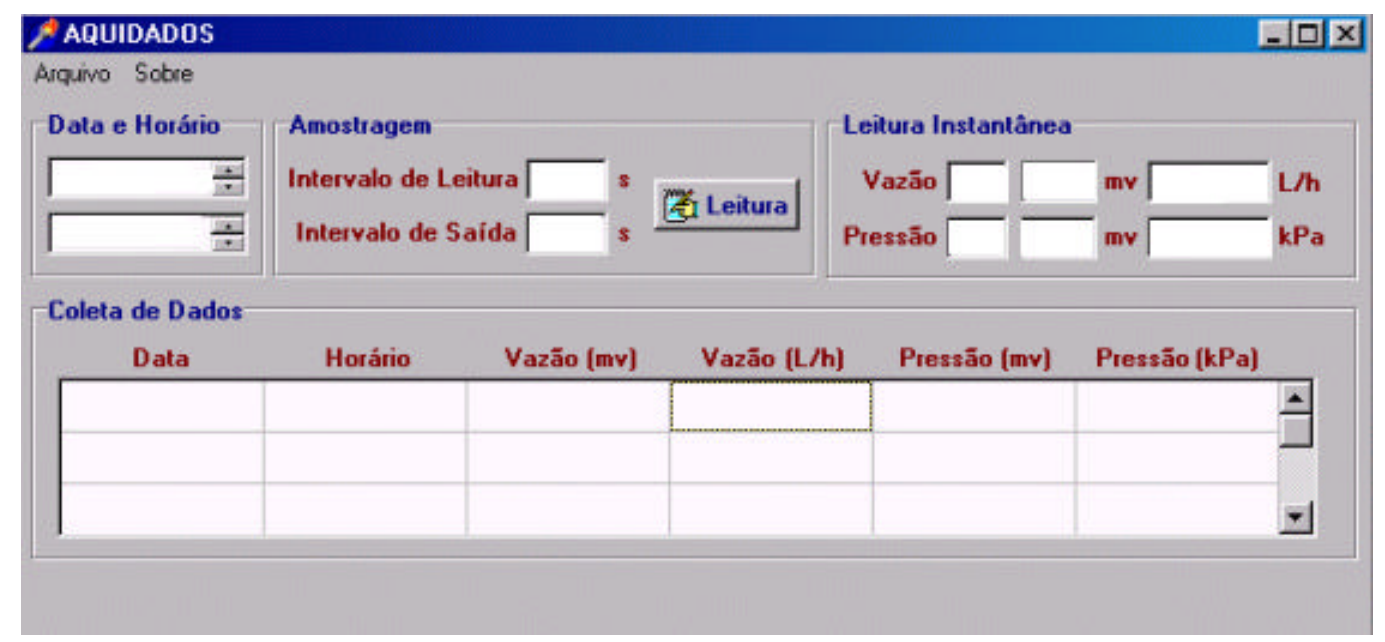

Figura 9 - Tela principal do programa Aquidados.

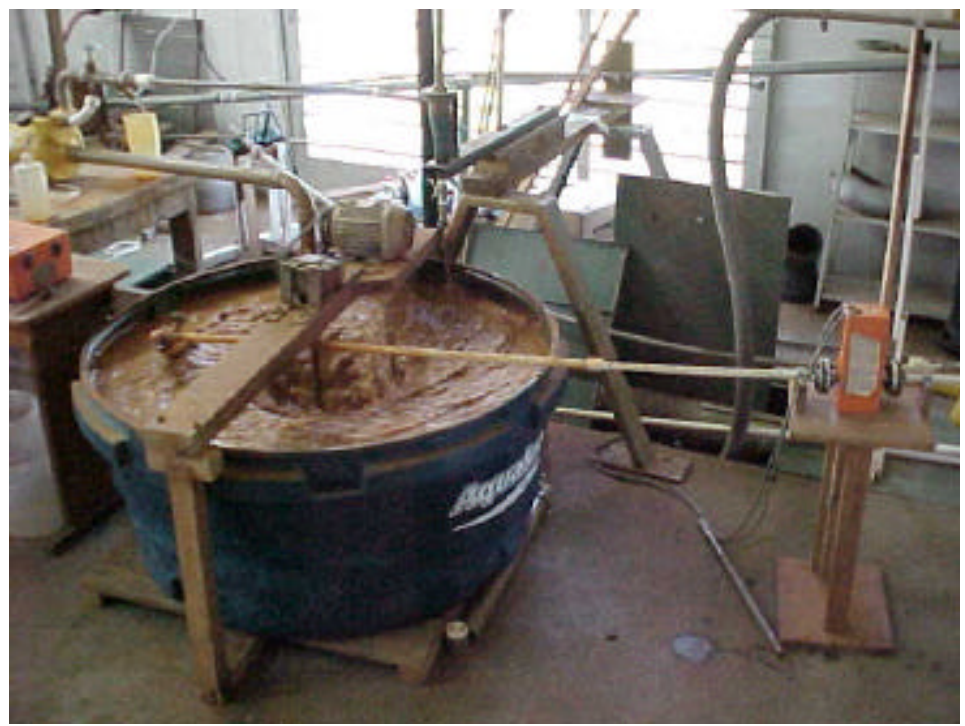

Figura 10 - Bancada experimental utilizada no ensaio dos hidrociclones, mostrando o reservatório, medidor de vazão, hidrociclone e o agitador submersível. 


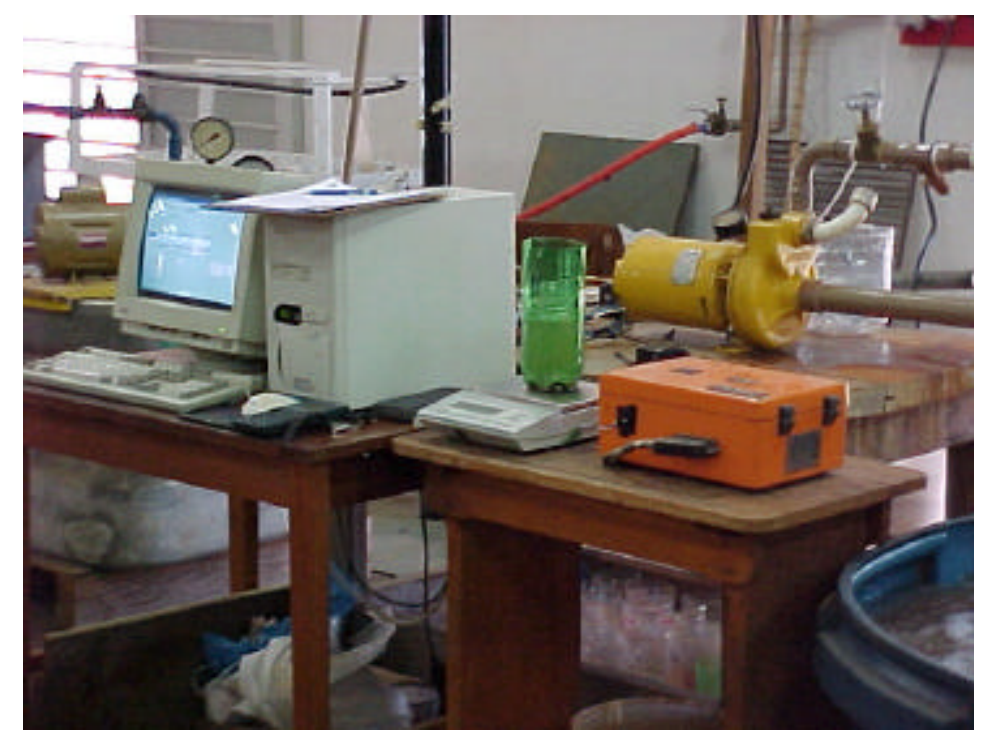

Figura 11 - Bancada experimental utilizada no ensaio dos hidrociclones, mostrando o conversor de sinal do medidor de vazão, a balança, o conjunto motobomba e o microcomputador.

\subsection{Procedimento experimental}

As suspensões de areia e solo utilizadas na alimentação foram preparadas adicionando-se $20 \mathrm{~kg}$ de areia e solo, previamente preparados, ao reservatório contendo 450 litros de água, resultando em suspensões com concentrações iniciais de sólidos, cujos valores estão apresentados na Tabela 10.

Tabela 10. Concentração inicial da suspensão de areia e solo.

\begin{tabular}{ccc}
\hline \multirow{2}{*}{ Material } & \multicolumn{3}{c}{ Concentração inicial } \\
& $\left(\mathrm{g} \mathrm{L}^{-1}\right)$ & \% volume \\
\hline Areia & 44,44 & 1,68 \\
Solo & 44,44 & 1,65 \\
\hline
\end{tabular}

Os ensaios experimentais seguiram os seguintes procedimentos:

Acionamento do sistema: a bancada era colocada em operação por meio do acionamento do conjunto motobomba. Em seguida eram ligados o microcomputador, medidor de 
vazão, o sensor de pressão e o agitador submersível. Com o programa Aquidados em execução, era fixada a queda de pressão desejada no hidrociclone, por intermédio do comando de uma válvula de gaveta, instalada no recalque da bomba, que variou: de 10, 20, 30, 40, 50 e $60 \mathrm{kPa}$ para os ensaios do hidrociclone I operando com suspensão de areia e solo; de 20, 50, 100 e $150 \mathrm{kPa}$ para os hidrociclones II, III e IV operando com suspensão de areia e; de 50, 100 e $150 \mathrm{kPa}$ para os hidrociclones II, III e IV operando com suspensão de solo. Esperava-se o sistema entrar em equilíbrio, tomava-se a temperatura da suspensão e iniciava-se a tomada de dados. A razão de líquido $R L$ era ajustada para o valor aproximado de $10 \%$, por meio do comando de uma válvula de gaveta instalada, na seção de saída da suspensão concentrada.

Tomada de dados: na tela inicial do programa Aquidados, ajustava-se o intervalo de leitura e de saída de dados para 60 s e na seqüência acionava-se o botão Leitura. Durante o tempo de coleta dos dados de vazão e queda de pressão, tomava-se a amostra da suspensão concentrada, para o intervalo de tempo de $30 \mathrm{~s}$, e em seguida pesava-se a mesma, de modo a obter a vazão mássica da referida corrente. Uma vez encerrada a leitura da vazão e do diferencial de pressão, procedia-se a coleta da suspensão de alimentação. Este procedimento era repetido por mais duas vezes, de modo a obter três repetições para cada ponto de diferencial de pressão amostrado. Após a pesagem as amostras ficavam em descanso por um período de 6 a 10 horas, para que os sólidos presentes sedimentassem e fosse possível retirar o excesso de água, com o uso de um pequeno sifão. A Figura 12 apresenta os diferentes instantes da tomada de dados.

Medida da concentração: a concentração das amostras foi determinada utilizando-se o processo gravimétrico. Após a retirada do excesso de água, as amostras eram transferidas para recipientes de alumínio, previamente tarados e identificados, e levadas a estufa por um período de 24 horas, onde eram secas a temperatura de $110^{\circ} \mathrm{C}$. Em seguida eram pesadas, o que possibilitava o conhecimento da quantidade de sólidos e, como era conhecida a quantidade de água, calculava-se a concentração de sólidos em base de massa por volume $\left(\mathrm{g} \mathrm{L}^{-1}\right)$.

Análise granulométrica: a determinação da distribuição do tamanho das partículas da areia e do solo seguiu procedimentos distintos, reunindo-se as três amostras de cada 
repetição em uma só, tendo em vista a pequena quantidade de sólidos coletados, principalmente na corrente de alimentação. Para a areia foi utilizado o método das peneiras e para o solo o método da sedimentação (Allen, 1990). Na análise granulométrica da areia foi utilizado um jogo de 10 peneiras, previamente taradas, cuja abertura da malha, em ordem decrescente, foi de 1000, 590, 500, 420, 297, 250, 149, 105, 74 e $53 \mu \mathrm{m}$. Inicialmente pesava-se a quantidade total de areia seca, retirada das amostras (3 repetições) coletadas durante a tomada de dados; colocava-se a amostra na primeira peneira (maior abertura) e levava-se ao agitador por um período de 12 minutos; em seguida as peneiras eram pesadas, obtendo-se a fração mássica $X$, maior que a malha da peneira correspondente. $\mathrm{Na}$ análise granulométrica do solo, o método baseia-se no

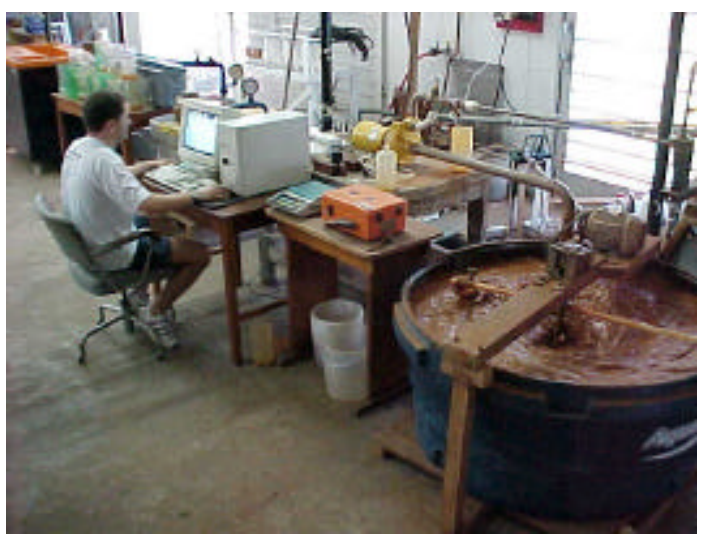

(a)

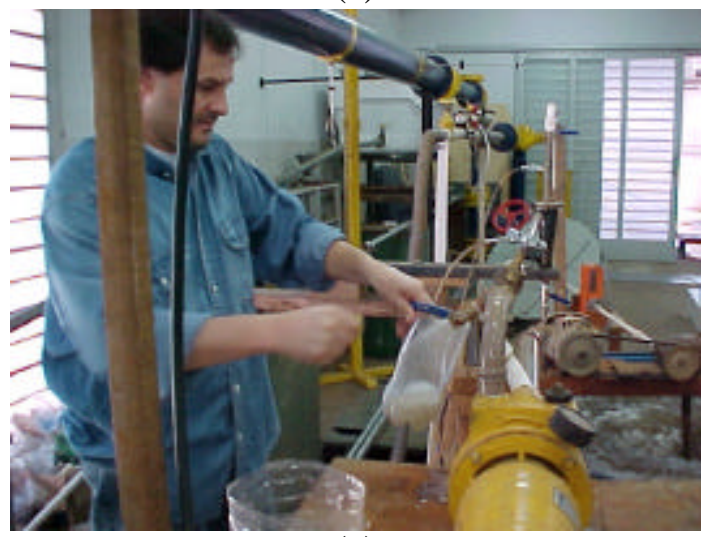

(c)

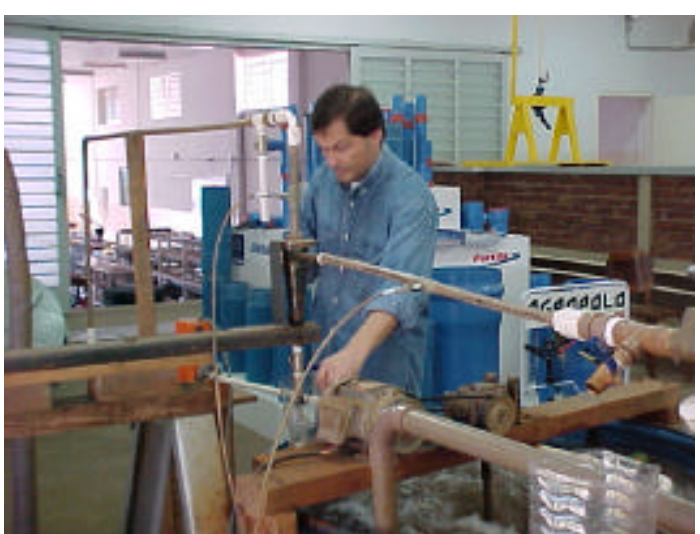

(b)

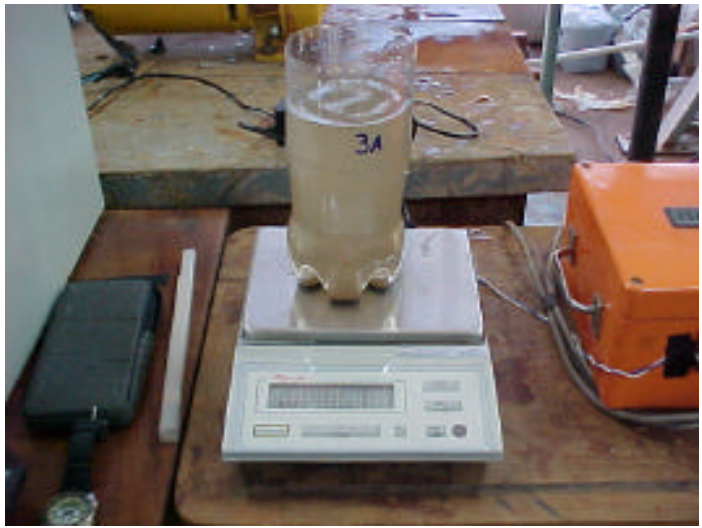

(d)

Figura 12 - Tomada de dados: acionamento do programa Aquidados (a); tomada da vazão do concentrado (b); coleta da amostra da alimentação (c) e pesagem das amostras (d). 
princípio da sedimentação gravitacional, sendo que a variação nas concentrações das amostras colhidas, de tempos em tempos, permite o cálculo da fração cumulativa, em massa, menor que certo diâmetro $d$, determinado pela lei de Stokes. A amostra de solo seco era pesada e colocada em um recipiente com água destilada por 24 horas e em seguida levada a um agitador de alta rotação $(16000 \mathrm{rpm})$ por 20 minutos, de modo a proporcionar a desagregação das partículas; na sequiência era transferida para uma proveta graduada de $1000 \mathrm{~mL}$ e seu volume completado com água destilada; procedia-se a agitação manual da amostra com o uso de um disco plano por 60 segundos; no final deste período de agitação, marcava o tempo zero de coleta das amostras, as quais eram feitas imergindo uma pipeta, com capacidade de $10 \mathrm{~mL}, 10 \mathrm{~cm}$ no interior da proveta, nos tempos de 10, 30, 60, 120, 180, 300, 600, 1200 e 1800 segundos; os volumes coletados com a pipeta eram colocados em recipientes previamente tarados e em seguida deixados na estufa a $110^{\circ} \mathrm{C}$ por 24 horas; ao fim deste período, as amostras eram pesadas em balança analítica, com capacidade de leitura de 0,0001 g, possibilitando assim o cálculo da fração mássica $X$, menor que certo diâmetro de Stokes, utilizando-se a Equação (41).

$$
X=\frac{C}{C_{o}}
$$

em que,

$\mathrm{X}$ - fração mássica menor que dado diâmetro, adimensional;

$\mathrm{C}$ - concentração da amostra coletada no tempo $\mathrm{t}, \mathrm{g} \mathrm{L}^{-1} ; \mathrm{e}$

$\mathrm{C}_{\mathrm{o}}$ - concentração inicial, $\mathrm{g} \mathrm{L}^{-1}$.

A concentração inicial na proveta permaneceu entre os limites de $0,2 \%$ e $1 \%$ em volume, conforme recomendação de Allen (1990). Segundo o autor, o limite mínimo garante um menor erro na pesagem das amostras e o limite superior minimiza o efeito da concentração sobre a velocidade terminal das partículas. Por ocasião do início de cada ensaio era feita a leitura da temperatura da amostra na proveta. Para cada tempo definido na coleta, calculou-se o correspondente diâmetro de Stokes, com o uso da Equação (42), 
obtendo-se os diâmetros aproximados de $7,8,12,17,22,27,38,54$ e $93 \mu \mathrm{m}$, respectivamente.

$$
d s_{t k}=\left[\frac{18 \mu h}{g t\left(\rho_{s}-\rho\right)}\right]^{0,5}
$$

em que,

$\mathrm{ds}_{\mathrm{tk}}$ - diâmetro de Stokes, m;

$\mathrm{h}$ - profundidade do ponto de amostragem com a pipeta, m; e

$\mathrm{t}$ - intervalo de tempo da coleta, $\mathrm{s}$.

Todas as curvas de distribuição granulométrica foram ajustadas ao modelo de RosinRammler-Bennet $R R B$ (Scheid, 1992), identificado pela Equação (43). A Figura 13 apresenta alguns detalhes da determinação granulométrica.

$$
X=1-e^{\left[-\left(\frac{d}{d^{*}}\right)^{n}\right]}
$$

em que,

$\mathrm{X}$ - fração cumulativa em massa das partículas com diâmetro inferior a $d$, adimensional;

d - diâmetro das partículas, $\mu \mathrm{m} ; \mathrm{e}$

$\mathrm{d}^{*}$ e $\mathrm{n}$ - constantes do modelo.

Cálculo da vazão de alimentação: a vazão total de alimentação foi determinada pela soma da vazão obtida pelo sistema de aquisição de dados, instalado no microcomputador e a vazão obtida no concentrado. Antes de proceder a soma das vazões foi necessário determinar a concentração de sólidos no concentrado, para que fosse possível transformar a vazão mássica obtida no ensaio, em vazão volumétrica.

Queda de pressão no hidrociclone: foram determinadas as curvas de queda de pressão versus vazão de alimentação dos hidrociclones, fixando-se pressões que variaram de 5 a $120 \mathrm{kPa}$ e de 5 a $190 \mathrm{kPa}$ para o hidrociclone I e os hidrociclones II, III e IV, respectivamente, num total de aproximadamente 50 pontos experimentais para cada hidrociclone. 


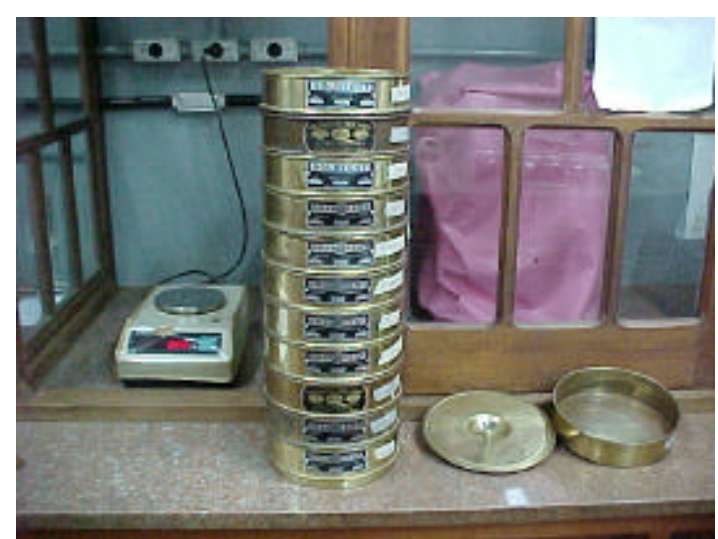

(a)

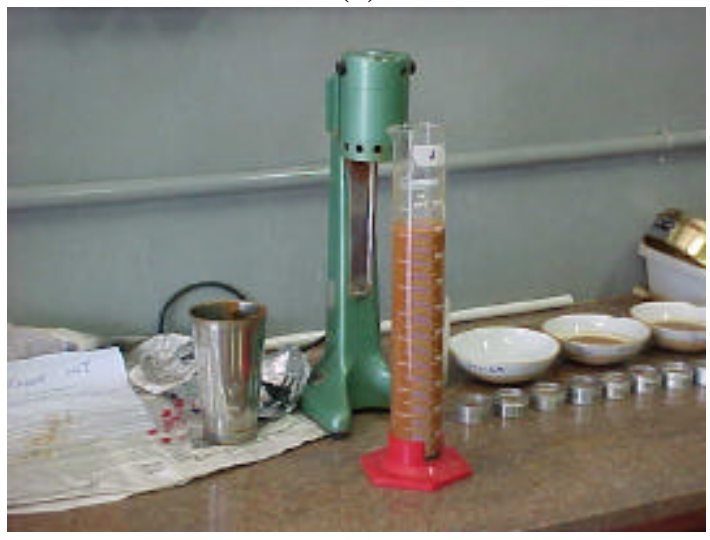

(c)

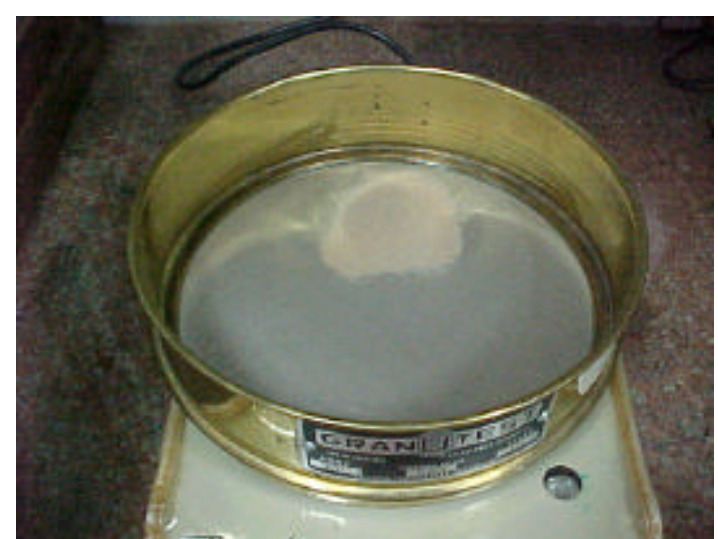

(b)

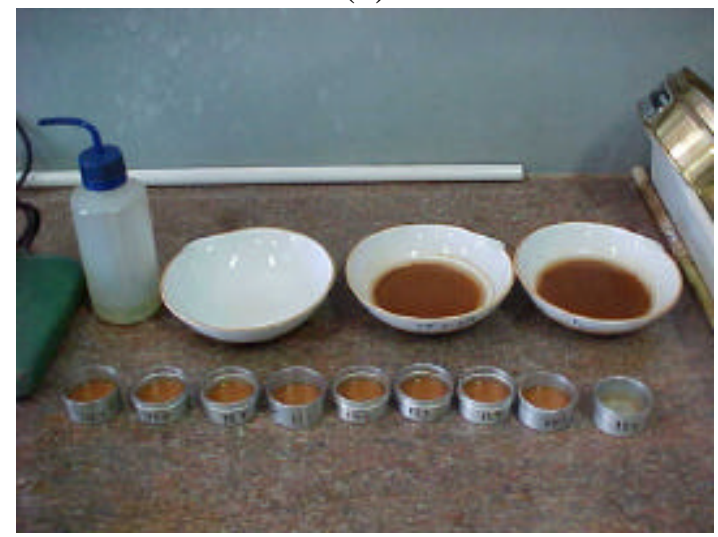

(d)

Figura 13 - Jogo de peneiras utilizadas na análise da areia (a); pesagem da fração mássica retida na peneira (b); proveta utilizada no ensaio de sedimentação do solo (c) e amostras coletadas nos diferentes tempos de sedimentação (d). 


\section{RESULTADOS E DISCUSSÃO}

\subsection{Análise granulométrica}

Os dados obtidos com a análise granulométrica da areia e solo coletados na suspensão de alimentação e concentrado, foram tabulados e agrupados na forma de distribuição cumulativa, igual ou menor que determinado tamanho (Anexo A). Estes dados foram plotados em gráfico e ajustados ao modelo de Rosin-Rammler-Bennet. As Figuras 14 a 16 apresentam os pontos experimentais e as curvas ajustadas da distribuição granulométrica, das amostras coletadas no ensaio dos quatro hidrociclones, sob os diferenciais de pressão fixados para a suspensão de areia. As Figuras 18 a 21 apresentam os pontos experimentais e as curvas ajustadas da distribuição granulométrica, das amostras coletadas no ensaio dos quatro hidrociclones sob os diferenciais de pressão fixados para a suspensão de solo. No Anexo B se encontram as equações ajustadas pelo modelo de Rosin-Rammler-Bennet e seus respectivos coeficientes de determinação.

A faixa de operação do diferencial de pressão para cada um dos quatro hidrociclones variou, haja visto as características da bancada experimental, dos hidrociclones e da suspensão utilizada. O hidrociclone I pode ser testado com diferenciais de pressão, que variaram de $10 \mathrm{kPa}$ a $60 \mathrm{kPa}$. Para esse hidrociclone não foi possível operar com diferencial de pressão superior, tendo em vista o limite operacional do conjunto motobomba utilizado. Para os hidrociclones II, III e IV, não foi possível operar com diferencial de pressão inferior a $20 \mathrm{kPa}$ e $50 \mathrm{kPa}$, para a suspensão de areia e solo, respectivamente. Pelo fato destes hidrociclones apresentarem a seção do tubo de alimentação menor, o diferencial de pressão é maior do que o observado para o hidrociclone I, operando com mesma vazão de alimentação. Assim, para fixação do 

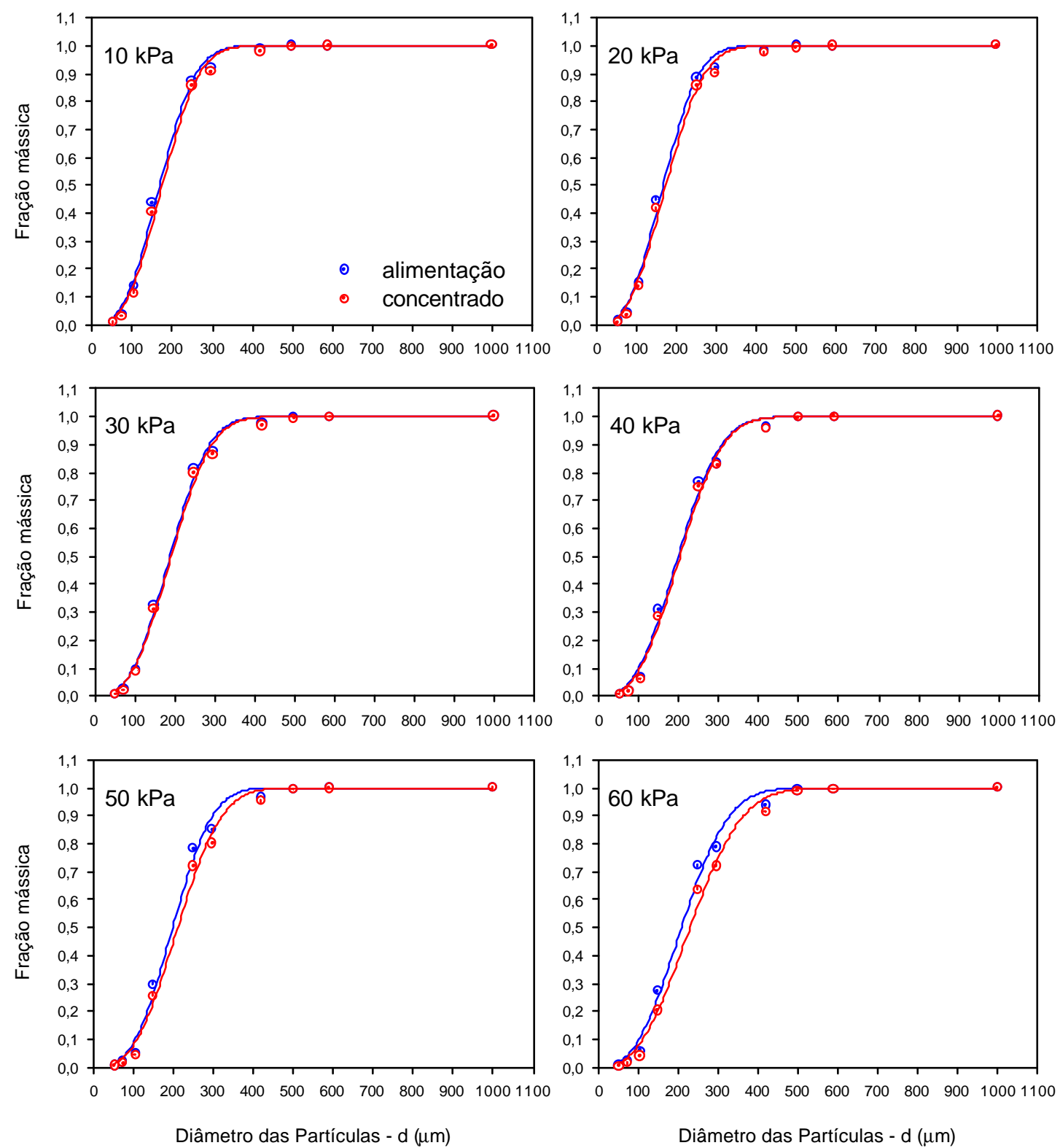

Figura 14 - Distribuição granulométrica da areia, pontos experimentais e curvas ajustadas, na alimentação e no concentrado, para o hidrociclone I.

diferencial de $20 \mathrm{kPa}$ ou $50 \mathrm{kPa}$, a vazão de alimentação necessária era mínima, o que acarretava uma abertura mínima na válvula de gaveta, utilizada no controle do escoamento, provocando a retenção de material sólido (areia ou solo) e conseqüente 
desestabilização do ponto de operação, com queda do diferencial de pressão e alteração na concentração da suspensão de alimentação.

Observa-se por meio da análise das curvas de distribuição granulométrica da areia, que não houve grandes diferenças no comportamento das mesmas, e que os dados experimentais ajustaram-se bem ao modelo de Rosin-Rammler-Bennet, conforme mostram os coeficientes de determinação apresentados no Anexo B. O diâmetro médio das partículas de areia na alimentação variou de aproximadamente $160 \mu \mathrm{m}$ a $200 \mu \mathrm{m}$ e $120 \mu \mathrm{m}$ a $205 \mu \mathrm{m}$ para o hidrociclone I e para os hidrociclones II, III e IV, respectivamente; no concentrado variou de aproximadamente $175 \mu \mathrm{m}$ a $215 \mu \mathrm{m}$ e de
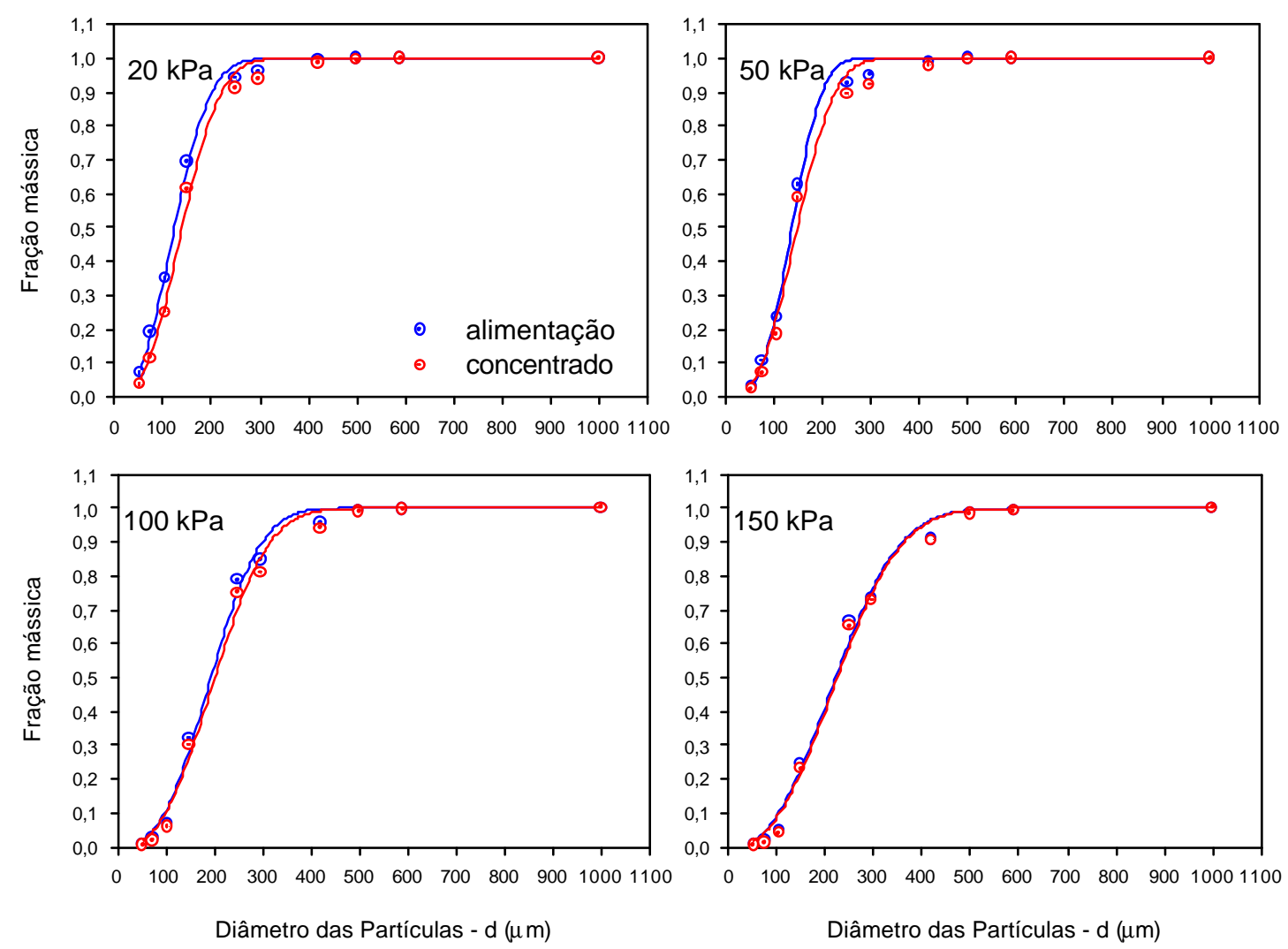

Figura 15 - Distribuição granulométrica da areia, pontos experimentais e curvas ajustadas, na alimentação e no concentrado para o hidrociclone II. 

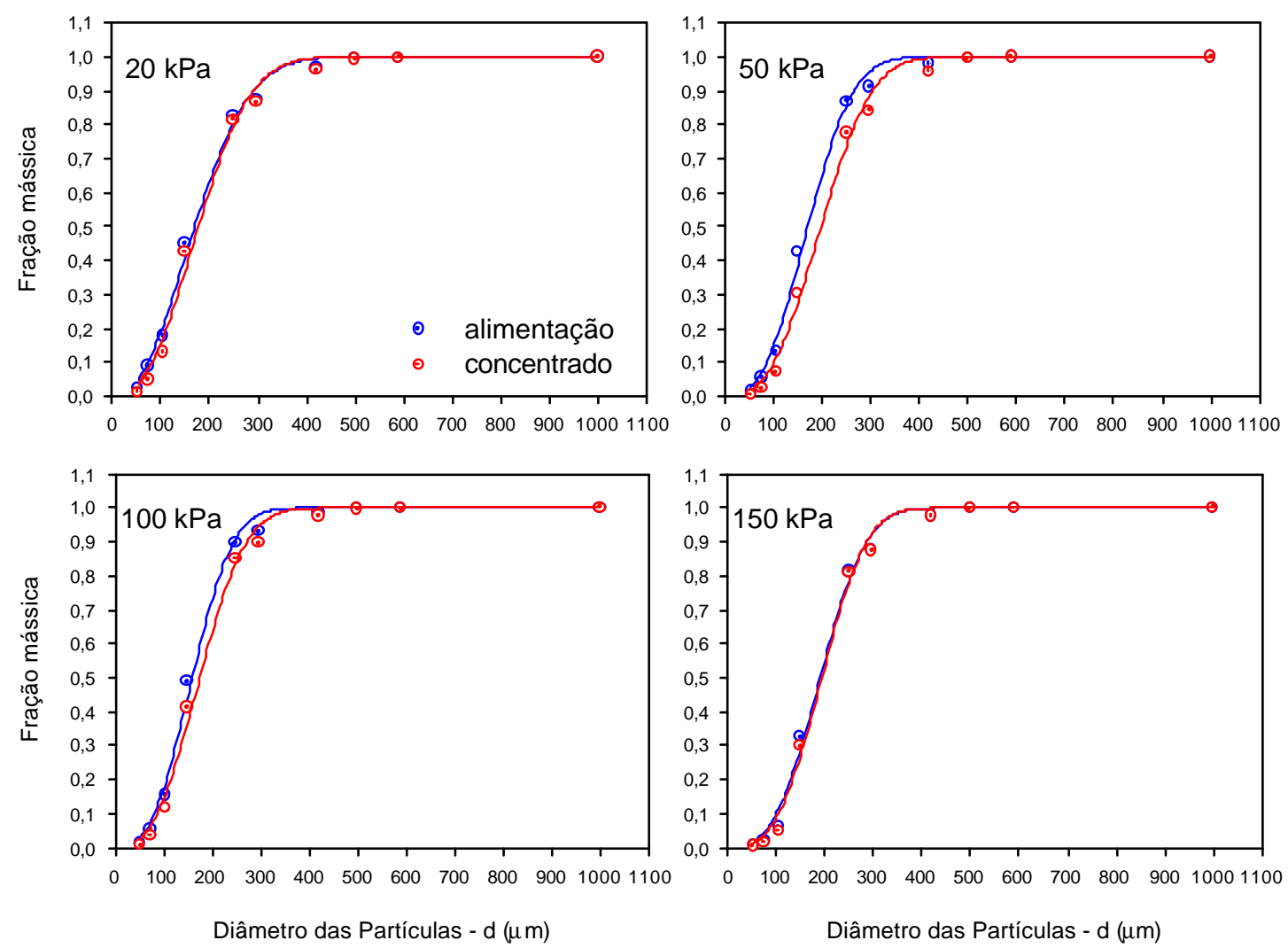

Figura 16 - Distribuição granulométrica da areia, pontos experimentais e curvas ajustadas, na alimentação e no concentrado para o hidrociclone III.

$140 \mu \mathrm{m}$ a $210 \mu \mathrm{m}$ para o hidrociclone I e para os hidrociclones II, III e IV, respectivamente. A diferença pode ser explicada pelo fato de que, a medida que operavase os hidrociclones com maiores diferenciais de pressão, as vazões correspondentes faziam com que houvesse maior agitação das partículas de maior dimensão, o que não pode ser evitado com a presença do agitador submersível.

As curvas de distribuição granulométrica da suspensão com solo mostraram uma tendência diferente daquela observada com a suspensão de areia. Neste caso, as curvas apresentaram-se horizontais e constantes, possivelmente pelo fato de que o solo utilizado apresentava alto teor de argila, 73,55\% (diâmetro menor do que $2 \mu \mathrm{m}$ ) e silte,18,26\% (partículas com diâmetro compreendido entre $2 \mu \mathrm{m}$ e $50 \mu \mathrm{m}$ ), resultando em aumento do 
percentual de partículas com diâmetro inferior ou igual ao diâmetro analisado, principalmente na suspensão de alimentação. Verificou-se também, que para a suspensão com solo, as curvas do concentrado encontravam-se bem mais afastadas das curvas da alimentação, resultando da maior concentração de partículas da fração areia, naquela suspensão. A tendência de queda (menor percentagem de partículas com igual ou menor diâmetro) das curvas com o aumento do diferencial de pressão, principalmente para os hidrociclones II, III e IV, pode ser explicado pelo fato de que, o aumento na vazão do sistema possibilitou maior aspiração de partículas com maior diâmetro. As equações das curvas ajustadas ao modelo de Rosin-Rammler-Bennet são apresentadas, com seus respectivos coeficientes de determinação, no Anexo B.
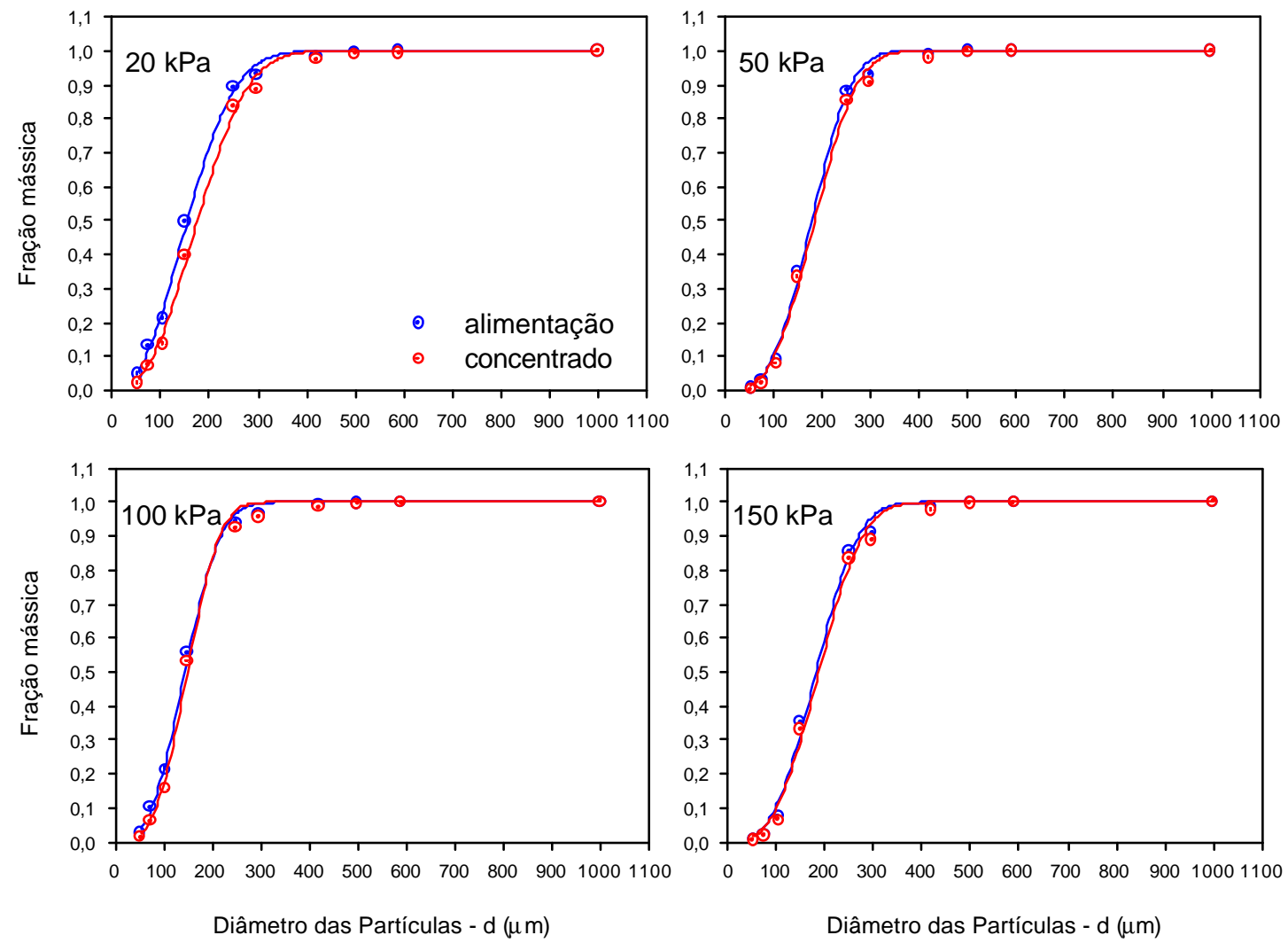

Figura 17 - Distribuição granulométrica da areia, pontos experimentais e curvas ajustadas, na alimentação e no concentrado, para o hidrociclone IV. 

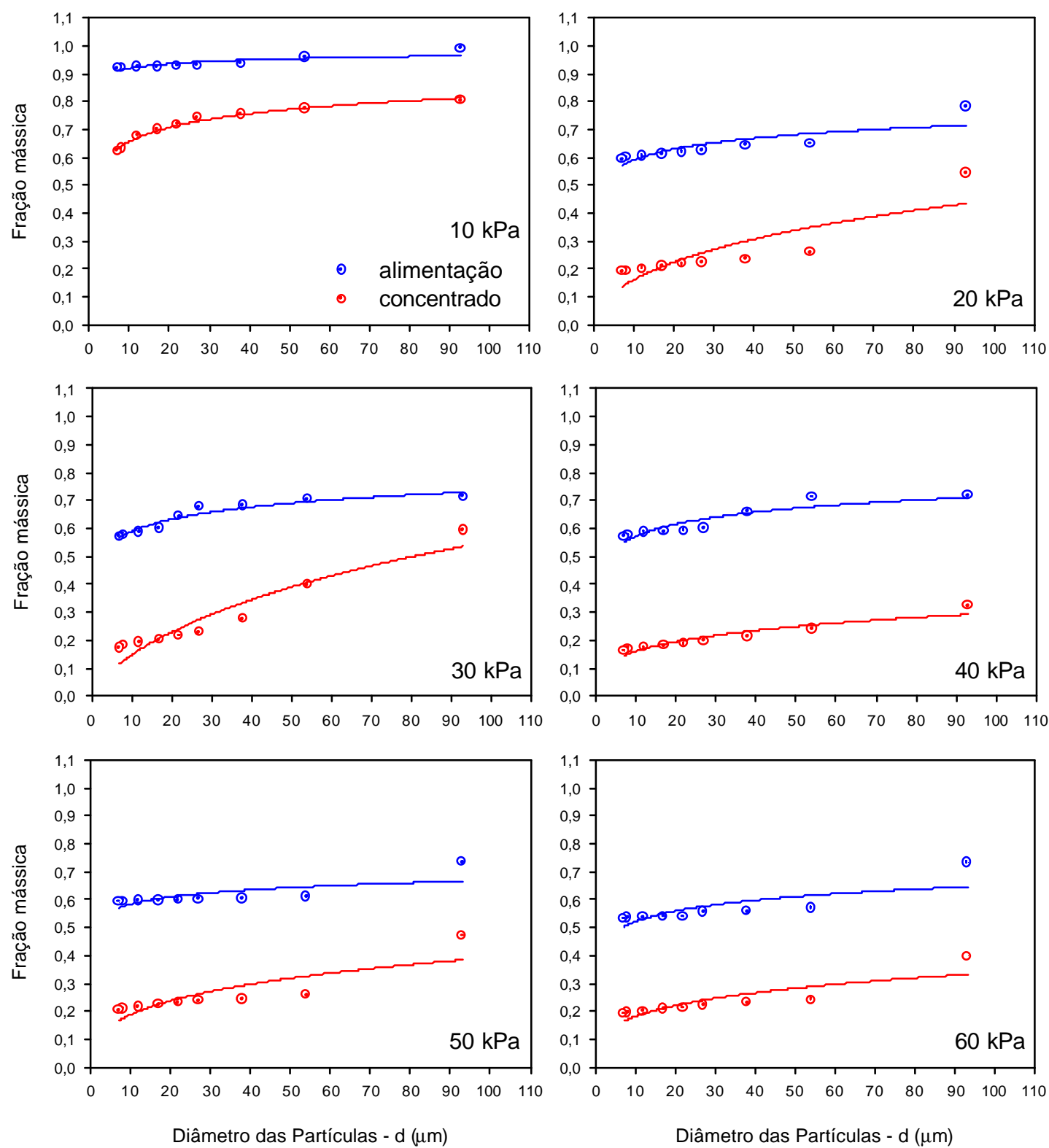

Figura 18 - Distribuição granulométrica do solo, pontos experimentais e curvas ajustadas, na alimentação e no concentrado, para o hidrociclone I. 

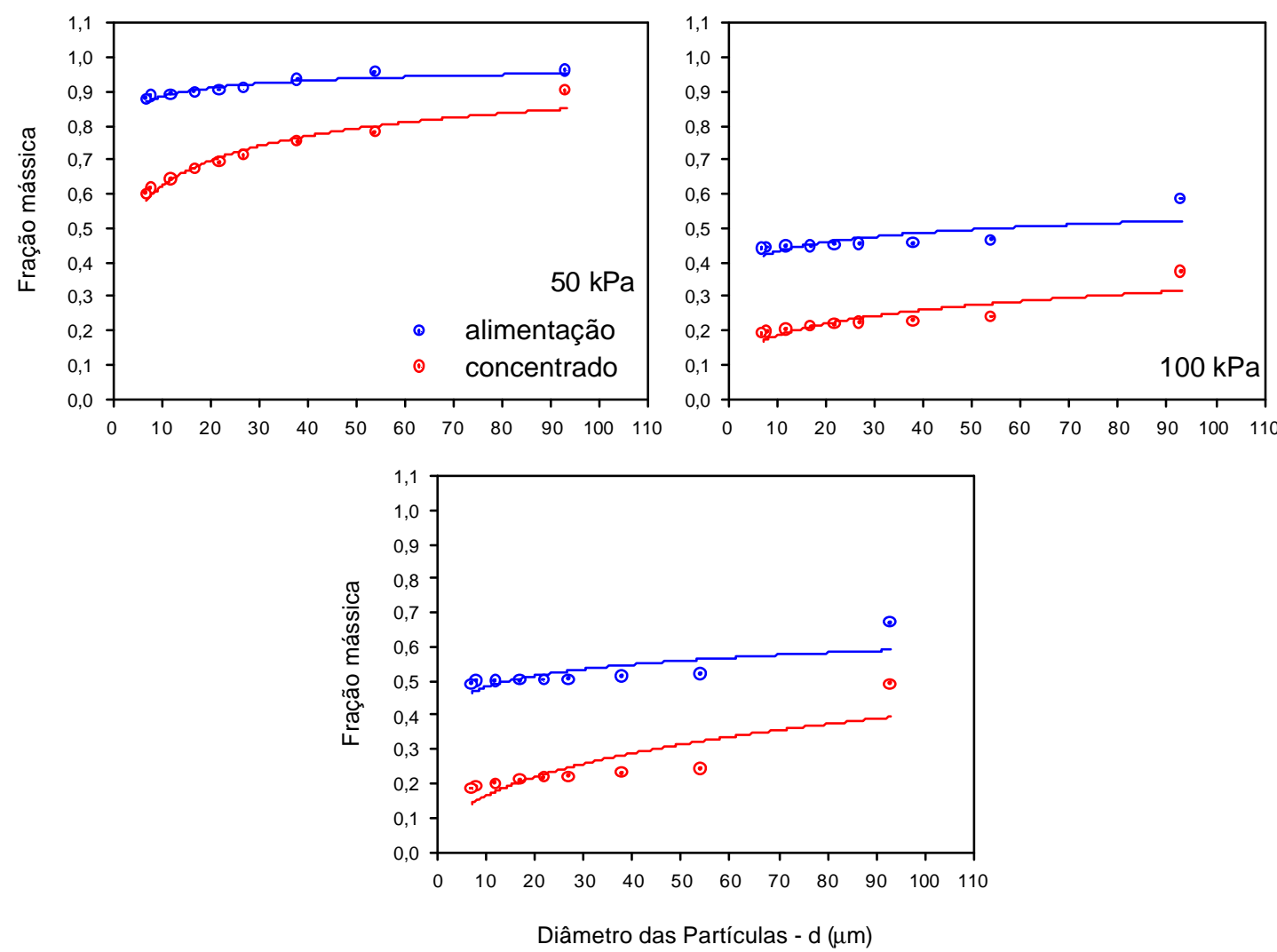

Figura 19 - Distribuição granulométrica do solo, pontos experimentais e curvas ajustadas, na alimentação e no concentrado para o hidrociclone II.

A ênfase dada a análise da distribuição granulométrica da areia e do solo, presentes nas suspensões da alimentação e do concentrado, é justificada, por representar uma etapa fundamental no desenvolvimento do trabalho. Erros que possam vir a ser cometidos durante a mesma, refletiriam nos cálculos posteriores. Segundo Allen (1990), alguns erros são inerentes do método de análise granulométrica utilizado, no entanto, procurou-se padronizar os ensaios para que os erros fossem minimizados. 

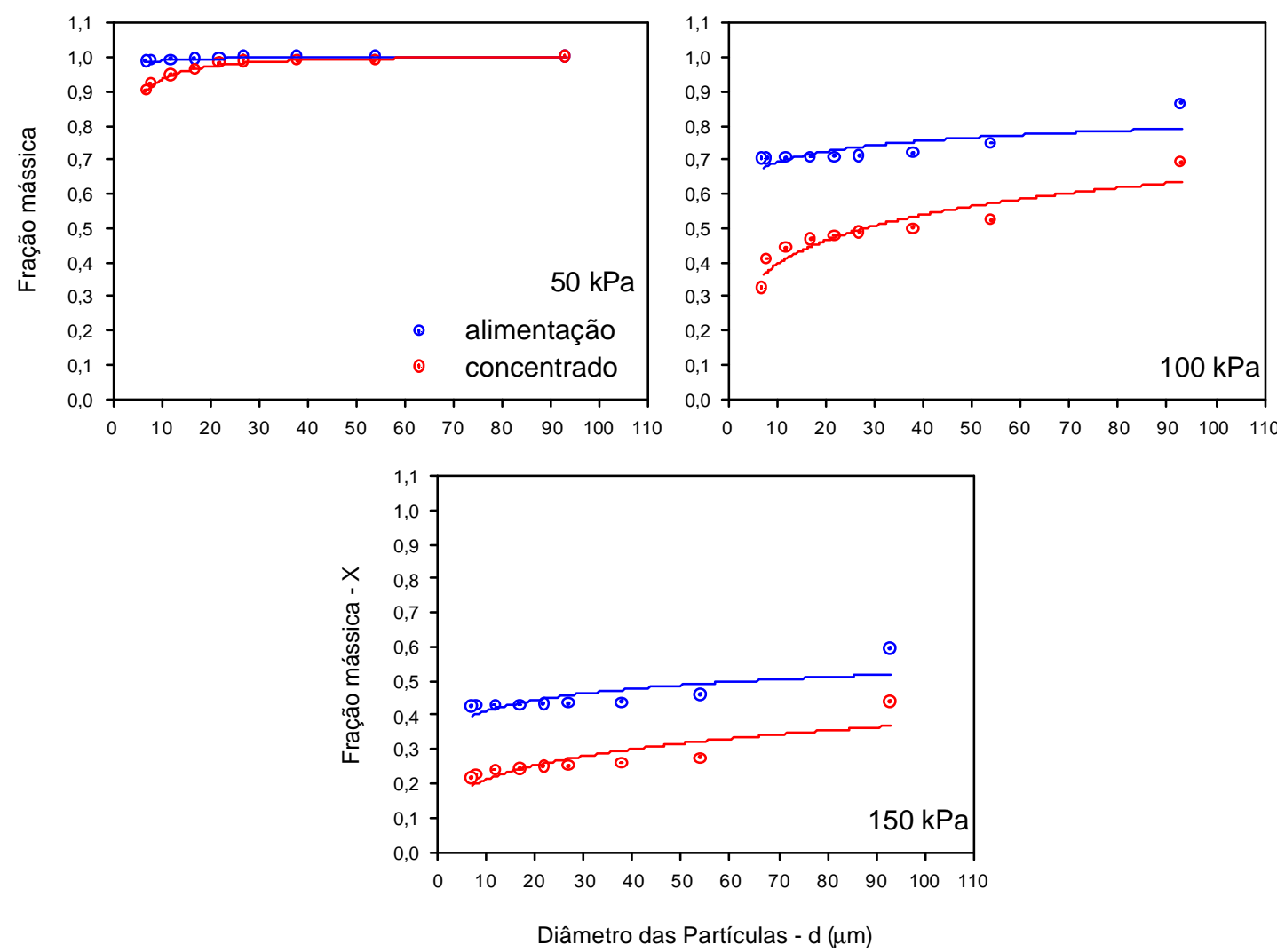

Figura 20 - Distribuição granulométrica do solo, pontos experimentais e curvas ajustadas, na alimentação e no concentrado para o hidrociclone III.

\subsection{Desempenho dos hidrociclones}

\subsubsection{Diferencial de pressão}

Na Figura 22 são apresentados os pontos experimentais e as curvas ajustadas do diferencial de pressão versus vazão, para os quatro hidrociclones ensaiados. Observa-se por meio da análise do gráfico que o diferencial de pressão, nos hidrociclones aumentou do I para o IV, o que já era esperado, haja visto o critério de dimensionamento dos tubos e alimentação retangulares. As equações obtidas por meio da análise de regressão, e seus respectivos coeficientes de determinação são apresentados na sequiência. 

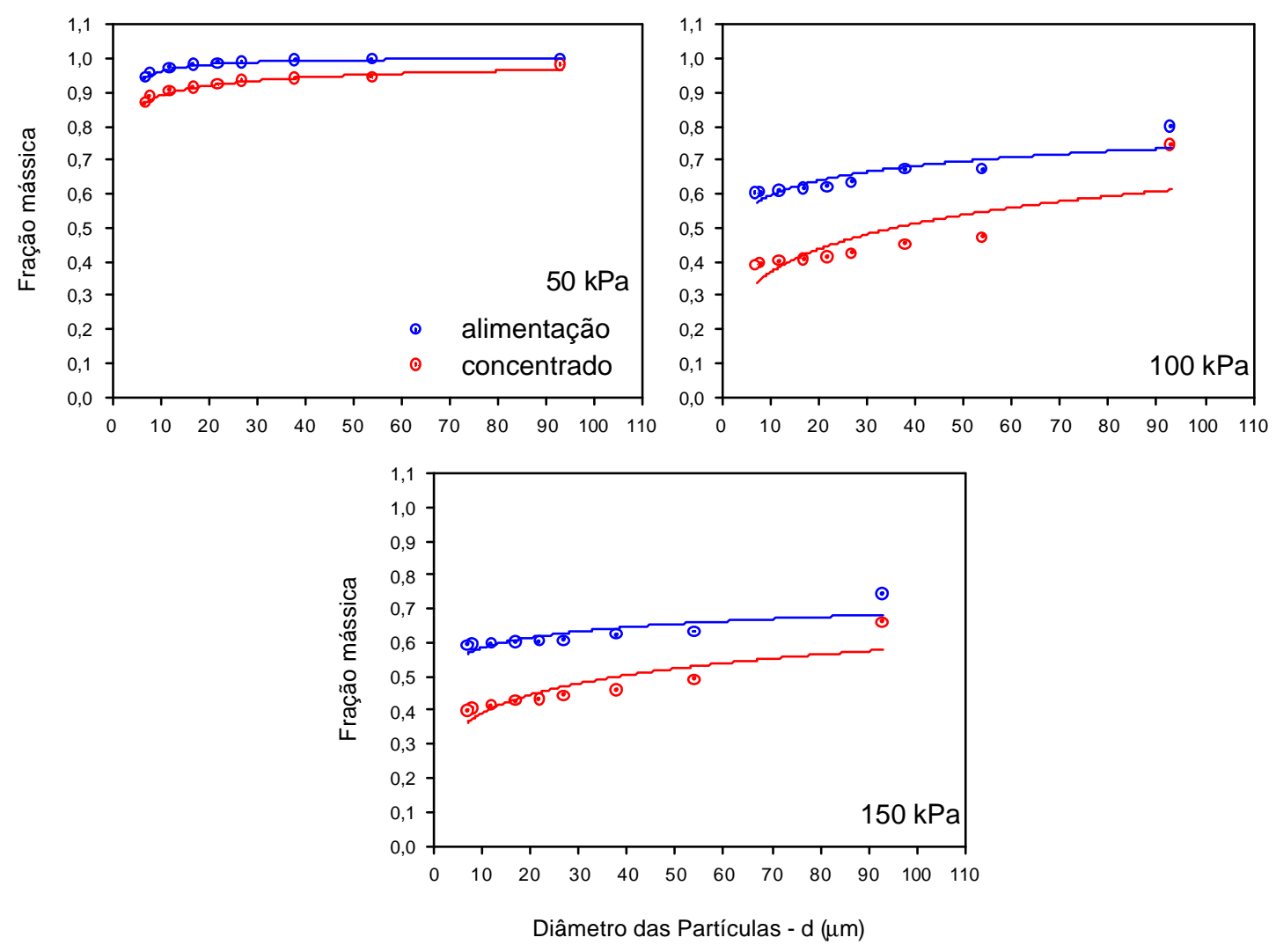

Figura 21 - Distribuição granulométrica do solo, pontos experimentais e curvas ajustadas, na alimentação e no concentrado para o hidrociclone IV.

Os ensaios de perda de carga foram conduzidos com água, cuja temperatura variou entre $21^{\circ} \mathrm{C}$ e $22^{\circ} \mathrm{C}$. Não foram utilizadas as suspensões de areia e solo, pois em ensaios anteriores, constatou-se não haver diferença entre as curvas de perda de carga obtidas, com as suspensões e com a água, para as concentrações analisadas. Esse procedimento teve como objetivo evitar problemas de entupimento, verificados em ensaios anteriores, com os hidrociclones III e IV. 


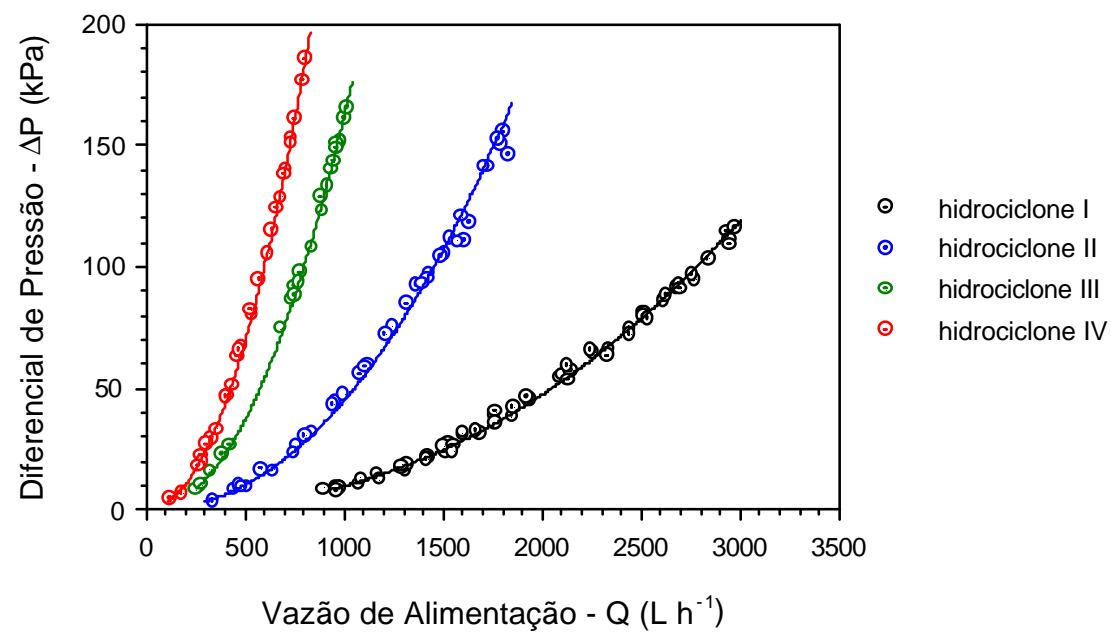

Figura 22 - Queda de pressão em função da vazão de alimentação para os hidrociclones ensaiados.

- Hidrociclone I: $\quad \Delta P_{(k P a)}=1.10^{-6} Q_{\left(L h^{-1}\right)}^{2,275} \quad \mathrm{r}^{2}=0,991$

- Hidrociclone II: $\quad \Delta P_{(k P a)}=2.10^{-5} Q_{\left(L h^{-1}\right)}^{2,142} \quad \mathrm{r}^{2}=0,994$

- Hidrociclone III: $\Delta P_{(k P a)}=6 \cdot 10^{-5} Q_{\left(L h^{-1}\right)}^{2,136} \quad \mathrm{r}^{2}=0,998$

- Hidrociclone IV: $\Delta P_{(k P a)}=2 \cdot 10^{-4} Q_{\left(L h^{-1}\right)}^{2,066} \quad \mathrm{r}^{2}=0,992$

\subsubsection{Hidrociclone I}

As Tabelas 11 e 12 apresentam os dados experimentais médios de desempenho do hidrociclone I operando com suspensão de areia e solo, respectivamente. Pode-se observar nas duas tabelas, que a concentração de partículas na suspensão variou com o aumento do diferencial de pressão, principalmente, do primeiro para os demais diferenciais. Não foi possível manter constante a concentração da suspensão aspirada pela bomba centrífuga, a medida em que eram alteradas as condições dinâmicas da bancada, uma vez que a velocidade de rotação do agitador submersível, encontrava-se no limite acima do qual ocorria perda de suspensão de dentro para fora do reservatório. 
Como não se dispunha de outro agitador, optou-se por continuar os ensaios assumindose a diferença na concentração das suspensões.

Tabela 11. Dados médios dos ensaios experimentais realizados com o hidrociclone I operando com suspensão de areia.

\begin{tabular}{ccccccccrrrr}
\hline $\begin{array}{c}\Delta \mathrm{P} \\
(\mathrm{kPa})\end{array}$ & $\begin{array}{c}\left.\mathrm{Q}^{-1}\right) \\
\left(\mathrm{L} \mathrm{h}^{-1}\right)\end{array}$ & $\begin{array}{c}\mathrm{Q}_{\mathrm{u}} \\
\left(\mathrm{L} \mathrm{h}^{-1}\right)\end{array}$ & $\begin{array}{c}{[\mathrm{A}]} \\
\left(\mathrm{g} \mathrm{L}^{-1}\right)\end{array}$ & $\begin{array}{c}{[\mathrm{C}]} \\
\left(\mathrm{g} \mathrm{L}^{-1}\right)\end{array}$ & $\begin{array}{c}\mathrm{Cv} \\
(\%)\end{array}$ & $\begin{array}{c}\mathrm{Cv}_{\mathrm{u}} \\
(\%)\end{array}$ & $\begin{array}{r}\mathrm{RL} \\
(\%)\end{array}$ & $\begin{array}{c}\mathrm{Ws} \\
\left(\mathrm{kg} \mathrm{h}^{-1}\right)\end{array}$ & $\begin{array}{c}\mathrm{Ws}_{\mathrm{u}} \\
\left(\mathrm{kg} \mathrm{h}^{-1}\right)\end{array}$ & $\begin{array}{c}\mathrm{ET} \\
(\%)\end{array}$ & $\begin{array}{c}\text { ET } \\
(\%)\end{array}$ \\
\hline 10,80 & 1159,9 & 133,5 & 2,81 & 23,26 & 0,106 & 0,879 & 11,42 & 3,265 & 3,104 & 95,08 & 94,45 \\
22,30 & 1582,8 & 223,3 & 2,99 & 21,09 & 0,113 & 0,797 & 13,66 & 4,849 & 4,708 & 97,09 & 96,62 \\
29,50 & 1826,8 & 133,7 & 6,19 & 69,34 & 0,234 & 2,627 & 7,14 & 11,314 & 9,269 & 81,93 & 80,54 \\
40,40 & 2002,2 & 207,6 & 6,11 & 45,50 & 0,231 & 2,720 & 10,22 & 12,239 & 9,444 & 77,16 & 74,56 \\
52,00 & 2386,2 & 249,4 & 5,93 & 42,99 & 0,224 & 1,625 & 10,25 & 14,139 & 10,273 & 72,79 & 69,99 \\
62,70 & 2603,6 & 259,2 & 7,01 & 47,95 & 0,265 & 1,813 & 9,80 & 18,255 & 12,427 & 68,07 & 64,61 \\
\hline
\end{tabular}

Nota: [ A ] - concentração de sólidos na alimentação; [ C ] - concentração de sólidos no concentrado.

Tabela 12. Dados médios dos ensaios experimentais realizados com o hidrociclone I operando com suspensão de solo.

\begin{tabular}{ccccccccrrrr}
\hline $\begin{array}{c}\Delta \mathrm{P} \\
(\mathrm{kPa})\end{array}$ & $\begin{array}{c}\mathrm{Q} \\
\left(\mathrm{L} \mathrm{h}^{-1}\right)\end{array}$ & $\begin{array}{c}\mathrm{Q}_{\mathrm{u}} \\
\left(\mathrm{L} \mathrm{h}^{-1}\right)\end{array}$ & $\begin{array}{c}{[\mathrm{A}]} \\
\left(\mathrm{g} \mathrm{L}^{-1}\right)\end{array}$ & $\begin{array}{c}{[\mathrm{C}]} \\
\left(\mathrm{g} \mathrm{L}^{-1}\right)\end{array}$ & $\begin{array}{c}\mathrm{Cv} \\
(\%)\end{array}$ & $\begin{array}{r}\mathrm{Cv}_{\mathrm{u}} \\
(\%)\end{array}$ & $\begin{array}{r}\mathrm{RL} \\
(\%)\end{array}$ & $\begin{array}{c}\mathrm{Ws} \\
\left(\mathrm{kg} \mathrm{h}^{-1}\right)\end{array}$ & $\begin{array}{c}\mathrm{Ws}_{\mathrm{u}} \\
\left(\mathrm{kg} \mathrm{h}^{-1}\right)\end{array}$ & $\begin{array}{r}\mathrm{ET} \\
(\%)\end{array}$ & $\begin{array}{c}\text { ET } \\
(\%)\end{array}$ \\
\hline 11,90 & 1160,9 & 156,5 & 7,29 & 13,98 & 0,270 & 0,518 & 13,48 & 8,436 & 2,188 & 25,93 & 14,38 \\
22,60 & 1595,1 & 143,9 & 11,46 & 51,10 & 0,424 & 1,893 & 8,89 & 18,279 & 7,356 & 40,29 & 34,46 \\
29,60 & 1813,8 & 141,5 & 11,32 & 58,03 & 0,419 & 2,149 & 7,69 & 20,542 & 8,141 & 39,63 & 34,62 \\
43,50 & 2128,9 & 201,2 & 11,10 & 51,68 & 0,411 & 1,914 & 9,31 & 23,643 & 10,403 & 43,94 & 38,19 \\
51,90 & 2284,8 & 220,4 & 10,89 & 43,07 & 0,403 & 1,595 & 9,53 & 24,383 & 9,497 & 38,15 & 31,63 \\
63,60 & 2534,8 & 244,7 & 12,12 & 48,24 & 0,449 & 1,787 & 9,52 & 30,727 & 11,796 & 38,42 & 31,94 \\
\hline
\end{tabular}

A vazão de alimentação variou de $1159,9 \mathrm{~L} \mathrm{~h}^{-1}$ a $2603,6 \mathrm{~L} \mathrm{~h}^{-1}$ e de $1160,9 \mathrm{~L} \mathrm{~h}^{-1}$ a $2534,8 \mathrm{~L} \mathrm{~h}^{-1}$, para a operação com suspensão de areia e solo, respectivamente. A temperatura das suspensões variou entre $21^{\circ} \mathrm{C}$ e $22^{\circ} \mathrm{C}$, durante os ensaios.

Os maiores valores da eficiência total reduzida $E T$, para os ensaios utilizando suspensão de areia, foram verificados para os diferenciais de pressão de $10,80 \mathrm{kPa}$ e 22,30 $\mathrm{kPa}$ com valores de 94,45\% e 96,62\%, respectivamente, decrescendo até 64,61\% para o diferencial de $62,70 \mathrm{kPa}$. Para a operação com suspensão de solo, a eficiência total reduzida $E T$ ' variou de $14,38 \%$ a $38,19 \%$ para os diferenciais de $11,90 \mathrm{kPa}$ e 43,50 $\mathrm{kPa}$, respectivamente, diminuindo para $31,94 \%$ no diferencial de $63,60 \mathrm{kPa}$. 
De modo geral, a eficiência total reduzida $E T^{\prime}$ do hidrociclone I sempre foi superior, quando o mesmo operou com a suspensão de areia, para diferenciais de pressão semelhantes, o que de certa forma já era esperado, levando-se em consideração as características granulométricas da areia. A média geral da eficiência total reduzida ET', considerando-se todos os diferenciais de pressão, foi de 80,13\% e 30,87\% para a operação com suspensão de areia e solo, respectivamente. Jacobs \& Penney (1987) afirmam que a capacidade de separação dos hidrociclones depende de seu tamanho e geometria, tamanho das partículas e sua geometria, concentração de sólidos, velocidade na entrada, razão de líquido e diferença de densidade entre as partículas e o fluido. As maiores concentrações da suspensão de areia, para os diferenciais superiores a 22,30 $\mathrm{kPa}$, mostraram não ter influência no desempenho do hidrociclone. Mesmo aumentandose a vazão de alimentação e, conseqüentemente a velocidade na entrada, não houve ganho na eficiência, o que pode ser conseqüência da maior turbulência no interior do hidrociclone. Para a suspensão de solo, as menores eficiências podem ser explicadas pelo menor tamanho das partículas.

\subsubsection{Hidrociclones II, III e IV}

Os dados experimentais obtidos, com os ensaios dos hidrociclones com tubo de alimentação retangular, são apresentados nas Tabelas 13, 14, 15, 16, 17 e 18. Neste caso, também se verifica a variação na concentração de sólidos, das suspensões com a alteração no diferencial de pressão. No entanto, pode-se observar que as concentrações das suspensões de alimentação se mostraram sensivelmente inferiores, principalmente para os diferenciais de $20 \mathrm{kPa}$ e $50 \mathrm{kPa}$, àquelas verificadas no hidrociclone I. Fato que pode ser explicado pela ocorrência de menor vazão na alimentação e conseqüente diminuição na agitação do reservatório, para esses hidrociclones.

As vazões de alimentação verificadas durante os ensaios variaram de $806,5 \mathrm{Lh}^{-1}$ a $2028,4 \mathrm{~L} \mathrm{~h}^{-1}, 401,3 \mathrm{~L} \mathrm{~h}^{-1}$ a $1095,3 \mathrm{~L} \mathrm{~h}^{-1}$ e $322,8 \mathrm{~L} \mathrm{~h}^{-1}$ a $847,7 \mathrm{~L} \mathrm{~h}^{-1}$ para os hidrociclones II, III e IV, respectivamente. 
Tabela 13. Dados médios dos ensaios experimentais realizados com o hidrociclone II operando com suspensão de areia.

\begin{tabular}{rrrrrccccccc}
\hline $\begin{array}{c}\Delta \mathrm{P} \\
(\mathrm{kPa})\end{array}$ & $\begin{array}{c}\mathrm{Q} \\
\left(\mathrm{L} \mathrm{h}^{-1}\right)\end{array}$ & $\begin{array}{c}\mathrm{Q}_{\mathrm{u}} \\
\left(\mathrm{L} \mathrm{h}^{-1}\right)\end{array}$ & $\begin{array}{c}{[\mathrm{A}]} \\
\left(\mathrm{g} \mathrm{L}^{-1}\right)\end{array}$ & $\begin{array}{c}{[\mathrm{C}]} \\
\left(\mathrm{g} \mathrm{L}^{-1}\right)\end{array}$ & $\begin{array}{c}\mathrm{Cv} \\
(\%)\end{array}$ & $\begin{array}{c}\mathrm{Cv}_{\mathrm{u}} \\
(\%)\end{array}$ & $\begin{array}{c}\mathrm{RL} \\
(\%)\end{array}$ & $\begin{array}{c}\mathrm{Ws} \\
\left(\mathrm{kg} \mathrm{h}^{-1}\right)\end{array}$ & $\begin{array}{c}\mathrm{Ws}_{\mathrm{u}} \\
\left(\mathrm{kg} \mathrm{h}^{-1}\right)\end{array}$ & $\begin{array}{c}\mathrm{ET} \\
(\%)\end{array}$ & $\begin{array}{c}\mathrm{ET} \\
(\%)\end{array}$ \\
\hline 23,90 & 806,5 & 94,5 & 0,35 & 2,08 & 0,013 & 0,079 & 11,70 & 0,281 & 0,197 & 72,73 & 69,13 \\
51,10 & 1165,0 & 155,5 & 0,91 & 3,48 & 0,034 & 0,132 & 13,30 & 1,063 & 0,541 & 57,79 & 51,29 \\
99,60 & 1621,8 & 195,3 & 5,69 & 25,92 & 0,215 & 0,980 & 12,00 & 9,244 & 5,069 & 59,99 & 54,47 \\
151,70 & 2017,0 & 250,4 & 7,95 & 30,63 & 0,301 & 1,159 & 12,30 & 16,059 & 7,222 & 44,84 & 37,08 \\
\hline
\end{tabular}

Tabela 14. Dados médios dos ensaios experimentais realizados com o hidrociclone II operando com suspensão de solo.

\begin{tabular}{rccccccccccc}
\hline \multicolumn{1}{c}{$\begin{array}{c}\Delta \mathrm{P} \\
(\mathrm{kPa})\end{array}$} & $\begin{array}{c}\mathrm{Q} \\
\left(\mathrm{L} \mathrm{h}^{-1}\right)\end{array}$ & $\begin{array}{c}\mathrm{Q}_{\mathrm{u}} \\
\left(\mathrm{L} \mathrm{h}^{-1}\right)\end{array}$ & $\begin{array}{c}{[\mathrm{A}]} \\
\left(\mathrm{g} \mathrm{L}^{-1}\right)\end{array}$ & $\begin{array}{c}{[\mathrm{C}]} \\
\left(\mathrm{g} \mathrm{L}^{-1}\right)\end{array}$ & $\begin{array}{c}\mathrm{Cv} \\
(\%)\end{array}$ & $\begin{array}{c}\mathrm{Cv}_{\mathrm{u}} \\
(\%)\end{array}$ & $\begin{array}{c}\mathrm{RL} \\
(\%)\end{array}$ & $\begin{array}{c}\mathrm{Ws} \\
\left(\mathrm{kg} \mathrm{h}^{-1}\right)\end{array}$ & $\begin{array}{c}\mathrm{Ws}_{\mathrm{u}} \\
\left(\mathrm{kg} \mathrm{h}^{-1}\right)\end{array}$ & $\begin{array}{c}\mathrm{ET} \\
(\%)\end{array}$ & $\begin{array}{c}\text { ET } \\
(\%)\end{array}$ \\
\hline 48,50 & 1121,9 & 203,7 & 6,94 & 10,64 & 0,257 & 0,394 & 18,23 & 7,721 & 2,157 & 27,90 & 11,83 \\
104,60 & 1667,3 & 190,7 & 14,23 & 42,03 & 0,527 & 1,556 & 11,32 & 23,758 & 8,029 & 33,88 & 25,45 \\
152,10 & 2028,4 & 195,3 & 12,30 & 46,80 & 0,456 & 1,733 & 9,50 & 24,954 & 8,509 & 33,97 & 27,08 \\
\hline
\end{tabular}

Tabela 15. Dados médios dos ensaios experimentais realizados com o hidrociclone III operando com suspensão de areia.

\begin{tabular}{rrrrrccccccc}
\hline $\begin{array}{c}\Delta \mathrm{P} \\
(\mathrm{kPa})\end{array}$ & $\begin{array}{c}\mathrm{Q}^{-1} \\
\left(\mathrm{~L} \mathrm{~h}^{-1}\right)\end{array}$ & $\begin{array}{c}\mathrm{Q}_{\mathrm{u}} \\
\left(\mathrm{L} \mathrm{h}^{-1}\right)\end{array}$ & $\begin{array}{c}{[\mathrm{A}]} \\
\left(\mathrm{g} \mathrm{L}^{-1}\right)\end{array}$ & $\begin{array}{c}{[\mathrm{C}]} \\
\left(\mathrm{g} \mathrm{L}^{-1}\right)\end{array}$ & $\begin{array}{c}\mathrm{Cv} \\
(\%)\end{array}$ & $\begin{array}{c}\mathrm{Cv}_{\mathrm{u}} \\
(\%)\end{array}$ & $\begin{array}{c}\mathrm{RL} \\
(\%)\end{array}$ & $\begin{array}{c}\mathrm{Ws} \\
\left(\mathrm{kg} \mathrm{h}^{-1}\right)\end{array}$ & $\begin{array}{c}\mathrm{Ws}_{\mathrm{u}} \\
\left(\mathrm{kg} \mathrm{h}^{-1}\right)\end{array}$ & $\begin{array}{c}\mathrm{ET} \\
(\%)\end{array}$ & $\begin{array}{c}\mathrm{ET}^{\prime} \\
(\%)\end{array}$ \\
\hline 23,90 & 401,3 & 53,0 & 0,11 & 0,35 & 0,004 & 0,013 & 13,10 & 0,042 & 0,019 & 43,86 & 35,46 \\
54,30 & 602,9 & 92,8 & 0,18 & 0,50 & 0,007 & 0,019 & 15,40 & 0,108 & 0,046 & 42,64 & 32,21 \\
102,20 & 842,6 & 122,6 & 0,40 & 1,16 & 0,015 & 0,044 & 14,50 & 0,339 & 0,143 & 42,09 & 32,23 \\
151,10 & 1012,9 & 100,3 & 3,42 & 18,01 & 0,295 & 0,681 & 9,80 & 3,468 & 1,806 & 52,07 & 46,84 \\
\hline
\end{tabular}

Tabela 16. Dados médios dos ensaios experimentais realizados com o hidrociclone III operando com suspensão de solo.

\begin{tabular}{rrrrrrrrrrrr}
\hline $\begin{array}{c}\Delta \mathrm{P} \\
(\mathrm{kPa})\end{array}$ & $\begin{array}{c}\mathrm{Q} \\
\left(\mathrm{L} \mathrm{h}^{-1}\right)\end{array}$ & $\begin{array}{c}\mathrm{Q}_{\mathrm{u}} \\
\left(\mathrm{L} \mathrm{h}^{-1}\right)\end{array}$ & $\begin{array}{c}{[\mathrm{A}]} \\
\left(\mathrm{g} \mathrm{L}^{-1}\right)\end{array}$ & $\begin{array}{c}{[\mathrm{C}]} \\
\left(\mathrm{g} \mathrm{L}^{-1}\right)\end{array}$ & $\begin{array}{c}\mathrm{Cv} \\
(\%)\end{array}$ & $\begin{array}{r}\mathrm{Cv}_{\mathrm{u}} \\
(\%)\end{array}$ & $\begin{array}{c}\mathrm{RL} \\
(\%)\end{array}$ & $\begin{array}{c}\mathrm{Ws} \\
\left(\mathrm{kg} \mathrm{h}^{-1}\right)\end{array}$ & $\begin{array}{c}\mathrm{Ws}_{\mathrm{u}} \\
\left(\mathrm{kg} \mathrm{h}^{-1}\right)\end{array}$ & $\begin{array}{c}\mathrm{ET} \\
(\%)\end{array}$ & $\begin{array}{r}\text { ET } \\
(\%)\end{array}$ \\
\hline 48,90 & 615,4 & 113,1 & 7,37 & 10,05 & 0,273 & 0,372 & 18,36 & 4,491 & 1,141 & 25,84 & 9,16 \\
104,20 & 891,6 & 116,6 & 5,75 & 14,69 & 0,213 & 0,544 & 13,04 & 5,169 & 1,708 & 34,25 & 24,40 \\
152,00 & 1095,3 & 133,9 & 16,44 & 37,83 & 0,609 & 1,401 & 12,13 & 18,004 & 5,062 & 28,13 & 18,20 \\
\hline
\end{tabular}


Tabela 17. Dados médios dos ensaios experimentais realizados com o hidrociclone IV operando com suspensão de areia.

\begin{tabular}{rccccccccccc}
\hline $\begin{array}{c}\Delta \mathrm{P} \\
(\mathrm{kPa})\end{array}$ & $\begin{array}{c}\mathrm{Q} \\
\left(\mathrm{L} \mathrm{h}^{-1}\right)\end{array}$ & $\begin{array}{c}\mathrm{Q}_{\mathrm{u}} \\
\left(\mathrm{L} \mathrm{h}^{-1}\right)\end{array}$ & $\begin{array}{c}{[\mathrm{A}]} \\
\left(\mathrm{g} \mathrm{L}^{-1}\right)\end{array}$ & $\begin{array}{c}{[\mathrm{C}]} \\
\left(\mathrm{g} \mathrm{L}^{-1}\right)\end{array}$ & $\begin{array}{c}\mathrm{Cv} \\
(\%)\end{array}$ & $\begin{array}{c}\mathrm{Cv}_{\mathrm{u}} \\
(\%)\end{array}$ & $\begin{array}{c}\mathrm{RL} \\
(\%)\end{array}$ & $\begin{array}{c}\mathrm{Ws} \\
\left(\mathrm{kg} \mathrm{h}^{-1}\right)\end{array}$ & $\begin{array}{c}\mathrm{Ws}_{\mathrm{u}} \\
\left(\mathrm{kg} \mathrm{h}^{-1}\right)\end{array}$ & $\begin{array}{c}\mathrm{ET} \\
(\%)\end{array}$ & $\begin{array}{c}\mathrm{ET} \\
(\%)\end{array}$ \\
\hline 28,00 & 322,8 & 39,6 & 0,02 & 0,04 & 0,001 & 0,002 & 12,30 & 0,007 & 0,002 & 24,76 & 14,25 \\
54,90 & 497,6 & 51,3 & 0,35 & 1,67 & 0,013 & 0,063 & 10,30 & 0,174 & 0,086 & 49,26 & 43,03 \\
101,00 & 631,9 & 72,1 & 1,62 & 6,77 & 0,061 & 0,256 & 11,40 & 1,024 & 0,489 & 47,72 & 41,00 \\
148,80 & 829,9 & 91,5 & 11,87 & 49,60 & 0,449 & 1,875 & 10,90 & 9,848 & 4,537 & 46,07 & 39,50 \\
\hline
\end{tabular}

Tabela 18. Dados médios dos ensaios experimentais realizados com o hidrociclone IV operando com suspensão de solo.

\begin{tabular}{rccccccccccr}
\hline $\begin{array}{c}\Delta \mathrm{P} \\
(\mathrm{kPa})\end{array}$ & $\begin{array}{c}\mathrm{Q} \\
\left(\mathrm{L} \mathrm{h}^{-1}\right)\end{array}$ & $\begin{array}{c}\mathrm{Q}_{\mathrm{u}} \\
\left(\mathrm{L} \mathrm{h}^{-1}\right)\end{array}$ & $\begin{array}{c}{[\mathrm{A}]} \\
\left(\mathrm{g} \mathrm{L}^{-1}\right)\end{array}$ & $\begin{array}{c}{[\mathrm{C}]} \\
\left(\mathrm{g} \mathrm{L}^{-1}\right)\end{array}$ & $\begin{array}{c}\mathrm{Cv} \\
(\%)\end{array}$ & $\begin{array}{c}\mathrm{Cv}_{\mathrm{u}} \\
(\%)\end{array}$ & $\begin{array}{c}\mathrm{RL} \\
(\%)\end{array}$ & $\begin{array}{c}\mathrm{Ws} \\
\left(\mathrm{kg} \mathrm{h}^{-1}\right)\end{array}$ & $\begin{array}{c}\mathrm{Ws}_{\mathrm{u}} \\
\left(\mathrm{kg} \mathrm{h}^{-1}\right)\end{array}$ & $\begin{array}{c}\mathrm{ET} \\
(\%)\end{array}$ & $\begin{array}{r}\text { ET } \\
(\%)\end{array}$ \\
\hline 52,40 & 512,4 & 111,6 & 5,93 & 7,36 & 0,220 & 0,273 & 21,78 & 3,037 & 0,822 & 27,05 & 6,74 \\
105,50 & 652,7 & 139,9 & 8,54 & 12,86 & 0,316 & 0,476 & 21,40 & 5,571 & 1,798 & 32,28 & 13,84 \\
149,60 & 847,7 & 151,1 & 9,67 & 17,40 & 0,358 & 0,644 & 17,78 & 8,199 & 2,629 & 32,08 & 17,40 \\
\hline
\end{tabular}

A eficiência total reduzida $E T^{\prime}$, de cada um dos três hidrociclones apresentou a mesma tendência, observada no hidrociclone I. Os maiores valores foram verificados para a suspensão de areia, tendo como média geral de todos os diferenciais de pressão, os seguintes valores: hidrociclone II 52,99\% e 21,45\% para a suspensão de areia e solo, respectivamente; hidrociclone III 36,69\% e 17,25\% para a suspensão de areia e solo, respectivamente; hidrociclone IV 34,45\% e 12,66\% para a suspensão de areia e solo, respectivamente.

Comparando o desempenho dos quatro hidrociclones, tomando como referência a eficiência total reduzida $E T^{\prime}$ e adotando-se os diferenciais de pressão próximos a $50 \mathrm{kPa}$, comum a todos os quatro, verifica-se que as vazões dos três hidrociclones II, III, e IV decrescem em média 51,04\%, 73,92\% e 78,38\%, respectivamente, em relação ao hidrociclone I. Essa queda de vazão não resultou em ganho de eficiência para estes três hidrociclones, pelo contrário, observa-se que a eficiência total reduzida, para as mesmas condições de ensaio fixadas acima, diminuíram de 26,72\%, 53,98\% e 38,52\% para a suspensão de areia e de 62,60\%,71,04\% e 78,69\% para a suspensão de solo, para os 
hidrociclones II, III e IV, respectivamente. Os gráficos que apresentam o comportamento da eficiência total $E T$ e a eficiência total reduzida $E T$ ', em função dos diferenciais de pressão são apresentados no Anexo C.

Um problema verificado durante os ensaios dos hidrociclones III e IV foi a tendência ao entupimento. Não foram poucas as ocasiões, em que durante o ensaio, tanto com a suspensão de areia como a de solo, houve a necessidade de parar o sistema e abrir o hidrociclone para desobstruir o tubo de alimentação.

O Anexo D apresenta os resultados da determinação dos números adimensionais, cujo produto entre o número de Stokes e de Euler $S t k_{50} E u$, baseou-se na Equação (17) sugerida por Medronho (1984). O número de Euler Eu foi determinado por meio da Equação (15), e o número de Reynolds Re por meio da Equação (16). Os valores calculados para a faixa de operação dos quatro hidrociclones ensaiados se apresentam próximos aos valores apresentados por Svarovsky (1984), Silva (1989) e Pai Neto et al. (2000).

\subsubsection{Eficiência total}

Fez-se até aqui uma discussão com relação ao desempenho dos hidrociclones, tomando como referencial a eficiência total reduzida $E T$ '. Essa eficiência exclui o efeito $T$ (divisão do escoamento principal em duas correntes, garantindo assim, uma "eficiência mínima de separação") presente nos hidrociclones. Assim procedendo, pode-se analisar o desempenho dos mesmos sem levar em consideração a razão de líquido, que apresentou uma variação média entre os ensaios, considerando apenas as partículas separadas pela ação da força centrífuga.

Para fins de aplicação prática dos hidrociclones, no caso particular da préfiltragem da água utilizada na irrigação, o interesse volta-se para o poder de remoção total das partículas suspensas.

A Tabela 19 apresenta valores médios da eficiência total ET calculados a partir das eficiências totais, observadas em cada diferencial de pressão utilizado no ensaio dos hidrociclones, bem como, o diferencial de pressão médio e a vazão de alimentação 
média correspondente. A análise desta tabela mostra o comportamento geral de cada hidrociclone, no que diz respeito ao seu poder total de separação e o diferencial de pressão necessário para tal. Em relação a suspensão de areia verifica-se que o maior valor de eficiência foi $82,02 \%$ obtido com o hidrociclone I, sendo menores, 58,84\%, $45,17 \%$ e $41,95 \%$ para os hidrociclones II, III e IV, respectivamente. Para a suspensão de solo a maior eficiência também foi observada no hidrociclone I, no entanto, a diferença com relação aos outros três hidrociclones não foi tão significativa, porém foi alcançada com aproximadamente 1/3 do diferencial de pressão.

Tabela 19. Valores médios da eficiência total, diferencial de pressão e vazão de alimentação calculados a partir de todos os ensaios realizados com os hidrociclones operando com as suspensões de areia e solo.

\begin{tabular}{ccccc}
\hline Hidrociclone & Suspensão & $\overline{E T} *(\%)$ & $\overline{\Delta P} * *(\mathrm{kPa})$ & $\mathrm{Q}\left(\mathrm{L} \mathrm{h}^{-1}\right)$ \\
\hline \multirow{2}{*}{ I } & areia & 82,02 & 36,28 & 1926,92 \\
& solo & 37,73 & 37,23 & 1919,72 \\
II & areia & 58,84 & 81,58 & 1402,58 \\
& solo & 31,92 & 101,73 & 1605,87 \\
III & areia & 45,17 & 82,88 & 714,93 \\
& solo & 29,41 & 101,70 & 867,43 \\
IV & areia & 41,95 & 83,18 & 570,55 \\
& solo & 30,47 & 102,50 & 670,93 \\
\hline
\end{tabular}

Nota: * Eficiência total média de todos os ensaios; ** Diferencial de pressão médio de todos os ensaios.

Os resultados mostram que o aumento do diferencial de pressão dos hidrociclones, dotados com tubulação de alimentação retangular, não resultou em aumento da eficiência dos mesmos, e sim na diminuição da vazão com conseqüente queda da força centrífuga gerada em seu interior. Isto mostra o menor poder de separação destes hidrociclones, quando comparados ao hidrociclone dotado com tubo de alimentação circular.

As Figuras 23 a 26 mostram a variação da concentração de sólidos na suspensão de alimentação e na suspensão diluída, com base na eficiência total de separação, para os diferenciais de pressão fixados nos ensaios. A diferença entre as curvas representa a 
massa total de partículas retiradas por unidade de volume da suspensão, e a curva tracejada mostra a quantidade de partículas que passaram pelo hidrociclone sem serem separadas. Apesar da operação ter sido conduzida com concentrações elevadas na suspensão, verifica-se que a separação imprimida pelos hidrociclones foi considerável, principalmente pelo hidrociclone I, o que demonstra a importância do uso desses filtros na pré-filtragem da água utilizada na irrigação. Seu uso não só possibilitaria a utilização dos filtros de tela e areia, sob determinadas concentrações de sólidos suspensos na água (conforme recomendação presente na Tabela 4), como também reduziria sensivelmente o número de operações de limpeza daqueles filtros durante o ciclo de irrigação.

(a)

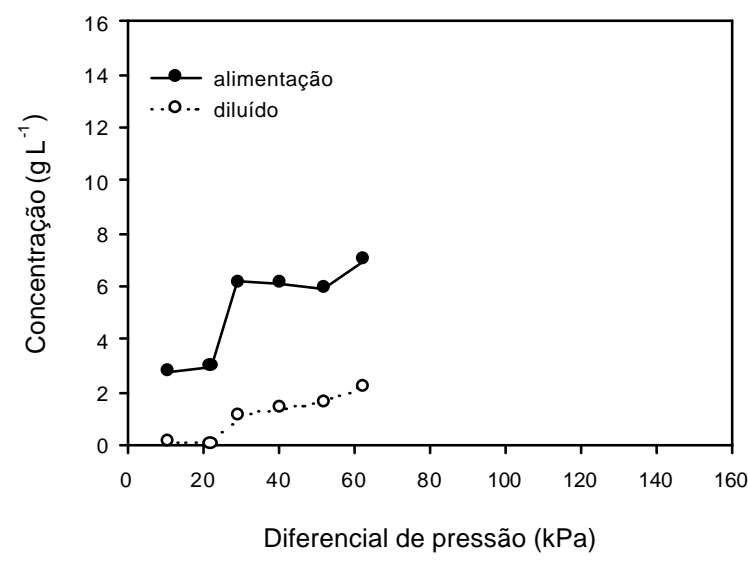

(b)

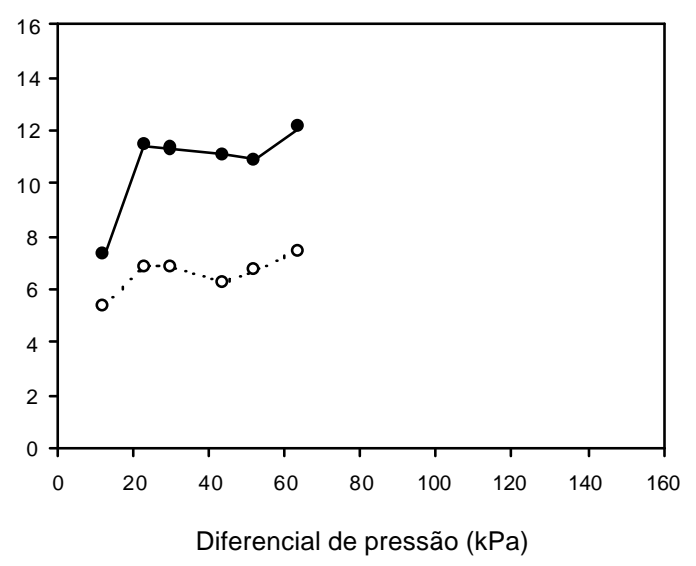

Figura 23 - Concentração da suspensão de areia (a) e solo (b) na alimentação e no diluído para o hidrociclone I.

Como base nos resultados, toma-se como exemplo duas situações em que o hidrociclone I apresentou o melhor desempenho. A operação com suspensão de areia, em que a vazão de alimentação foi de $1582,8 \mathrm{~L} \mathrm{~h}^{-1}$, a operação do conjunto motobomba, no período de 1 hora, lançaria num hipotético sistema de irrigação, sem o uso do hidrociclone, 4732,6 g de areia. Para a mesma vazão, com o uso do hidrociclone, a quantidade de areia diminuiria para 137,7 g, quantidade 34,4 vezes menor. Em outras palavras, o sistema provido com o hidrociclone teria que operar 34,4 horas para lançar a mesma quantidade de areia que lançaria em 1 hora sem o uso do hidrociclone. A mesma 
análise feita para a suspensão de solo, em que a vazão de alimentação foi $2128,9 \mathrm{~L} \mathrm{~h}^{-1}$, o conjunto motobomba, com e sem o uso do hidrociclone, lançaria no sistema 23630,8 g e $13248,1 \mathrm{~g}$ de solo, respectivamente, o que representa uma quantidade 1,78 vezes menor.

(a)

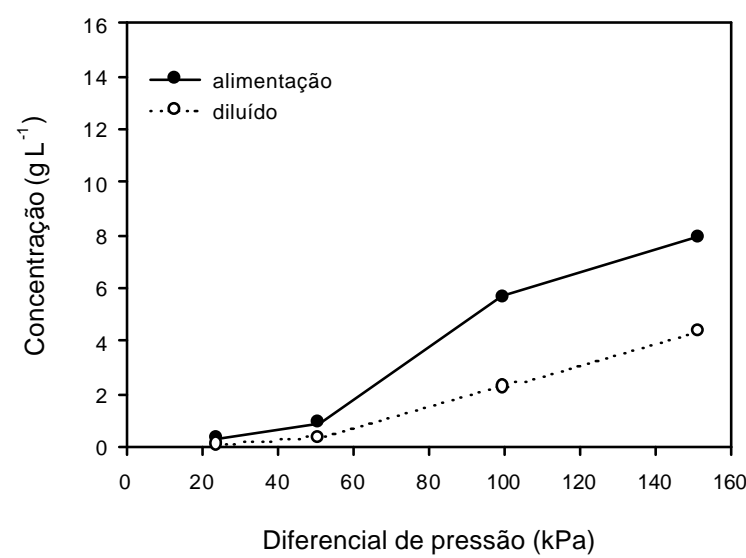

(b)

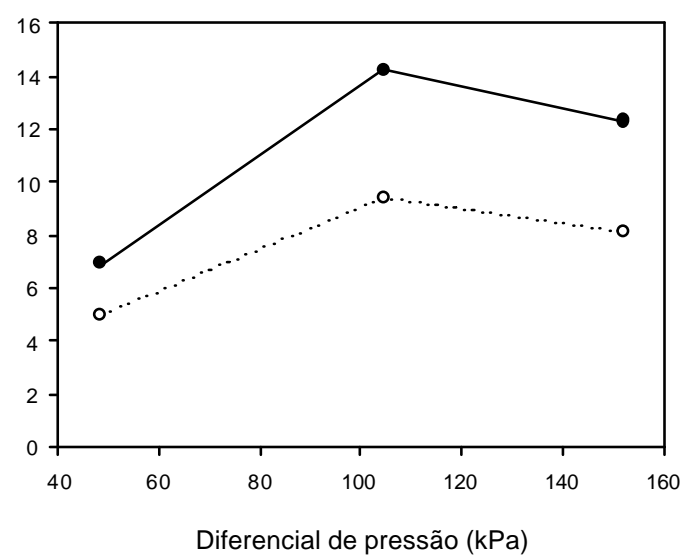

Figura 24 - Concentração da suspensão de areia (a) e solo (b) na alimentação e no diluído para o hidrociclone II.

(a)

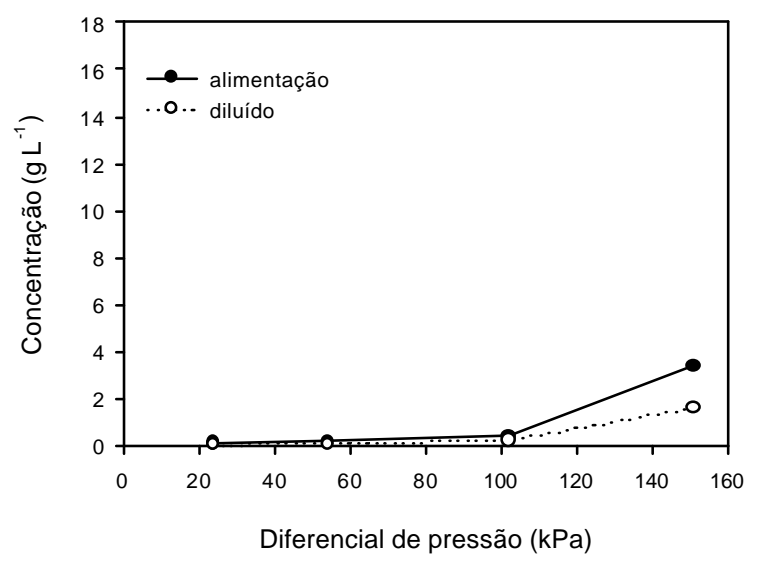

(b)

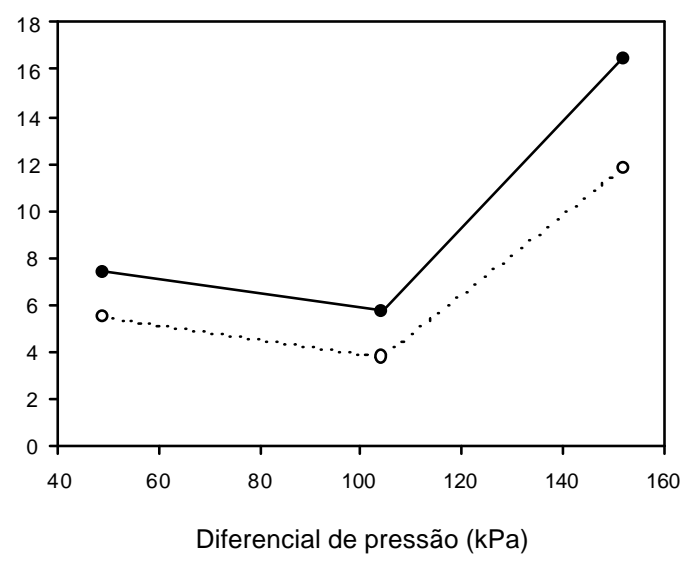

Figura 25 - Concentração da suspensão de areia (a) e solo (b) na alimentação e no diluído para o hidrociclone III. 
(a)

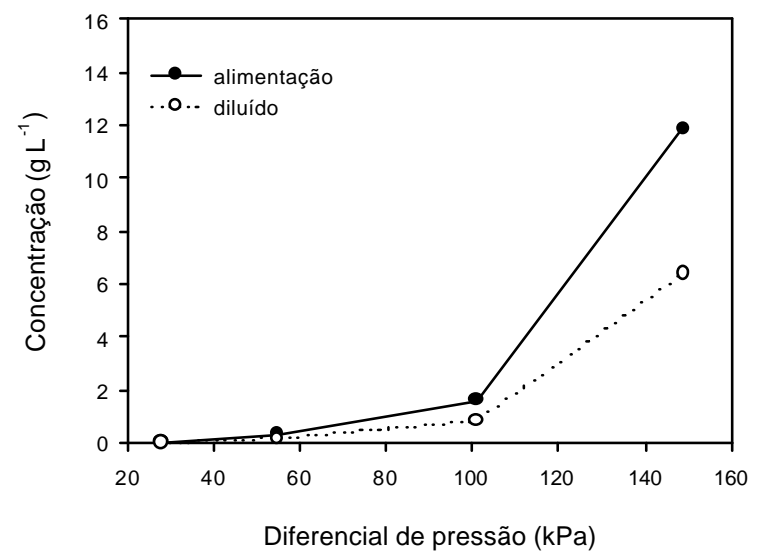

(b)

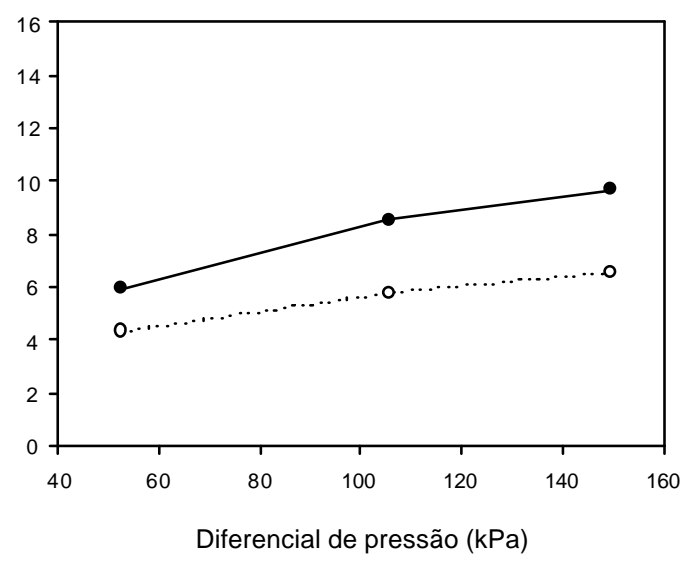

Figura 26 - Concentração da suspensão de areia (a) e solo (b) na alimentação e no diluído para o hidrociclone IV.

\subsection{Comparação dos dados experimentais com os obtidos pelos modelos de Plitt (1976) e Lynch \& Rao (1975)}

Os dados experimentais do diferencial de pressão e vazão na alimentação foram comparados com os dados estimados pelos modelos de Plitt (1976) e de Lynch \& Rao (1975), que são amplamente utilizados para prever o desempenho de hidrociclones.

As Figuras 27, 28, 29 e 30 apresentam os valores experimentais do diferencial de pressão versus os valores estimados pelo modelo de Plitt (1976), para os quatro hidrociclones testados. Pode-se observar por meio da análise dos mesmos que, para o hidrociclone I, o modelo superestimou os valores do diferencial de pressão, com desvio médio de 30,41\% e 25,79\% para a operação com as suspensões de areia e solo, respectivamente. Para os hidrociclones com bocal de alimentação retangular, o modelo subestimou os valores, com erro médio de: $-32,24 \%$ e $-35,27 \%$ para o hidrociclone II, operando com suspensão de areia e solo, respectivamente; -76,66\% e -74,63\% para o hidrociclone III, operando com suspensão de areia e solo, respectivamente; e -83,24\% e $-82,29 \%$ para o hidrociclone IV, operando com suspensão de areia e solo, respectivamente. Os resultados demonstram que o modelo sugerido por Plitt (1976), não 
deve ser utilizado para prever o diferencial de pressão de hidrociclones, principalmente quando construídos com bocais retangulares.

(a)

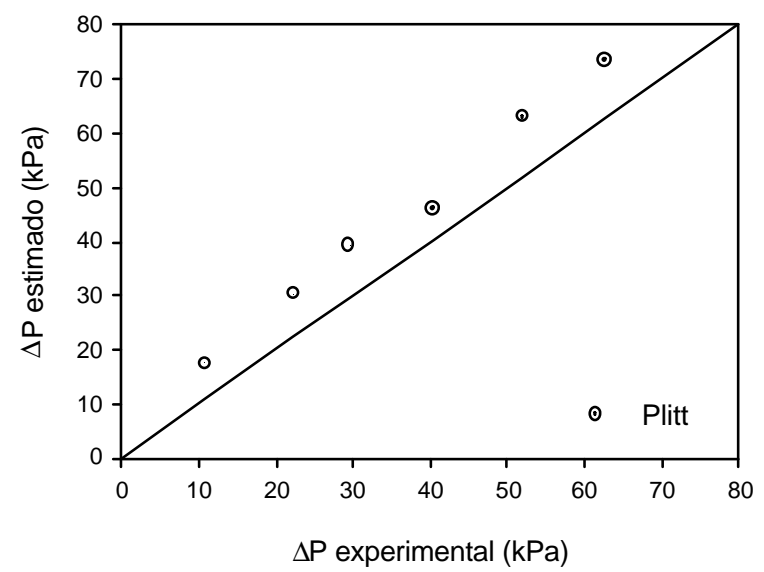

(b)

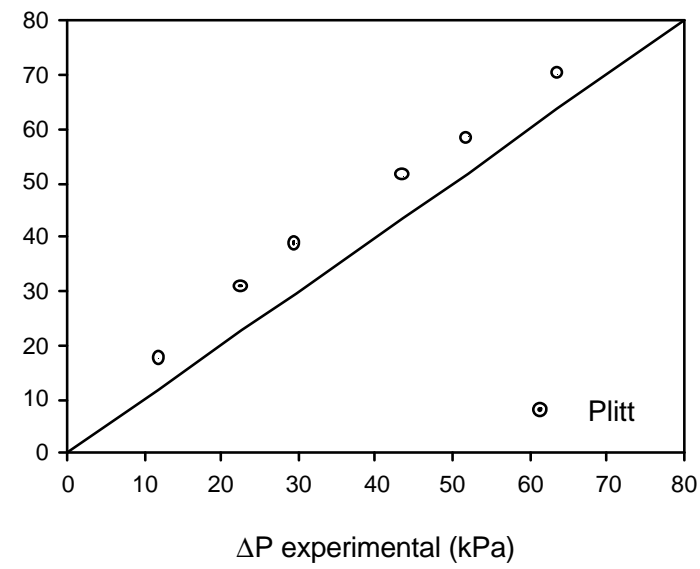

Figura 27 - Diferencial de pressão no hidrociclone I estimados pelo modelo de Plitt versus os valores experimentais, para a suspensão de areia (a) e solo (b).

(a)

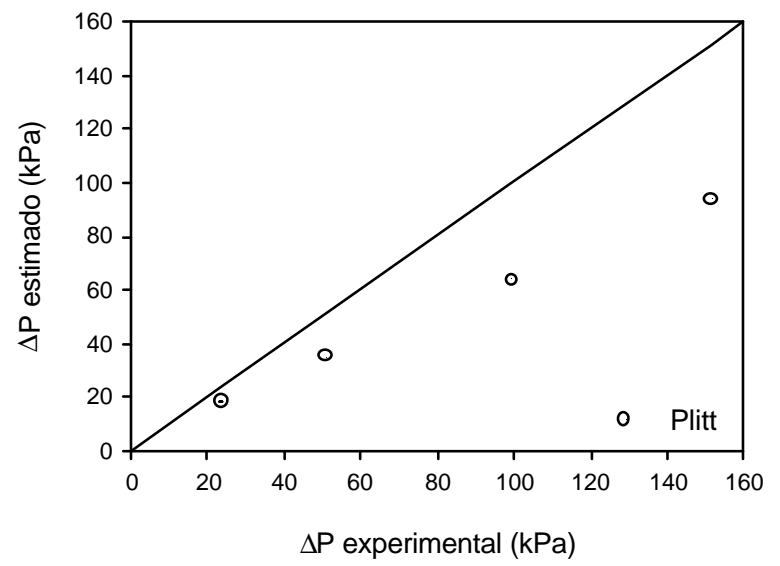

(b)

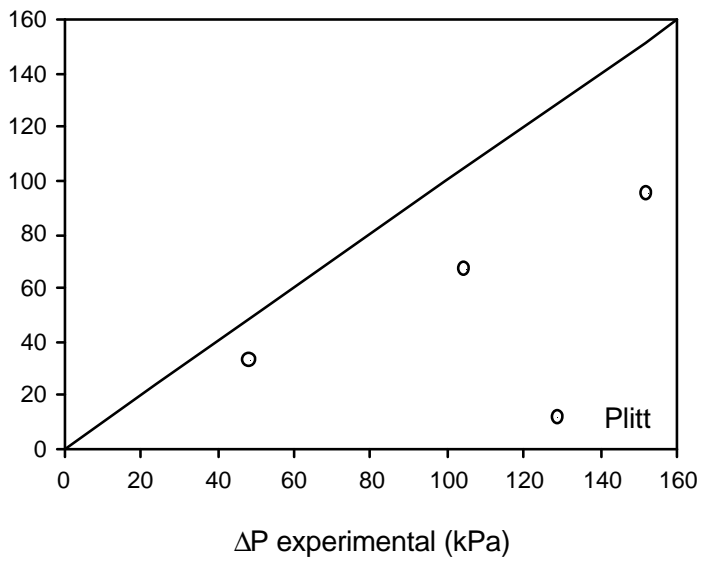

Figura 28 - Diferencial de pressão no hidrociclone II estimados pelo modelo de Plitt versus os valores experimentais, para a suspensão de areia (a) e solo (b). 
(a)

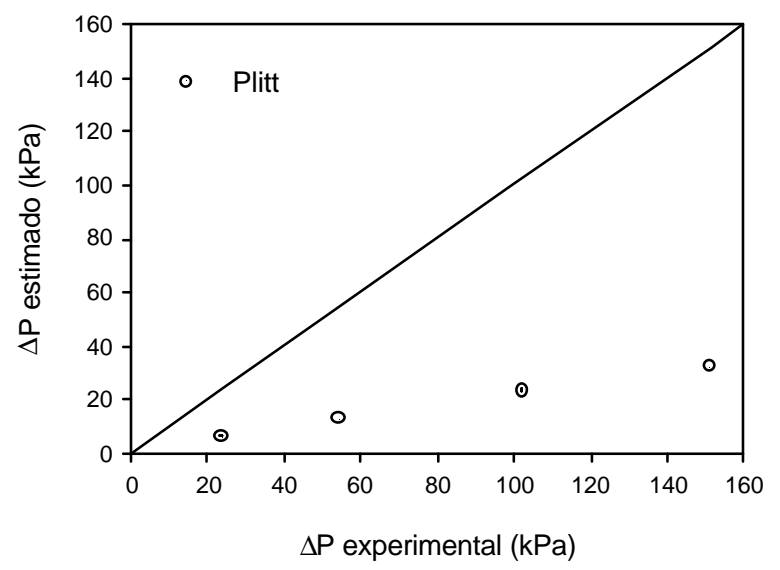

(b)

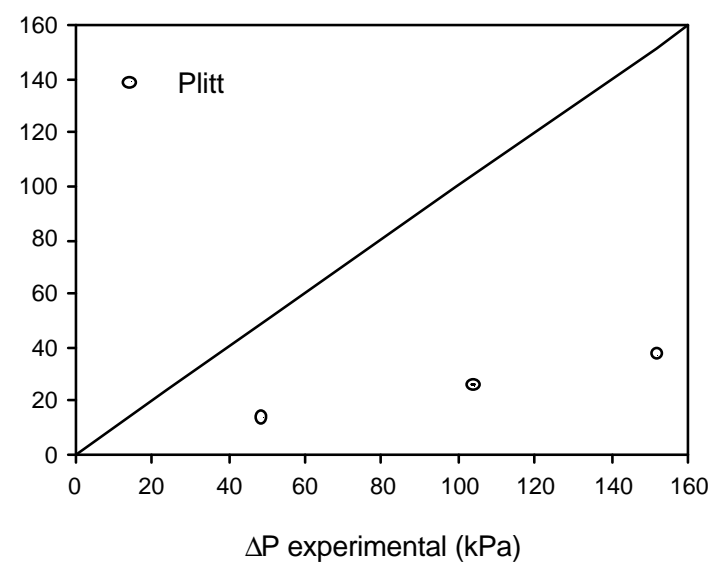

Figura 29 - Diferencial de pressão no hidrociclone III estimados pelo modelo de Plitt versus os valores experimentais, para a suspensão de areia (a) e solo (b).

(a)

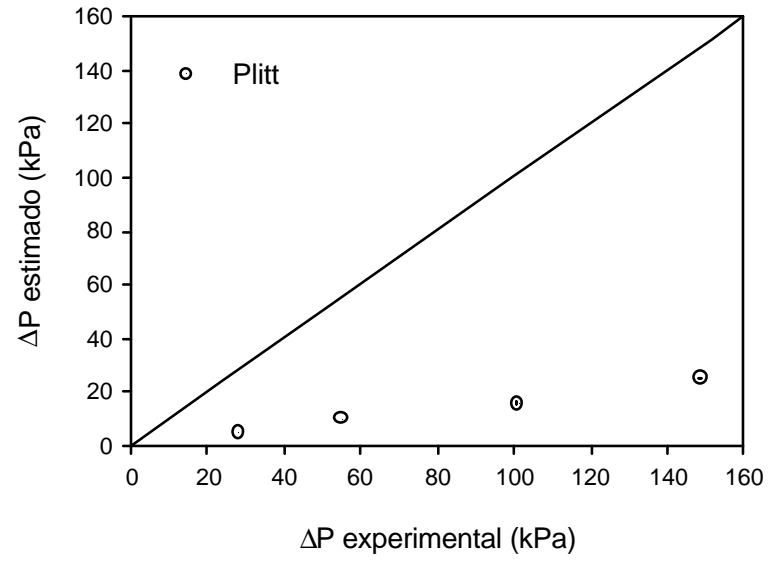

(b)

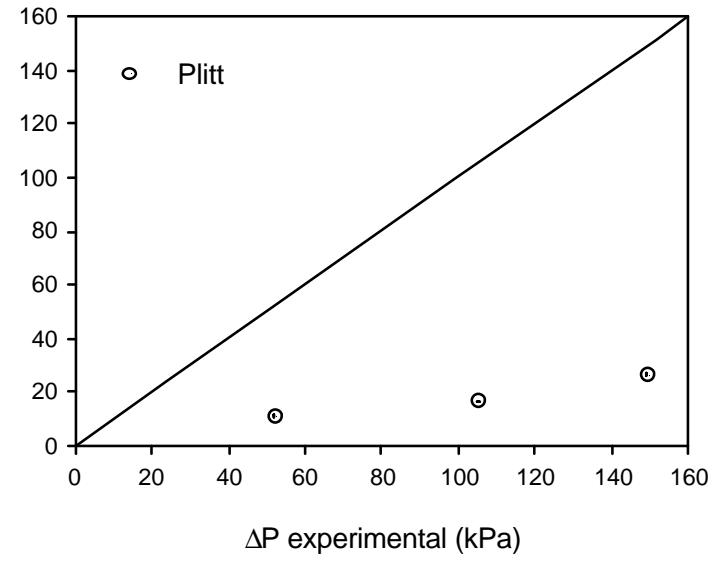

Figura 30 - Diferencial de pressão no hidrociclone IV estimados pelo modelo de Plitt versus os valores experimentais, para a suspensão de areia (a) e solo (b).

A comparação dos dados experimentais da vazão de alimentação com os dados estimados pelos modelos de Plitt (1976) e Lynch \& Rao (1975), é apresentada nas Figuras 31, 32, 33 e 34. Para o hidrociclone I o modelo de Plitt (1976) estimou de forma 
razoável os valores de vazão, apresentando erro médio de $-13,33 \%$ e $-11,67 \%$, para a operação com suspensão de areia e solo, respectivamente. Para o mesmo hidrociclone o modelo de Lynch \& Rao (1975) superestimou os valores, apresentando o erro médio de $68,34 \%$ e $70,73 \%$ para as suspensões de solo e areia, respectivamente.

(a)

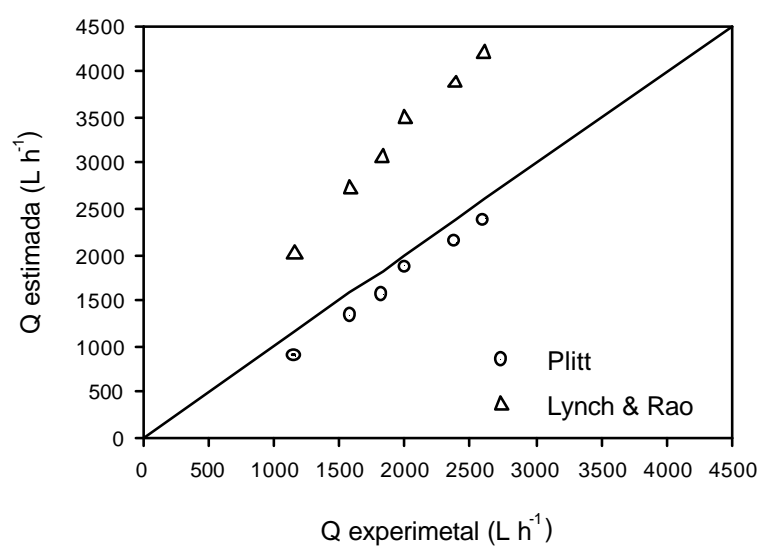

(b)

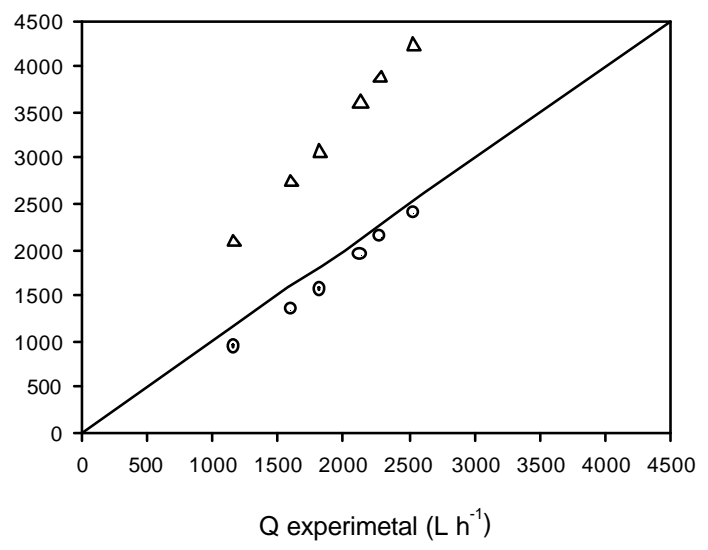

Figura 31 - Vazão no hidrociclone I estimada pelo modelo de Plitt e Lynch \& Rao versus os valores experimentais, para a suspensão de areia (a) e solo (b).

(a)

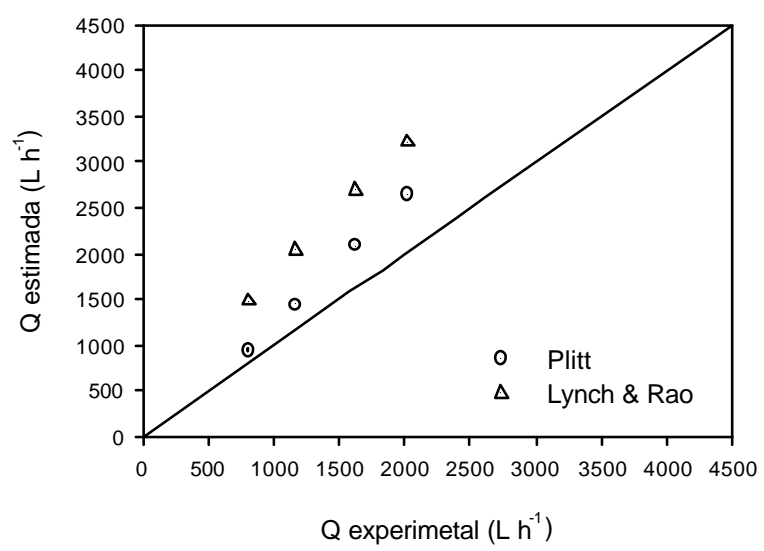

(b)

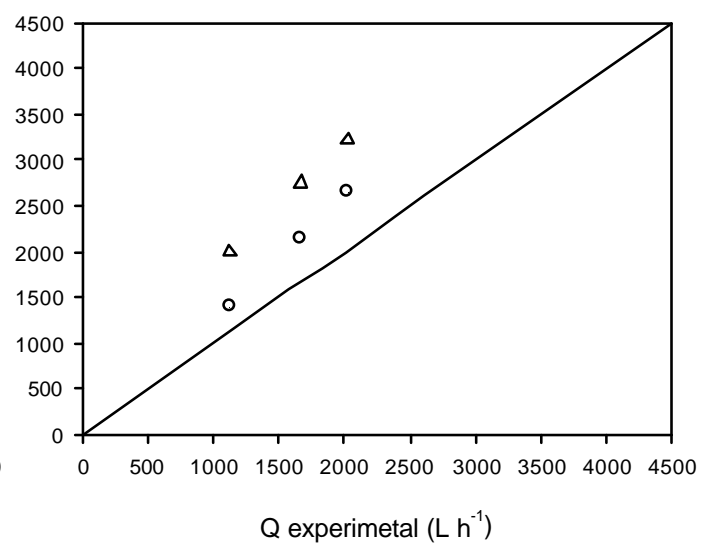

Figura 32 - Vazão no hidrociclone II estimada pelo modelo de Plitt e Lynch \& Rao versus os valores experimentais, para a suspensão de areia (a) e solo (b). 
(a)

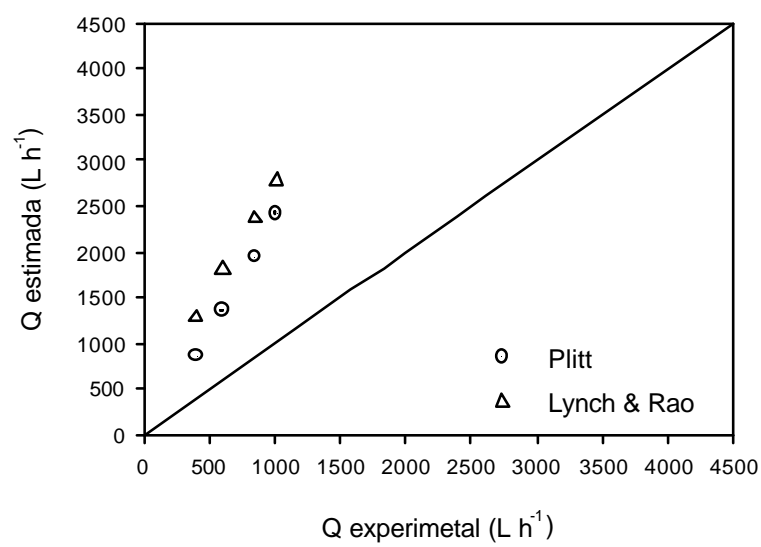

(b)

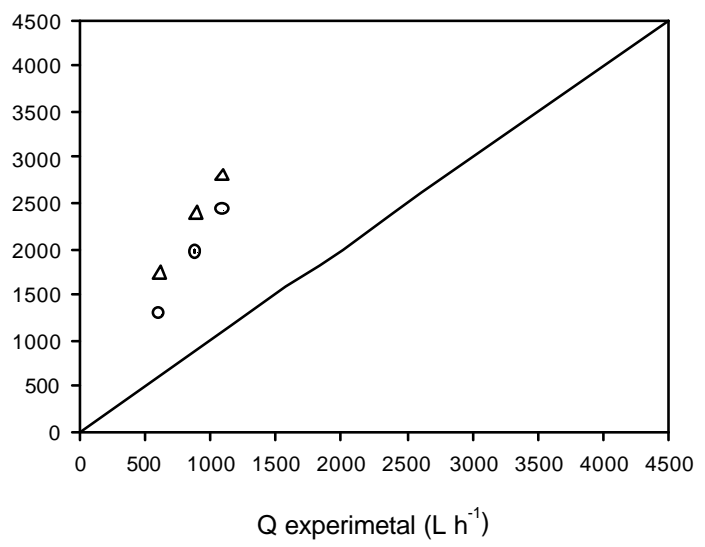

Figura 33 - Vazão no hidrociclone III estimada pelo modelo de Plitt e Lynch \& Rao versus os valores experimentais, para a suspensão de areia (a) e solo (b).

(a)

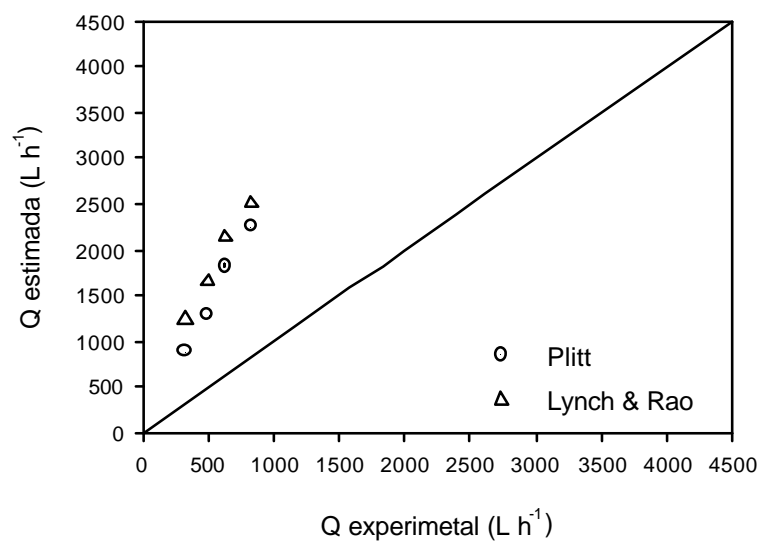

(b)

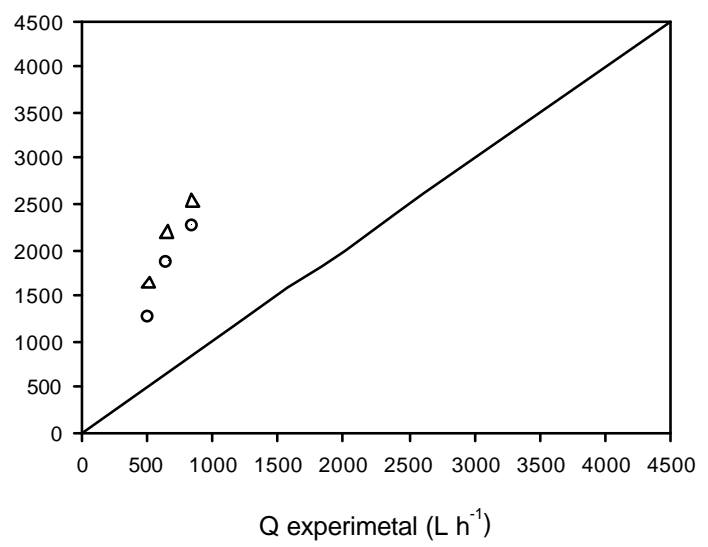

Figura 34 - Vazão no hidrociclone IV estimada pelo modelo de Plitt e Lynch \& Rao versus os valores experimentais, para a suspensão de areia (a) e solo (b).

Com os hidrociclones II, III e IV, as comparações mostraram que os dois modelos superestimam a vazão de alimentação. Para o hidrociclone II, operando com suspensão de areia, o erro médio foi de: $24,82 \%$ e $71,01 \%$ para o modelos de Plitt e Lynch \& Rao, respectivamente; para a suspensão de solo foi de 27,89\% e 67,13\% para 
os modelos de Plitt e Lynch \& Rao, respectivamente. Para os hidrociclones III e IV os erros médios foram superiores a 100\%, chegando em alguns casos a alcançar valores acima de $200 \%$.

Os resultados obtidos com a comparação se mostraram coerentes com resultados obtidos por pesquisadores testando hidrociclones com outros tipos de suspensões. Um exemplo foi o trabalho conduzido por Coelho \& Medronho (1992), em que testaram 5 hidrociclones de diferentes geometrias, operando com suspensão de $\mathrm{CaCO}_{3}$, com diferentes concentrações. Os autores concluíram que o modelo de Lynch \& Rao não deve ser utilizado na estimativa do desempenho de hidrociclones, e que das equações sugeridas por Plitt, a da vazão foi a que apresentou os melhores resultados, encontrando um erro médio, na comparação desta grandeza de \pm 13,50\%. Dalboni \& Chaves (1992) afirmam que os modelos empíricos são gerados a partir de dados operacionais levantados experimentalmente e que uma vez reunidos, os dados geram correlações, (geralmente por meio de técnicas de regressão) que fazem associar parâmetros de desempenho do processo às variáveis operacionais. Os autores, que por este motivo a aplicação de modelos desta natureza exige, necessariamente, uma etapa inicial de adequação das equações à operação específica que se deseja estudar. 


\section{CONCLUSÕES}

Pela análise dos resultados experimentais apresentados e para as condições específicas do trabalho, conclui-se que:

- Os dados obtidos com a análise granulométrica, tanto da suspensão de areia, quanto da suspensão de solo, ajustaram-se ao modelo de Rosin-Rammel-Bennet, com coeficientes de determinação médios iguais a 0,997 e 0,858, respectivamente.

- As curvas de distribuição granulométrica da areia não apresentaram grandes diferenças entre as amostras coletadas na alimentação e no concentrado.

- A alteração do bocal de alimentação para a forma retangular não acarretou em aumento da eficiência total dos hidrociclones, e sim no aumento da perda de carga dos mesmos com a conseqüente diminuição da vazão, quando comparado ao hidrociclone I, dotado com bocal de alimentação circular.

- Os hidrociclones dotados com bocal de alimentação retangular apresentaram problemas de entupimento, o que não foi observado no hidrociclone dotado com tubo de alimentação circular.

- O hidrociclone dotado com o bocal circular sempre apresentou eficiência total superior as obtidas com os hidrociclones dotados com bocal retangular, operando sob diferenciais de pressão semelhantes, tanto para a suspensão de areia, quanto para a suspensão de solo.

- O aumento do diferencial de pressão dos hidrociclones II, III e IV não resultou em aumento da eficiência total dos mesmos, e sim na diminuição da sua capacidade de vazão com conseqüente diminuição do poder de separação.

- O poder de separação dos hidrociclones para a suspensão de areia foi sempre superior quando comparado com a suspensão de solo, principalmente para o hidrociclone I, que 
apresentou as maiores eficiências totais operando com baixos diferenciais de pressão. Isto demonstra o potencial deste equipamento para o uso na pré-filtragem da água utilizada na irrigação.

- A comparação dos dados experimentais com dados estimados pelos modelos de Plitt (1976) e Lynch \& Rao (1975), mostrou que o modelo de Plitt superestimou o diferencial de pressão para o hidrociclone I, e subestimou para os hidrociclones II, III e IV.

- O modelo de Plitt subestimou os valores de vazão para o hidrociclone I, e o modelo de Lynch \& Rao superestimou. Para os hidrociclones II, III e IV, os dois modelos superestimaram a vazão.

- A construção do hidrociclone foi relativamente fácil e de baixo custo, com material disponível em lojas que trabalham com material de construção civil e de fibra de vidro. 
ANEXOS 


\section{ANEXO A}

Resultados na análise granulométrica da areia e do solo, na alimentação e no concentrado, para todos os ensaios realizados com os hidrociclones.

\begin{tabular}{|c|c|c|c|c|c|c|c|c|c|c|c|c|}
\hline \multirow{2}{*}{$\mathrm{d}(\mu \mathrm{m})$} & \multicolumn{2}{|c|}{$10 \mathrm{kPa}$} & \multicolumn{2}{|c|}{$20 \mathrm{kPa}$} & \multicolumn{2}{|c|}{$30 \mathrm{kPa}$} & \multicolumn{2}{|c|}{$40 \mathrm{kPa}$} & \multicolumn{2}{|c|}{$50 \mathrm{kPa}$} & \multicolumn{2}{|c|}{$60 \mathrm{kPa}$} \\
\hline & $\mathrm{X}(\%)$ & $\mathrm{X}_{\mathrm{U}}(\%)$ & $\mathrm{X}(\%)$ & $\mathrm{X}_{\mathrm{U}}(\%)$ & $\mathrm{X}(\%)$ & $\mathrm{X}_{\mathrm{U}}(\%)$ & $\mathrm{X}(\%)$ & $\mathrm{X}_{\mathrm{U}}(\%)$ & $\mathrm{X}(\%)$ & $\mathrm{X}_{\mathrm{U}}(\%)$ & $\mathrm{X}(\%)$ & $\mathrm{X}_{\mathrm{U}}(\%)$ \\
\hline 1000 & 100 & 99,98 & 100 & 100 & 100 & 100 & 100 & 100 & 100 & 100 & 100 & 100 \\
\hline 590 & 99,93 & 99,88 & 99,90 & 99,78 & 99,89 & 99,80 & 99,85 & 99,83 & 99,83 & 99,78 & 99,51 & 99,42 \\
\hline 500 & 99,91 & 99,72 & 99,78 & 99,21 & 99,78 & 99,25 & 99,58 & 99,54 & 99,49 & 99,32 & 98,99 & 98,70 \\
\hline 420 & 98,37 & 97,73 & 98,14 & 97,44 & 97,32 & 96,69 & 95,98 & 95,66 & 96,37 & 95,08 & 93,53 & 91,19 \\
\hline 297 & 91,82 & 90,52 & 92,08 & 90,05 & 87,35 & 86,25 & 83,07 & 82,72 & 84,97 & 80,06 & 78,65 & 71,72 \\
\hline 250 & 87,31 & 85,52 & 88,37 & 85,54 & 81,06 & 79,58 & 76,51 & 74,71 & 78,14 & 71,86 & 72,11 & 63,48 \\
\hline 149 & 43,61 & 40,21 & 44,57 & 41,56 & 32,28 & 31,06 & 30,84 & 28,37 & 29,42 & 25,38 & 27,09 & 20,07 \\
\hline 105 & 13,78 & 11,26 & 14,87 & 13,77 & 9,13 & 8,67 & 6,63 & 5,96 & 4,95 & 4,14 & 5,69 & 3,77 \\
\hline 74 & 3,72 & 3,00 & 4,35 & 3,52 & 2,19 & 1,88 & 1,94 & 1,53 & 1,68 & 1,21 & 2,29 & 1,23 \\
\hline 53 & 0,99 & 0,75 & 1,38 & 0,89 & 0,65 & 0,51 & 0,60 & 0,46 & 0,54 & 0,32 & 0,49 & 0,26 \\
\hline
\end{tabular}

Hidrociclone I - suspensão de solo

\begin{tabular}{|c|c|c|c|c|c|c|c|c|c|c|c|c|}
\hline \multirow{2}{*}{$\mathrm{d}(\mu \mathrm{m})$} & \multicolumn{2}{|c|}{$10 \mathrm{kPa}$} & \multicolumn{2}{|c|}{$20 \mathrm{kPa}$} & \multicolumn{2}{|c|}{$30 \mathrm{kPa}$} & \multicolumn{2}{|c|}{$40 \mathrm{kPa}$} & \multicolumn{2}{|c|}{$50 \mathrm{kPa}$} & \multicolumn{2}{|c|}{$60 \mathrm{kPa}$} \\
\hline & $\mathrm{X}(\%)$ & $\mathrm{X}_{\mathrm{U}}(\%)$ & $\mathrm{X}(\%)$ & $\mathrm{X}_{\mathrm{U}}(\%)$ & $\mathrm{X}(\%)$ & $\mathrm{X}_{\mathrm{U}}(\%)$ & $\mathrm{X}(\%)$ & $\mathrm{X}_{\mathrm{U}}(\%)$ & $\mathrm{X}(\%)$ & $\mathrm{X}_{\mathrm{U}}(\%)$ & $\mathrm{X}(\%)$ & $\mathrm{X}_{\mathrm{U}}(\%)$ \\
\hline 93 & 99,01 & 80,32 & 78,20 & 54,23 & 71,37 & 59,22 & 71,84 & 32,31 & 73,36 & 47,09 & 73,11 & 39,59 \\
\hline 54 & 95,79 & 77,32 & 64,87 & 26 , & 70,38 & 39, & 71,18 & & & & 56,79 & 23,95 \\
\hline 38 & 93,57 & 7 & 64,26 & & & & & & & & & 16 \\
\hline 27 & 92,88 & 74 , & 62,49 & 22 & U & 22 & & & & & & 22,10 \\
\hline 22 & 92,75 & 71,72 & 61,70 & 22 , & & 21, & & & 59,89 & & 53,84 & 21,23 \\
\hline 17 & 92,48 & 69,90 & 61,10 & 21, & 59 & & 58,75 & & 59,71 & & 53,82 & 20,91 \\
\hline 12 & 92,33 & 67,62 & 60,52 & 20,14 & 58,59 & 19,15 & 58,64 & & 59,53 & & 53,65 & 20,02 \\
\hline 8 & 92,13 & 63,25 & 59,93 & 19,46 & 57,80 & 17,97 & 57,63 & 16,95 & 59,37 & 20,83 & 53,38 & 19,46 \\
\hline 7 & 91,87 & 62,32 & 59,33 & 19,16 & 57,15 & 17,14 & 57,11 & 16,13 & 59,22 & 20,38 & 53,15 & 19,12 \\
\hline
\end{tabular}

Hidrociclone II - suspensão de areia

\begin{tabular}{ccccccccc}
\hline \multirow{2}{*}{$\mathrm{d}(\mu \mathrm{m})$} & \multicolumn{2}{c}{$20 \mathrm{kPa}$} & \multicolumn{2}{c}{$50 \mathrm{kPa}$} & \multicolumn{2}{c}{$100 \mathrm{kPa}$} & \multicolumn{2}{c}{$150 \mathrm{kPa}$} \\
\cline { 2 - 8 } & $\mathrm{X}(\%)$ & \multicolumn{1}{c}{$\mathrm{X}_{\mathrm{U}}(\%)$} & $\mathrm{X}(\%)$ & $\mathrm{X}_{\mathrm{U}}(\%)$ & $\mathrm{X}(\%)$ & \multicolumn{1}{c}{$\mathrm{X}_{\mathrm{U}}(\%)$} & $\mathrm{X}(\%)$ & $\mathrm{X}_{\mathrm{U}}(\%)$ \\
\hline 1000 & 100 & 100 & 100 & 100 & 100 & 100 & 100 & 100 \\
590 & 99,93 & 99,78 & 99,96 & 99,86 & 99,68 & 99,47 & 99,23 & 99,11 \\
500 & 99,79 & 99,37 & 99,79 & 99,59 & 99,24 & 98,80 & 98,42 & 98,21 \\
420 & 99,24 & 98,51 & 98,61 & 97,68 & 95,52 & 93,89 & 90,77 & 90,43 \\
297 & 96,03 & 93,85 & 94,87 & 92,10 & 84,52 & 80,87 & 73,63 & 72,78 \\
250 & 94,12 & 91,13 & 92,66 & 89,37 & 78,62 & 74,94 & 66,42 & 65,14 \\
149 & 69,43 & 61,32 & 62,47 & 58,72 & 32,01 & 30,02 & 24,41 & 23,08 \\
105 & 34,95 & 25,05 & 23,34 & 18,39 & 6,89 & 5,88 & 4,79 & 3,98 \\
74 & 19,15 & 11,43 & 10,62 & 7,08 & 2,36 & 1,74 & 1,67 & 1,16 \\
53 & 7,05 & 3,74 & 3,28 & 2,32 & 0,78 & 0,42 & 0,54 & 0,36 \\
\hline
\end{tabular}

Hidrociclone II kPa - suspensão de solo

\begin{tabular}{ccccccc}
\hline \multirow{2}{*}{$\mathrm{d}(\mu \mathrm{m})$} & \multicolumn{2}{c}{$50 \mathrm{kPa}$} & \multicolumn{2}{c}{$100 \mathrm{kPa}$} & \multicolumn{2}{c}{$150 \mathrm{kPa}$} \\
\cline { 2 - 7 } & $\mathrm{X}(\%)$ & $\mathrm{X}_{\mathrm{U}}(\%)$ & $\mathrm{X}(\%)$ & $\mathrm{X}_{\mathrm{U}}(\%)$ & $\mathrm{X}(\%)$ & $\mathrm{X}_{\mathrm{U}}(\%)$ \\
\hline 93 & 95,80 & 89,99 & 58,34 & 37,01 & 67,01 & 48,98 \\
54 & 95,34 & 77,86 & 46,27 & 23,76 & 51,73 & 24,13 \\
38 & 93,21 & 75,14 & 45,37 & 22,49 & 51,18 & 22,93 \\
27 & 90,79 & 71,05 & 44,99 & 21,90 & 50,35 & 21,78 \\
22 & 90,15 & 68,97 & 44,85 & 21,49 & 50,15 & 21,51 \\
17 & 89,59 & 67,15 & 44,47 & 20,97 & 49,94 & 20,83 \\
12 & 88,98 & 64,08 & 44,31 & 20,09 & 49,87 & 19,81 \\
8 & 88,45 & 61,29 & 44,06 & 19,38 & 49,79 & 18,91 \\
7 & 87,62 & 59,79 & 43,73 & 18,95 & 48,92 & 18,27 \\
\hline
\end{tabular}




\section{ANEXOA}

Resultados na análise granulométrica da areia e do solo, na alimentação e no concentrado, para todos os ensaios realizados com os hidrociclones.

\begin{tabular}{ccccccccc}
\multicolumn{1}{l}{ Hidrociclone III - suspensão de areia } \\
\hline $\mathrm{d}(\mu \mathrm{m})$ & \multicolumn{2}{c}{$20 \mathrm{kPa}$} & \multicolumn{2}{c}{$50 \mathrm{kPa}$} & \multicolumn{2}{c}{$100 \mathrm{kPa}$} & \multicolumn{2}{c}{$150 \mathrm{kPa}$} \\
\cline { 2 - 8 } & $\mathrm{X}(\%)$ & $\mathrm{X}_{\mathrm{U}}(\%)$ & $\mathrm{X}(\%)$ & $\mathrm{X}_{\mathrm{U}}(\%)$ & $\mathrm{X}(\%)$ & $\mathrm{X}_{\mathrm{U}}(\%)$ & $\mathrm{X}(\%)$ & $\mathrm{X}_{\mathrm{U}}(\%)$ \\
\hline 1000 & 100 & 100 & 100 & 100 & 100 & 100 & 100 \\
590 & 99,73 & 99,68 & 99,84 & 99,78 & 99,92 & 99,85 & 99,95 & 99,92 \\
500 & 99,41 & 99,29 & 99,68 & 99,47 & 99,79 & 99,68 & 99,81 & 99,75 \\
420 & 96,39 & 95,98 & 97,91 & 95,67 & 98,40 & 97,64 & 97,56 & 97,43 \\
297 & 87,23 & 86,53 & 91,05 & 84,01 & 92,98 & 89,65 & 87,48 & 87,31 \\
250 & 82,37 & 81,39 & 86,74 & 77,47 & 89,68 & 84,96 & 81,32 & 81,00 \\
149 & 44,90 & 42,48 & 42,47 & 30,27 & 48,92 & 41,09 & 32,54 & 29,90 \\
105 & 17,63 & 12,87 & 13,14 & 7,03 & 15,27 & 11,62 & 6,12 & 4,86 \\
74 & 8,97 & 4,85 & 5,44 & 2,38 & 5,27 & 3,50 & 2,04 & 1,49 \\
53 & 2,45 & 1,19 & 1,42 & 0,43 & 1,20 & 0,70 & 0,62 & 0,37 \\
\hline
\end{tabular}

Hidrociclone III - suspensão de solo

\begin{tabular}{ccccccc}
\hline $\mathrm{d}(\mu \mathrm{m})$ & \multicolumn{2}{c}{$50 \mathrm{kPa}$} & \multicolumn{2}{c}{$100 \mathrm{kPa}$} & \multicolumn{2}{c}{$150 \mathrm{kPa}$} \\
\cline { 2 - 7 } & $\mathrm{X}(\%)$ & $\mathrm{X}_{\mathrm{U}}(\%)$ & $\mathrm{X}(\%)$ & $\mathrm{X}_{\mathrm{U}}(\%)$ & $\mathrm{X}(\%)$ & $\mathrm{X}_{\mathrm{U}}(\%)$ \\
\hline 93 & 100 & 100 & 86,21 & 68,94 & 59,16 & 43,62 \\
54 & 100 & 98,89 & 74,58 & 52,09 & 45,74 & 27,30 \\
38 & 100 & 98,80 & 71,78 & 49,64 & 43,56 & 25,81 \\
27 & 99,86 & 98,58 & 70,79 & 48,41 & 43,24 & 25,01 \\
22 & 99,43 & 98,11 & 70,59 & 47,43 & 43,00 & 24,78 \\
17 & 99,32 & 96,40 & 70,53 & 46,43 & 42,74 & 24,16 \\
12 & 99,01 & 94,41 & 70,40 & 44,00 & 42,69 & 23,73 \\
8 & 98,87 & 92,00 & 70,21 & 40,73 & 42,59 & 22,36 \\
7 & 98,60 & 90,06 & 70,05 & 32,16 & 42,31 & 21,28 \\
\hline
\end{tabular}

Hidrociclone IV - suspensão de areia

\begin{tabular}{ccccccccc}
\hline $\mathrm{d}(\mu \mathrm{m})$ & \multicolumn{2}{c}{$20 \mathrm{kPa}$} & \multicolumn{2}{c}{$50 \mathrm{kPa}$} & \multicolumn{2}{c}{$100 \mathrm{kPa}$} & \multicolumn{2}{c}{$150 \mathrm{kPa}$} \\
\cline { 2 - 8 } & $\mathrm{X}(\%)$ & \multicolumn{1}{c}{$\mathrm{X}_{\mathrm{U}}(\%)$} & $\mathrm{X}(\%)$ & $\mathrm{X}_{\mathrm{U}}(\%)$ & $\mathrm{X}(\%)$ & $\mathrm{X}_{\mathrm{U}}(\%)$ & $\mathrm{X}(\%)$ & $\mathrm{X}_{\mathrm{U}}(\%)$ \\
\hline 1000 & 100 & 100 & 100 & 100 & 100 & 100 & 100 & 100 \\
590 & 99,85 & 99,22 & 99,96 & 99,89 & 99,87 & 99,73 & 99,92 & 99,81 \\
500 & 99,70 & 99,01 & 99,87 & 99,66 & 99,67 & 99,31 & 99,81 & 99,45 \\
420 & 98,32 & 97,32 & 98,71 & 97,91 & 99,08 & 98,54 & 98,31 & 97,56 \\
297 & 92,84 & 88,61 & 92,93 & 90,70 & 96,24 & 95,37 & 90,89 & 88,74 \\
250 & 89,18 & 83,67 & 88,19 & 85,05 & 94,00 & 92,36 & 85,40 & 83,27 \\
149 & 49,54 & 39,77 & 34,98 & 33,25 & 55,70 & 53,06 & 35,35 & 33,06 \\
105 & 21,19 & 13,70 & 8,85 & 7,93 & 21,23 & 15,70 & 7,53 & 6,37 \\
74 & 13,11 & 7,26 & 3,20 & 2,11 & 10,09 & 6,12 & 2,27 & 1,75 \\
53 & 4,73 & 2,15 & 0,68 & 0,22 & 2,37 & 1,29 & 0,64 & 0,34 \\
\hline
\end{tabular}

Hidrociclone IV - suspensão de solo

\begin{tabular}{ccccccc}
\hline $\mathrm{d}(\mu \mathrm{m})$ & \multicolumn{2}{c}{$50 \mathrm{kPa}$} & \multicolumn{2}{c}{$100 \mathrm{kPa}$} & \multicolumn{2}{c}{$150 \mathrm{kPa}$} \\
\cline { 2 - 7 } & $\mathrm{X}(\%)$ & $\mathrm{X}_{\mathrm{U}}(\%)$ & $\mathrm{X}(\%)$ & $\mathrm{X}_{\mathrm{U}}(\%)$ & $\mathrm{X}(\%)$ & $\mathrm{X}_{\mathrm{U}}(\%)$ \\
\hline 93 & 99,68 & 97,94 & 79,62 & 74,18 & 74,20 & 65,90 \\
54 & 99,37 & 94,17 & 67,03 & 46,89 & 63,05 & 48,97 \\
38 & 99,17 & 93,78 & 66,96 & 44,93 & 62,30 & 45,83 \\
27 & 98,61 & 93,09 & 63,15 & 42,18 & 60,39 & 44,14 \\
22 & 98,45 & 92,16 & 61,81 & 41,11 & 60,19 & 43,09 \\
17 & 97,90 & 91,28 & 61,42 & 40,42 & 59,93 & 42,56 \\
12 & 97,12 & 90,21 & 60,77 & 39,89 & 59,57 & 41,23 \\
8 & 95,52 & 88,47 & 60,15 & 39,25 & 59,24 & 40,28 \\
7 & 94,01 & 86,68 & 60,02 & 38,66 & 59,05 & 39,78 \\
\hline
\end{tabular}


ANEXO B

Equações obtidas pelo ajuste dos dados de distribuição granulométrica, na alimentação e no concentrado, da areia e do solo, ao modelo de Rosin-RammlerBennet e seus respectivos coeficientes de determinação, para $X$ (adimensional) e d $(\boldsymbol{\mu m})$.

\begin{tabular}{ccccc}
\hline Hidrociclone & $\Delta \mathrm{P}(\mathrm{kPa})$ & Suspensão & Equação & $\mathrm{R}^{2}$ \\
\hline \multirow{2}{*}{10} & alimentação & $X=1-\exp \left[-(d / 192,12)^{2,76}\right]$ & 0,998 \\
& concentrado & $X_{u}=1-\exp \left[-(d / 199,43)^{2,79}\right]$ & 0,998 \\
& alimentação & $X=1-\exp \left[-(d / 189,21)^{2,75}\right]$ & 0,998 \\
& concentrado & $X_{u}=1-\exp \left[-(d / 197,82)^{2,68}\right]$ & 0,998 \\
I & alimentação & $X=1-\exp \left[-(d / 214,78)^{2,84}\right]$ & 0,998 \\
& concentrado & $X_{u}=1-\exp \left[-(d / 218,64)^{2,83}\right]$ & 0,998 \\
& alimentação & $X=1-\exp \left[-(d / 226,18)^{2,72}\right]$ & 0,997 \\
& concentrado & $X_{u}=1-\exp \left[-(d / 230,57)^{2,79}\right]$ & 0,998 \\
& alimentação & $X=1-\exp \left[-(d / 223,67)^{2,93}\right]$ & 0,997 \\
& concentrado & $X_{u}=1-\exp \left[-(d / 239,08)^{2,82}\right]$ & 0,997 \\
& alimentação & $X=1-\exp \left[-(d / 239,51)^{2,63}\right]$ & 0,997 \\
& concentrado & $X_{u}=1-\exp \left[-(d / 264,35)^{2,60}\right]$ & 0,997 \\
\hline
\end{tabular}




\begin{abstract}
ANEXO B
Equações obtidas pelo ajuste dos dados de distribuição granulométrica, na alimentação e no concentrado, da areia e do solo, ao modelo de Rosin-RammlerBennet e seus respectivos coeficientes de determinação, para $X$ (adimensional) e d ( $\mu \mathrm{m})$.
\end{abstract}

\begin{tabular}{ccccc}
\hline Hidrociclone & $\Delta \mathrm{P}(\mathrm{kPa})$ & Suspensão & Equação & $\mathrm{R}^{2}$ \\
\hline \multirow{2}{*}{10} & alimentação & $X=1-\exp \left[-(d / 0,0057)^{0,12}\right]$ & 0,832 \\
& concentrado & $X_{u}=1-\exp \left[-(d / 7,1690)^{0,20}\right]$ & 0,992 \\
& alimentação & $X=1-\exp \left[-(d / 20,735)^{0,15}\right]$ & 0,834 \\
& concentrado & $X_{u}=1-\exp \left[-(d / 271,00)^{0,52}\right]$ & 0,826 \\
& alimentação & $X=1-\exp \left[-(d / 19,804)^{0,17}\right]$ & 0,965 \\
I solo) & concentrado & $X_{u}=1-\exp \left[-(d / 135,51)^{0,71}\right]$ & 0,946 \\
& alimentação & $X=1-\exp \left[-(d / 26,015)^{0,17}\right]$ & 0,916 \\
& concentrado & $X_{u}=1-\exp \left[-(d / 36,952)^{0,09}\right]$ & 0,700 \\
& alimentação & $X=1-\exp \left[-(d / 636,98)^{0,38}\right]$ & 0,818 \\
& concentrado & $X_{u}=1-\exp \left[-(d / 36,949)^{0,10}\right]$ & 0,700 \\
& alimentação & $X=1-\exp \left[-(d / 73,035)^{0,15}\right]$ & 0,758 \\
& concentrado & $X_{u}=1-\exp \left[-(d / 1662,5)^{0,31}\right]$ & 0,841 \\
\hline
\end{tabular}


ANEXO B

Equações obtidas pelo ajuste dos dados de distribuição granulométrica, na alimentação e no concentrado, da areia e do solo, ao modelo de Rosin-RammlerBennet e seus respectivos coeficientes de determinação, para $X$ (adimensional) e d $(\boldsymbol{\mu m})$.

\begin{tabular}{|c|c|c|c|c|}
\hline Hidrociclone & $\Delta \mathrm{P}(\mathrm{kPa})$ & Suspensão & Equação & $\mathrm{R} 2$ \\
\hline \multirow{8}{*}{$\begin{array}{c}\text { II } \\
\text { (areia) }\end{array}$} & \multirow[b]{2}{*}{20} & alimentação & $X=1-\exp \left[-(d / 143,07)^{2,47}\right]$ & 0,998 \\
\hline & & concentrado & $X_{u}=1-\exp \left[-(d / 160,20)^{2,61}\right]$ & 0,997 \\
\hline & \multirow{2}{*}{50} & alimentação & $X=1-\exp \left[-(d / 152,00)^{3,20}\right]$ & 0,997 \\
\hline & & concentrado & $X_{u}=1-\exp \left[-(d / 167,30)^{2,79}\right]$ & 0,994 \\
\hline & \multirow{2}{*}{100} & alimentação & $X=1-\exp \left[-(d / 221,25)^{2,76}\right]$ & 0,965 \\
\hline & & concentrado & $X_{u}=1-\exp \left[-(d / 231,51)^{2,66}\right]$ & 0,997 \\
\hline & \multirow[b]{2}{*}{150} & alimentação & $X=1-\exp \left[-(d / 256,44)^{2,47}\right]$ & 0,997 \\
\hline & & concentrado & $X_{u}=1-\exp \left[-(d / 260,21)^{2,51}\right]$ & 0,996 \\
\hline \multirow{6}{*}{$\begin{array}{c}\text { II } \\
\text { (solo) }\end{array}$} & \multirow{2}{*}{50} & alimentação & $X=1-\exp \left[-(d / 0,0671)^{0,15}\right]$ & 0,952 \\
\hline & & concentrado & $X_{u}=1-\exp \left\lfloor-(d / 11,055)^{0,29}\right\rfloor$ & 0,968 \\
\hline & \multirow{2}{*}{100} & alimentação & $X=1-\exp \left[-(d / 1195,0)^{0,12}\right]$ & 0,747 \\
\hline & & concentrado & $X_{u}=1-\exp \left[-(d / 3075,5)^{0,28}\right\rfloor$ & 0,848 \\
\hline & \multirow[b]{2}{*}{150} & alimentação & $X=1-\exp \left[-(d / 213,96)^{0,14}\right]$ & 0,728 \\
\hline & & concentrado & $X_{u}=1-\exp \left[-(d / 416,24)^{0,46}\right]$ & 0,822 \\
\hline
\end{tabular}


ANEXO B

Equações obtidas pelo ajuste dos dados de distribuição granulométrica, na alimentação e no concentrado, da areia e do solo, ao modelo de Rosin-RammlerBennet e seus respectivos coeficientes de determinação, para $X$ (adimensional) e d $(\boldsymbol{\mu m})$.

\begin{tabular}{|c|c|c|c|c|}
\hline Hidrociclone & $\Delta \mathrm{P}(\mathrm{kPa})$ & Suspensão & Equação & $\mathrm{R} 2$ \\
\hline \multirow{8}{*}{$\begin{array}{c}\text { III } \\
\text { (areia) }\end{array}$} & \multirow[b]{2}{*}{20} & alimentação & $X=1-\exp \left[-(d / 199,68)^{2,24}\right]$ & 0,998 \\
\hline & & concentrado & $X_{u}=1-\exp \left[-(d / 205,86)^{2,43}\right\rfloor$ & 0,997 \\
\hline & \multirow[b]{2}{*}{50} & alimentação & $X=1-\exp \left[-(d / 194,69)^{2,71}\right]$ & 0,998 \\
\hline & & concentrado & $X_{u}=1-\exp \left[-(d / 224,32)^{2,77}\right]$ & 0,998 \\
\hline & \multirow{2}{*}{100} & alimentação & $X=1-\exp \left[-(d / 181,78)^{2,79}\right]$ & 0,997 \\
\hline & & concentrado & $X_{u}=1-\exp \left[-(d / 199,96)^{2,72}\right]$ & 0,997 \\
\hline & \multirow[b]{2}{*}{150} & alimentação & $X=1-\exp \left[-(d / 214,98)^{2,94}\right]$ & 0,998 \\
\hline & & concentrado & $X_{u}=1-\exp \left[-(d / 217,79)^{3,07}\right\rfloor$ & 0,998 \\
\hline \multirow{6}{*}{$\begin{array}{c}\text { III } \\
\text { (solo) }\end{array}$} & \multirow{2}{*}{50} & alimentação & $X=1-\exp \left[-(d / 0,0119)^{0,23}\right]$ & 0,963 \\
\hline & & concentrado & $X_{u}=1-\exp \left[-(d / 0,8830)^{0,41}\right\rfloor$ & 0,994 \\
\hline & \multirow{2}{*}{100} & alimentação & $X=1-\exp \left[-(d / 2,8050)^{0,13}\right]$ & 0,758 \\
\hline & & concentrado & $X_{u}=1-\exp \left\lfloor-(d / 91,082)^{0,31}\right\rfloor$ & 0,927 \\
\hline & \multirow{2}{*}{150} & alimentação & $X=1-\exp \left[-(d / 813,65)^{0,14}\right]$ & 0,746 \\
\hline & & concentrado & $X_{u}=1-\exp \left[-(d / 1297,3)^{0,29}\right\rfloor$ & 0,839 \\
\hline
\end{tabular}


ANEXO B

Equações obtidas pelo ajuste dos dados de distribuição granulométrica, na alimentação e no concentrado, da areia e do solo, ao modelo de Rosin-RammlerBennet e seus respectivos coeficientes de determinação, para $X$ (adimensional) e d ( $\mu \mathrm{m})$.

\begin{tabular}{|c|c|c|c|c|}
\hline Hidrociclone & $\Delta \mathrm{P}(\mathrm{kPa})$ & Suspensão & Equação & $\mathrm{R} 2$ \\
\hline \multirow{8}{*}{$\begin{array}{c}\text { IV } \\
\text { (areia) }\end{array}$} & \multirow[b]{2}{*}{20} & alimentação & $X=1-\exp \left[-(d / 180,43)^{2,34}\right]$ & 0,999 \\
\hline & & concentrado & $X_{u}=1-\exp \left[-(d / 202,66)^{2,52}\right\rfloor$ & 0,998 \\
\hline & \multirow{2}{*}{50} & alimentação & $X=1-\exp \left[-(d / 199,28)^{3,19}\right]$ & 0,999 \\
\hline & & concentrado & $X_{u}=1-\exp \left[-(d / 206,69)^{3,09}\right]$ & 0,998 \\
\hline & \multirow[b]{2}{*}{100} & alimentação & $X=1-\exp \left\lfloor-(d / 163,99)^{2,91}\right\rfloor$ & 0,999 \\
\hline & & concentrado & $X_{u}=1-\exp \left[-(d / 167,36)^{3,28}\right]$ & 0,998 \\
\hline & \multirow[b]{2}{*}{150} & alimentação & $X=1-\exp \left[-(d / 204,48)^{3,05}\right]$ & 0,998 \\
\hline & & concentrado & $X_{u}=1-\exp \left\lfloor-(d / 211,04)^{3,02}\right\rfloor$ & 0,998 \\
\hline \multirow{6}{*}{$\begin{array}{c}\text { IV } \\
\text { (solo) }\end{array}$} & \multirow{2}{*}{50} & alimentação & $X=1-\exp \left[-(d / 0,2325)^{0,31}\right]$ & 0,989 \\
\hline & & concentrado & $X_{u}=1-\exp \left[-(d / 0,1640)^{0,192}\right\rfloor$ & 0,977 \\
\hline & \multirow{2}{*}{100} & alimentação & $X=1-\exp \left[-(d / 17,959)^{0,17}\right]$ & 0,869 \\
\hline & & concentrado & $X_{u}=1-\exp \left[-(d / 111,43)^{0,32}\right]$ & 0,805 \\
\hline & \multirow[b]{2}{*}{150} & alimentação & $X=1-\exp \left[-(d / 29,294)^{0,12}\right]$ & 0,803 \\
\hline & & concentrado & $X_{u}=1-\exp \left[-(d / 167,36)^{0,25}\right]$ & 0,866 \\
\hline
\end{tabular}




\section{ANEXO C}

Gráficos mostrando o comportamento da eficiência total e da eficiência total reduzida em função do diferencial de pressão para os hidrociclones ensaiados.
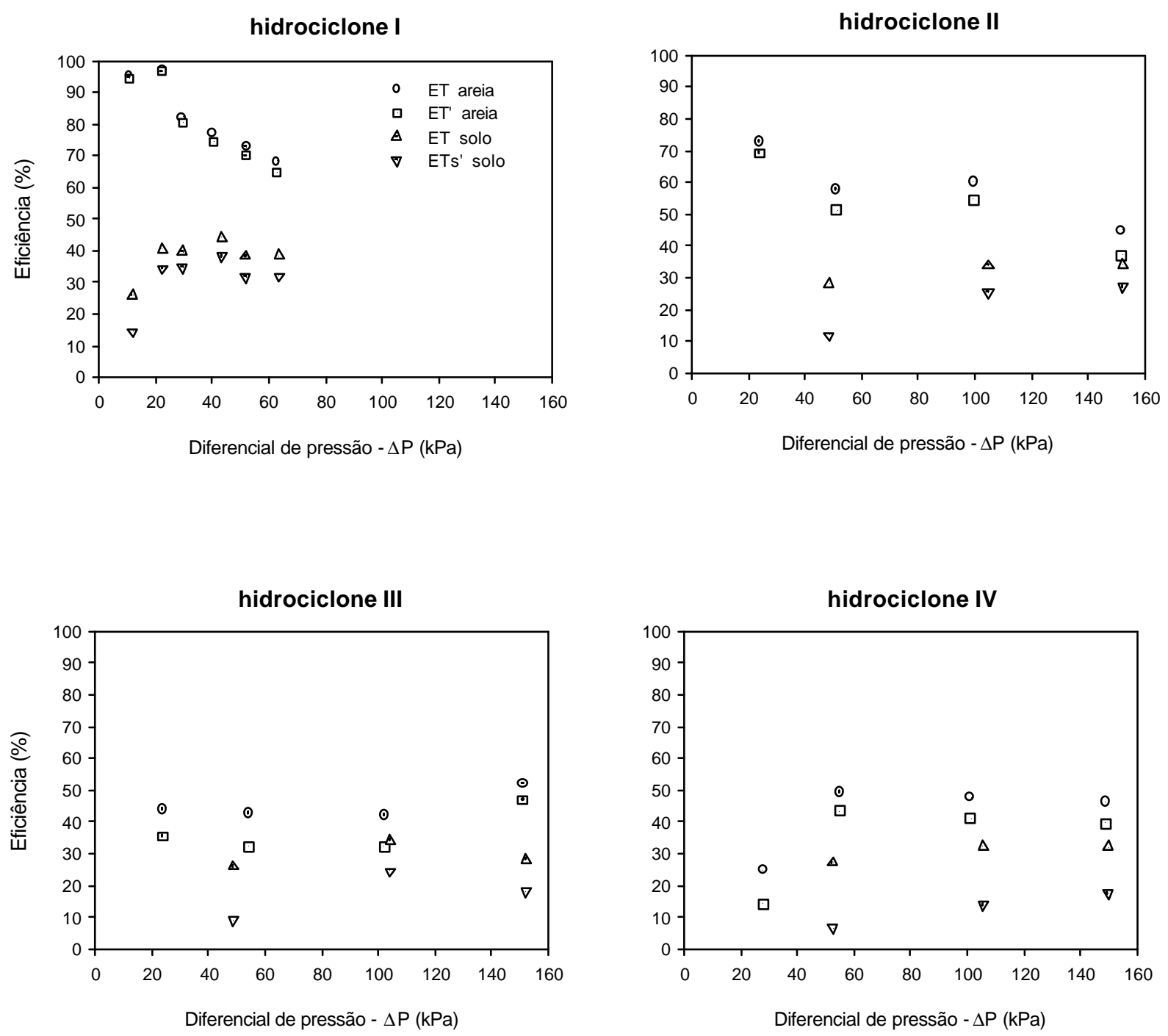


\section{ANEXO D}

Tabelas com o diferencial de pressão, vazão de alimentação, vazão do concentrado, concentração volumétrica na alimentação, razão de líquido, eficiência total e números adimensionais que caracterizam o hidrociclone: número de Reynolds $R e$, número de Euler $E u$ e o produto entre o número de Stokes e de Euler $S t k_{50} E u$.

Hidrociclone I - suspensão de areia

\begin{tabular}{ccccrcccccc}
\hline $\begin{array}{c}\Delta \mathrm{P} \\
(\mathrm{kPa})\end{array}$ & $\begin{array}{c}\mathrm{Q} \\
\left(\mathrm{L} \mathrm{h}^{-1}\right)\end{array}$ & $\begin{array}{c}\mathrm{Q}_{\mathrm{u}} \\
\left(\mathrm{L} \mathrm{h}^{-1}\right)\end{array}$ & $\begin{array}{c}\mathrm{Cv} \\
(\%)\end{array}$ & \multicolumn{1}{c}{$\begin{array}{c}\mathrm{RL} \\
(\%)\end{array}$} & $\begin{array}{c}\mathrm{ET} \\
(\%)\end{array}$ & $\begin{array}{r}\mathrm{ET} \\
(\%)\end{array}$ & $\begin{array}{c}\mathrm{Vc} \\
\left(\mathrm{m} \mathrm{s}^{-1}\right)\end{array}$ & $\mathrm{Re}$ & $\mathrm{Eu}$ & $\mathrm{Stk}_{50} \mathrm{Eu}$ \\
\hline 10,80 & 1159,9 & 133,5 & 0,106 & 11,42 & 95,08 & 94,45 & 0,164 & 8115,4 & 803,09 & 0,0849 \\
22,30 & 1582,8 & 223,3 & 0,113 & 13,66 & 97,09 & 96,62 & 0,224 & 11084,4 & 888,87 & 0,0797 \\
29,50 & 1826,8 & 133,7 & 0,234 & 7,14 & 81,93 & 80,54 & 0,258 & 12766,8 & 886,37 & 0,0993 \\
40,40 & 2002,2 & 207,6 & 0,231 & 10,22 & 77,16 & 74,56 & 0,283 & 14003,9 & 1008,88 & 0,0891 \\
52,00 & 2386,2 & 249,4 & 0,224 & 10,25 & 72,79 & 69,99 & 0,338 & 16725,6 & 910,33 & 0,0889 \\
62,70 & 2603,6 & 259,2 & 0,265 & 9,80 & 68,07 & 64,61 & 0,368 & 18210,1 & 925,98 & 0,0906 \\
\hline
\end{tabular}

Hidrociclone I - suspensão de solo

\begin{tabular}{ccccccccccc}
\hline $\begin{array}{c}\Delta \mathrm{P} \\
(\mathrm{kPa})\end{array}$ & $\begin{array}{c}\mathrm{Q} \\
\left(\mathrm{L} \mathrm{h}^{-1}\right)\end{array}$ & $\begin{array}{c}\mathrm{Q}_{\mathrm{u}} \\
\left(\mathrm{L} \mathrm{h}^{-1}\right)\end{array}$ & $\begin{array}{c}\mathrm{Cv} \\
(\%)\end{array}$ & $\begin{array}{c}\mathrm{RL} \\
(\%)\end{array}$ & $\begin{array}{c}\mathrm{ET} \\
(\%)\end{array}$ & $\begin{array}{c}\mathrm{ET} \\
(\%)\end{array}$ & $\begin{array}{c}\mathrm{Vc} \\
\left(\mathrm{m} \mathrm{s}^{-1}\right)\end{array}$ & $\mathrm{Re}$ & $\mathrm{Eu}$ & $\mathrm{Stk}_{50} \mathrm{Eu}$ \\
\hline 11,90 & 1160,9 & 156,5 & 0,270 & 13,48 & 25,93 & 14,38 & 0,164 & 8115,4 & 884,89 & 0,0812 \\
22,60 & 1595,1 & 143,9 & 0,424 & 8,89 & 40,29 & 34,46 & 0,226 & 11183,4 & 884,96 & 0,0947 \\
29,60 & 1813,8 & 141,5 & 0,419 & 7,69 & 39,63 & 34,62 & 0,257 & 12717,4 & 896,30 & 0,0988 \\
43,50 & 2128,9 & 201,2 & 0,411 & 9,31 & 43,94 & 38,19 & 0,301 & 14898,7 & 960,25 & 0,0933 \\
51,90 & 2284,8 & 220,4 & 0,403 & 9,53 & 38,15 & 31,63 & 0,323 & 15983,3 & 994,93 & 0,0925 \\
63,60 & 2534,8 & 244,7 & 0,449 & 9,52 & 38,42 & 31,94 & 0,359 & 17764,7 & 986,96 & 0,0929 \\
\hline
\end{tabular}

Hidrociclone II - suspensão de areia

\begin{tabular}{crrcccccccc}
\hline $\begin{array}{c}\Delta \mathrm{P} \\
(\mathrm{kPa})\end{array}$ & $\begin{array}{c}\mathrm{Q} \\
\left(\mathrm{L} \mathrm{h}^{-1}\right)\end{array}$ & $\begin{array}{c}\mathrm{Q}_{\mathrm{u}} \\
\left(\mathrm{L} \mathrm{h}^{-1}\right)\end{array}$ & $\begin{array}{c}\mathrm{Cv} \\
(\%)\end{array}$ & $\begin{array}{c}\mathrm{RL} \\
(\%)\end{array}$ & $\begin{array}{c}\mathrm{ET} \\
(\%)\end{array}$ & $\begin{array}{l}\mathrm{ET} \\
(\%)\end{array}$ & $\begin{array}{c}\mathrm{Vc} \\
\left(\mathrm{m} \mathrm{s}^{-1}\right)\end{array}$ & $\mathrm{Re}$ & $\mathrm{Eu}$ & $\mathrm{Stk}_{50} \mathrm{Eu}$ \\
\hline 23,90 & 806,5 & 94,5 & 0,013 & 11,70 & 72,73 & 69,13 & 0,114 & 5641,2 & 3678,1 & 0,0835 \\
51,10 & 1165,0 & 155,5 & 0,034 & 13,30 & 57,79 & 51,29 & 0,165 & 8164,8 & 3753,9 & 0,0799 \\
99,60 & 1621,8 & 195,3 & 0,215 & 12,00 & 59,99 & 54,47 & 0,229 & 11331,8 & 3798,6 & 0,0843 \\
151,70 & 2017,0 & 250,4 & 0,301 & 12,30 & 44,84 & 37,08 & 0,285 & 14102,9 & 3735,3 & 0,0842 \\
\hline
\end{tabular}

Hidrociclone II - suspensão de solo

\begin{tabular}{ccccccccccc}
\hline $\begin{array}{c}\Delta \mathrm{P} \\
\mathrm{kPa})\end{array}$ & $\begin{array}{c}\mathrm{Q} \\
\left(\mathrm{L} \mathrm{h}^{-1}\right)\end{array}$ & $\begin{array}{c}\mathrm{Q}_{\mathrm{u}} \\
\left(\mathrm{L} \mathrm{h}^{-1}\right)\end{array}$ & $\begin{array}{c}\mathrm{Cv} \\
(\%)\end{array}$ & \multicolumn{1}{c}{$\begin{array}{c}\mathrm{RL} \\
(\%)\end{array}$} & $\begin{array}{c}\mathrm{ET} \\
(\%)\end{array}$ & $\begin{array}{c}\mathrm{ET} \\
(\%)\end{array}$ & $\begin{array}{c}\mathrm{Vc} \\
\left(\mathrm{m} \mathrm{s}^{-1}\right)\end{array}$ & $\mathrm{Re}$ & $\mathrm{Eu}$ & $\mathrm{Stk}_{50} \mathrm{Eu}$ \\
\hline 48,50 & 1121,9 & 203,7 & 0,257 & 18,23 & 27,90 & 11,83 & 0,159 & 7867,9 & 3836,9 & 0,0719 \\
104,60 & 1667,3 & 190,7 & 0,527 & 11,32 & 33,88 & 25,45 & 0,236 & 11678,2 & 3756,1 & 0,0884 \\
152,10 & 2028,4 & 195,3 & 0,456 & 9,50 & 33,97 & 27,08 & 0,287 & 14201,9 & 3693,1 & 0,0931 \\
\hline
\end{tabular}




\section{ANEXO D}

Tabelas com o diferencial de pressão, vazão de alimentação, vazão do concentrado, concentração volumétrica na alimentação, razão de líquido, eficiência total e números adimensionais que caracterizam o hidrociclone: número de Reynolds $R e$, número de Euler $E u$ e o produto entre o número de Stokes e de Euler $S t k_{50} E u$.

Hidrociclone III - suspensão de areia

\begin{tabular}{crrrrrccccc}
\hline $\begin{array}{c}\Delta \mathrm{P} \\
(\mathrm{kPa})\end{array}$ & $\begin{array}{c}\mathrm{Q} \\
\left(\mathrm{L} \mathrm{h}^{-1}\right)\end{array}$ & $\begin{array}{c}\mathrm{Q}_{\mathrm{u}} \\
\left(\mathrm{L} \mathrm{h}^{-1}\right)\end{array}$ & $\begin{array}{c}\mathrm{Cv} \\
(\%)\end{array}$ & $\begin{array}{c}\mathrm{RL} \\
(\%)\end{array}$ & $\begin{array}{c}\mathrm{ET} \\
(\%)\end{array}$ & $\begin{array}{c}\mathrm{ET} \\
(\%)\end{array}$ & $\begin{array}{c}\mathrm{Vc} \\
\left(\mathrm{m} \mathrm{s}^{-1}\right)\end{array}$ & $\mathrm{Re}$ & $\mathrm{Eu}$ & $\mathrm{Stk}_{50} \mathrm{Eu}$ \\
\hline 23,90 & 401,3 & 53,0 & 0,004 & 13,10 & 43,86 & 35,46 & 0,057 & 2820,6 & 14712,2 & 0,0801 \\
54,30 & 602,9 & 92,8 & 0,007 & 15,40 & 42,64 & 32,21 & 0,085 & 4206,1 & 15031,1 & 0,0754 \\
102,20 & 842,6 & 122,6 & 0,015 & 14,50 & 42,09 & 32,23 & 0,119 & 5888,6 & 14434,0 & 0,0772 \\
151,10 & 1012,9 & 100,3 & 0,295 & 9,80 & 52,07 & 46,84 & 0,143 & 7076,2 & 14778,2 & 0,0908 \\
\hline
\end{tabular}

Hidrociclone III - suspensão de solo

\begin{tabular}{rrrrrrrrrrr}
\hline $\begin{array}{c}\Delta \mathrm{P} \\
(\mathrm{kPa})\end{array}$ & $\begin{array}{c}\mathrm{Q} \\
\left(\mathrm{L} \mathrm{h}^{-1}\right)\end{array}$ & $\begin{array}{c}\mathrm{Q}_{\mathrm{u}} \\
\left(\mathrm{L} \mathrm{h}^{-1}\right)\end{array}$ & $\begin{array}{c}\mathrm{Cv} \\
(\%)\end{array}$ & $\begin{array}{c}\mathrm{RL} \\
(\%)\end{array}$ & $\begin{array}{c}\mathrm{ET} \\
(\%)\end{array}$ & $\begin{array}{c}\mathrm{ET} \\
(\%)\end{array}$ & $\begin{array}{c}\mathrm{Vc} \\
\left(\mathrm{m} \mathrm{s}^{-1}\right)\end{array}$ & $\mathrm{Re}$ & $\mathrm{Eu}$ & $\mathrm{Stk}_{50} \mathrm{Eu}$ \\
\hline 48,90 & 615,4 & 113,1 & 0,273 & 18,36 & 25,84 & 9,16 & 0,087 & 4305,1 & 12921,1 & 0,0718 \\
104,20 & 891,6 & 116,6 & 0,213 & 13,04 & 34,25 & 24,40 & 0,126 & 6234,9 & 13126,7 & 0,0818 \\
152,00 & 1095,3 & 133,9 & 0,609 & 12,13 & 28,13 & 18,20 & 0,155 & 7670,0 & 12653,5 & 0,0869 \\
\hline
\end{tabular}

Hidrociclone IV - suspensão de areia

\begin{tabular}{rcccccccccc}
\hline $\begin{array}{c}\Delta \mathrm{P} \\
(\mathrm{kPa})\end{array}$ & $\begin{array}{c}\mathrm{Q} \\
\left(\mathrm{L} \mathrm{h}^{-1}\right)\end{array}$ & $\begin{array}{c}\mathrm{Q}_{\mathrm{u}} \\
\left(\mathrm{L} \mathrm{h}^{-1}\right)\end{array}$ & $\begin{array}{c}\mathrm{Cv} \\
(\%)\end{array}$ & $\begin{array}{c}\mathrm{RL} \\
(\%)\end{array}$ & $\begin{array}{c}\mathrm{ET} \\
(\%)\end{array}$ & $\begin{array}{c}\mathrm{ET} \\
(\%)\end{array}$ & $\begin{array}{c}\mathrm{Vc} \\
\left(\mathrm{m} \mathrm{s}^{-1}\right)\end{array}$ & $\mathrm{Re}$ & $\mathrm{Eu}$ & $\mathrm{Stk}_{50} \mathrm{Eu}$ \\
\hline 28,00 & 322,8 & 39,6 & 0,001 & 12,30 & 24,76 & 14,25 & 0,046 & 2276,3 & 26465,0 & 0,0819 \\
54,90 & 497,6 & 51,3 & 0,013 & 10,30 & 49,26 & 43,03 & 0,070 & 3463,9 & 22408,2 & 0,0871 \\
101,00 & 631,9 & 72,1 & 0,061 & 11,40 & 47,72 & 41,00 & 0,089 & 4404,1 & 25801,8 & 0,0846 \\
148,80 & 829,9 & 91,5 & 0,449 & 10,90 & 46,07 & 39,50 & 0,117 & 5789,6 & 21740,1 & 0,0889 \\
\hline
\end{tabular}

Hidrociclone IV - suspensão de solo

\begin{tabular}{ccccccccccc}
\hline $\begin{array}{c}\Delta \mathrm{P} \\
(\mathrm{kPa})\end{array}$ & $\begin{array}{c}\mathrm{Q} \\
\left(\mathrm{L} \mathrm{h}^{-1}\right)\end{array}$ & $\begin{array}{c}\mathrm{Q}_{\mathrm{u}} \\
\left(\mathrm{L} \mathrm{h}^{-1}\right)\end{array}$ & $\begin{array}{c}\mathrm{Cv} \\
(\%)\end{array}$ & $\begin{array}{c}\mathrm{RL} \\
(\%)\end{array}$ & $\begin{array}{c}\mathrm{ET} \\
(\%)\end{array}$ & $\begin{array}{c}\mathrm{ET} \\
(\%)\end{array}$ & $\begin{array}{c}\mathrm{Vc} \\
\left(\mathrm{m} \mathrm{s}^{-1}\right)\end{array}$ & $\mathrm{Re}$ & $\mathrm{Eu}$ & $\mathrm{Stk}_{50} \mathrm{Eu}$ \\
\hline 52,40 & 512,4 & 111,6 & 0,220 & 21,78 & 27,05 & 6,74 & 0,072 & 3562,8 & 20216,1 & 0,0660 \\
105,50 & 652,7 & 139,9 & 0,316 & 21,40 & 32,28 & 13,84 & 0,092 & 4552,5 & 24929,1 & 0,0672 \\
149,60 & 847,7 & 151,1 & 0,358 & 17,78 & 32,08 & 17,40 & 0,119 & 5888,6 & 21128,5 & 0,0672 \\
\hline
\end{tabular}




\section{REFERÊNCIAS BIBLIOGRÁFICAS}

ALLEN, T. Particle size measurement. 4.ed. London: Chapman and Hall, 1990. 832p.

ANTUNES, M.; MEDRONHO, R.A. Bradley hydrocyclones: design and performance analysis. In: INTERNATIONAL CONFERENCE ON HYDROCYCLONES, 4., Southampton, 1992. Hydrocyclones: analysis and applications. Dordrecht: Kluwer Academic, 1992. p.3-13.

AYERS, R.S.; WESTCOT, D.W. A qualidade da água na agricultura. Trad. de H.R. Gheyi, J.F. de Medeiros, F.A.V. Damasceno. Campina Grande: UFPB, 1991. 218p.

BERNARDO, S. Manual de irrigação. 5.ed. Viçosa: Imprensa Universitária, UFV, 1989. 596p.

BRADLEY, D. The hydrocyclone. Londres: Pergamon Press, 1965. 330p.

BUCKS, D.A.; NAKAYAMA, F.S.; GILBERT, R.G. Trickle irrigation water quality and preventive maintenance. Agricultural Water Manageament, v.2, n.2, p.149$162,1979$.

BUCKS, D.A.; NAKAYAMA, F.S. Injection of fertilizer and other chemicals for drip irrigation. In: AGRICULTURAL TURF IRRIGATION CONFERENCE, Houston, 1980. Proceedings. Houston: Irrigation Association, 1980. p.166-180. 
CABELLO, F.P. Riegos localizados de alta frecuencia: goteo, microaspersíon, exudación. 3.ed. Madri: Mundi-Prensa, 1996. 513p.

CASTILHO, L.R.; MEDRONHO, R.A. A simple procedure for design and performance prediction of Bradley and Rietema hydrocyclones. Minerals Engineering, v.13, n.2, p.183-191, 2000.

CHU, L.Y.; CHEN, W.M.; LEE, X.Z. Enhancement of hydrocyclone performance by controlling the inside turbulence structure. Chemical Engineering Science, v.57, n.1, p.207-212, 2002.

CILLIERS, J.J.; HARRISON, S.T.L. The application of mini-hydrocyclones in the concentration of yeast suspensions. Chemical Engineering Journal, v.65, n.1, p.2126, 1997.

COELHO, M.A.Z.; MEDRONHO, R.A. An evaluation of the Plitt e Lynch \& Rao models for the hydrocyclones. In: INTERNATIONAL CONFERENCE ON HYDROCYCLONES, 4., Southampton, 1992. Hydrocyclones: analysis and applications. Dordrecht: Kluwer Academic, 1992. p.63-72.

COELHO, M.A.Z; MEDRONHO, R.A. Equações para o projeto e performance de hidrociclones. In: CONGRESSO BRASILEIRO DE SISTEMAS PARTICULADOS, 22., Florianópolis, 1994. Anais. Florianópolis: UFSC, 1994. p.273-280.

CUENCA, R.H. Irrigation system design: an engineering approach. Englewood Cliffs: Prentice-Hall, 1989. 552p.

DAI, G.Q.; LI, J.M.; CHEN, W.M. Numerical prediction of the liquid flow within a hydrocyclone. Chemical Engineering Journal, v.74, n.3, p.217-223, 1999. 
DAY, P.R. Particle fractionation and particle size analysis. In: BLACK, C.A. (Ed.). Methods of soil analysis. Madison: American Society of Agronomy, 1965. cap.43, p.545-567.

DELBONI JUNIOR. H.; CHAVES, A.P. Ajuste de modelos empíricos de operação de ciclones. São Paulo: EPUSP, 1992. 10p. (Boletim técnico da Escola Politécnica da USP, Departamento de Engenharia de Minas, BT/PMI/005).

FLINTOFF, B.C.; PLITT, L.R.; TURAK, A.A. Cyclone modeling: a review of present technology. Canadian Institute of Mining, Metallurgy and Petroleum Bulletin, v.80, n.905, p.39-50, 1987.

GILBERT R.G.; FORD, H.W. Operational principles. In: NAKAYAMA, F.S.; BUCKS, D.A. Trickle irrigation for crop production: design, operation and management. Amsterdam: Elsevier, 1986. cap.3, p.142-163.

HOWELL, T.A.; STEVENSON, D.S.; GITLIN, H.M.; WU, IPai; WARRICK, A.W.; RAATS, P.A.C. Design and operation of trickle (drip) systems. In: JENSEN, M.E. (Ed.). Design and operation of farm irrigation systems. St. Joseph: ASAE, 1983. cap.16, p.663-717.

JACOBS, L.J.; PENNEY, W.R. Phase segregation. In: ROUSSEAU, R.W. (Ed.). Handbook of Separation Process Technology. New York: Wiley-Interscience, 1987. cap.3, p.160-218.

KELLER, J.; BLIESNER, R.D. Sprinkle and trickle irrigation. New York: Chapman \& Hall, 1990. 625p.

KELSALL, D.F. A further study of the hydraulic cyclone. Chemical Engineering Science, v.2, n.2, p.254-272, 1953. 
KIEHL, E.J. Manual de edafologia: relações solo-planta. São Paulo: Editora Agronômica Ceres, 1979. 264p.

KLIMA, M.S.; KIM, B.H. Dense-medium separation of heavy-metal particles from soil using a wide-angle hydrocyclone. Journal of Environmental Science and Health, v.33, p.1325-1340, 1998.

LÓPEZ, J.R.; ABREU, J.M.H.; REGALADO, A.P.; HERNÁNDEZ, J.F.G. Riego localizado. Madri: Mundi-Prensa, 1992. 405p.

LOPEZ, T.M. Cabezal de riego. In: LOPEZ, C.C.(Ed.). Fertirrigacion: cultivos horticolas y ornamentales. Madri: Mundi-Prensa, 1998. cap.6, p.247-263.

LYNCH, A.J.; RAO, T.C. Modelling and scale-up of hydrocyclone classifiers. In: INTERNATIONAL MINERAL PROCESSING CONGRESS, 11., Cagliari, 1975. Proceedings, Cagliari: Universita di Cagliari, 1975. p.245-269.

MARTI, S. Analysis of gas carry-under in gas-liquid cylindrical cyclones. In: CLAXTON, D.; SVAROVSKY, L.; THEW, M.T. (Ed.). Hydrocyclones. London: London \& Bury Saint Edmunds, 1996. p.399-421.

MEDRONHO, R.A. Scale-up of hydrocyclones at low feed concentrations. Inglaterra, 1984. 323p. Thesis (Ph.D.) - University of Bradford, United Kingdom.

NEVES, E. T. Curso de hidráulica. 6.ed. Porto Alegre: Editora Globo, 1979. 577p.

PAI NETO, E.D.; VALENTE, M.; CARDOSO, V.L.; DAMASCENO, J.J.R. Análise do desempenho de hidrociclones com fundo chato (compact disc). In: INTERAMERICAN CONGRESS OF CHEMICAL ENGINEERING, 19., e CONGRESSO BRASILEIRO DE ENGENHARIA QUÍMICA, 19., Águas de São Pedro, 2000. Proceedings, 13., e 19., Águas de São Pedro: UNICAMP, 2000. 
PEÇANHA, R.P.; MASSARANI, G. Avaliação do desempenho de hidrociclones. Revista Brasileira de Tecnologia, v.11, n.4, p.289-299, 1980.

PHILLIPS, K.P. Long-term operation of microirrigation filtration systems; successes, failures and operational solutions. In: INTERNATIONAL MICROIRRIGATION CONGRESS, 15., Orlando, 1995. Microirrigation for a chamging world: conserving resources/preserving the environment. Orlando: ASAE, 1995. p.579-585.

PLITT, L.R. The analysis of solid-solid separations in classifiers. Canadian Institute of Mining, Metallurgy and Petroleum Bulletin, v.64, p.42-47, 1971.

PLITT, L.R. A mathematical model of the hydrocyclone classifier. Canadian Institute of Mining, Metallurgy and Petroleum Bulletin, v.69, p.114-123, 1976.

RIETEMA, K. Performance and design of hydrocyclones I: general considerations. Chemical Engineering Science, v.15, n.3/4, p.298-302, 1961a.

RIETEMA, K. Performance and design of hydrocyclones II: pressure drop in the hydrocyclone. Chemical Engineering Science, v.15, n.3/4, p.303-309, 1961 b.

RIETEMA, K. Performance and design of hydrocyclones III: separating power of the hydrocyclone. Chemical Engineering Science, v.15, n.3/4, p.310-319, 1961c.

RIETEMA, K. Performance and design of hydrocyclones IV: design of hydrocyclone. Chemical Engineering Science, v.15, n.3/4, p.320-325, 1961d.

ROVINSKY, L.A. Application of separation theory to hydrocyclone design. Journal of Food Engineering, v.26, n.2, p.131-146, 1995. 
SOUZA, F.J.; VIEIRA, L.G.M.; DAMASCENO, J.J.R.; BARROZO, M.A.S. Analysis of the influence of the filtering medium on the behaviour of the filtering hydrocyclones. Powder Technology, v.117, n.3, p.259-267, 2000.

SCHEID, C.M. Estudo da influência da concentração de sólidos e de sangrias no desempenho de ciclones a gás. Rio de Janeiro, 1992. 94p. Dissertação (M.S.) Coordenação de Pós-Graduação e Pesquisa de Engenharia, Universidade Federal do Rio de Janeiro.

SILVA, M.A.P. da. Hidrociclones de Bradley: dimensionamento e análise de desempenho. Rio de Janeiro, 1989. 81p. Dissertação (M.S.) - Coordenação de PósGraduação e Pesquisa de Engenharia, Universidade Federal do Rio de Janeiro.

SMYTH, I.C.; THEW, M. T. A study of the effect of dissolved gas on the operation of liquid-liquid hydrocyclones. In: CLAXTON, D.; SVAROVSKY, L.; THEW, M.T. (Ed.). Hydrocyclones. London: London \& Bury Saint Edmunds, 1996. p.357-368.

SVAROVSKY, L. Hydrocyclones. Lancaster: Technomic, 1984. 198p.

SVAROVSKY, L. Solid-liquid separation. 3.ed. London: Butterworths, 1990. 716p.

THOMPSON G.T.; KRIDER, J.N. Farm resources and system selection. In: JENSEN, M.E. Design and operation of farm irrigation systems. St. Joseph: ASAE, 1983. cap.3, p.45-73.

TRAWINSKI, H.F. Hydrocyclones. In: PURCHAS, D.B. Solid-Liquid Separation Equipment Scale-up. Croydon: Upland Press, 1977. cap.7, p.241-287.

TRAWINSKI H.F. Pratical aspects of the design and industrial applications of the hydrocyclones: part 1. Filtration and Separation, v.6, p.371-367, 1969. 
VILELA, L.A.A.; GERVÁSIO, E.S.; SOCCOL, O.J.; BOTREL, T.A. Sistema para aquisição de dados de pressão e vazão usando microcomputador. Revista Brasileira de Agrocomputação, v.1, n.2, p.25-30, 2001.

YOSHIOKA, N.; HOTTA, Y. Liquid cyclone as a hydraulic classifier. Chemical Engineering Japan, v.19, p.632-641, 1955. 